Issued by Sandia National Laboratories, operated for the United States Department of Energy by Sandia Corporation.

NOTICE: This report was prepared as an account of work sponsored by an agency of the United States Government. Neither the United States Government nor any agency thereof, nor any of their employees, nor any of their contractors, subcontractors, or their employees, makes any warranty, express or implied, or assumes any legal liability or responsibility for the accuracy, completeness, or usefulness of any information, apparatus, product, or process disclosed, or represents that its use would not infringe privately owned rights. Reference herein to any specific commercial product, process, or service by trade name, trademark, manufacturer, or otherwise, does not necessarily constitute or imply its endorsement, recommendation, or favoring by the United States Government, any agency thereof, or any of their contractors or subcontractors. The views and opinions expressed herein do not necessarily state or reflect those of the United States Government, any agency thereof, or any of their contractors.

Printed in the United States of America. This report has been reproduced directly from the best available copy.

Available to $\mathrm{DOE}$ and $\mathrm{DOE}$ contractors from

Office of Scientific and Technical Information

P.O. Box 62

Oak Ridge, TN 37831

Prices available from (615) 576-8401, FTS 626-8401

Available to the public from

National Technical Information Service

U.S. Department of Commerce

5285 Port Royal Rd

Springfield, VA 22161

NTIS price codes

Printed copy: A04

Microfiche copy: A01

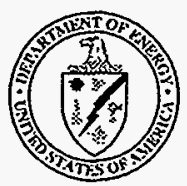




\section{DISCLAIMER}

Portions of this document may be illegible electronic image products. Images are produced from the best available original document. 
SAND98-1191

Unlimited Release

Printed July 1998

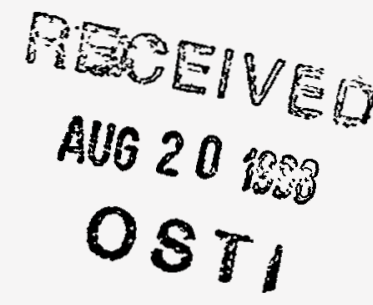

\title{
Exponential 6 Parameterization for the JCZ3-EOS
}

\author{
B. C. McGee, M. L. Hobbs, ${ }^{*}$ M. R. Baer \\ Energetic and Muli-Phase Processes \\ Sandia National Laboratories \\ P. O. Box 5800 \\ Albuquerque, New Mexico 87185-0834
}

\begin{abstract}
A database has been created for use with the Jacobs-Cowperthwaite-Zwisler-3 equation-of-state (JCZ3-EOS) to determine thermochemical equilibrium for detonation and expansion states of energetic materials. The JCZ3-EOS uses the exponential 6 intermolecular potential function to describe interactions between molecules. All product species are characterized by $r^{*}$, the radius of the minimum pair potential energy, and $\varepsilon / k$, the well depth energy normalized by Boltzmann's constant. These parameters constitute the JCZS (S for Sandia) EOS database describing 750 gases (including all the gases in the JANNAF tables), and have been obtained by using Lennard-Jones potential parameters, a corresponding states theory, pure liquid shock Hugoniot data, and fit values using an empirical EOS. This database can be used with the CHEETAH 1.40 or CHEETAH 2.0 interface to the TIGER computer program that predicts the equilibrium state of gas- and condensed-phase product species. The large JCZS-EOS database permits intermolecular potential based equilibrium calculations of energetic materials with complex elemental composition.
\end{abstract}

DISTRIBUTION OF THIS DOCUMENT IS UNLMAITED

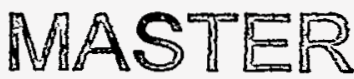

\footnotetext{
${ }^{*}$ Correspondence concerning this report should be addressed to M. L. Hobbs
} 


\section{Acknowledgment}

Many thanks to Arthur C. Ratzel for providing the opportunity and funding for this project. Helpful suggestions made by internal reviewers, R. G. Schmitt and S. A. Silling, are appreciated. 


\section{Table of Contents}

Table of Contents

List of Figures $\ldots \ldots \ldots \ldots \ldots \ldots \ldots \ldots \ldots \ldots \ldots \ldots \ldots \ldots \ldots \ldots$

List of Tables $\ldots \ldots \ldots \ldots \ldots \ldots \ldots \ldots \ldots \ldots \ldots \ldots \ldots \ldots \ldots \ldots \ldots \ldots \ldots$

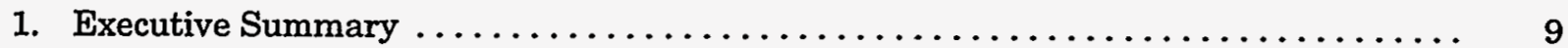

2. JCZ3-EOS Background $\ldots \ldots \ldots \ldots \ldots \ldots \ldots \ldots \ldots \ldots \ldots \ldots \ldots \ldots \ldots$

3. Obtaining the Exponential 6 Potential Force Constants from Lennard-Jones Potential Parameters...................................... 10

4. Estimating the Exponential 6 Potential Force Constants from Critical Properties .... 12

5. Estimating the Exponential 6 Potential Force Constants through Correlation and

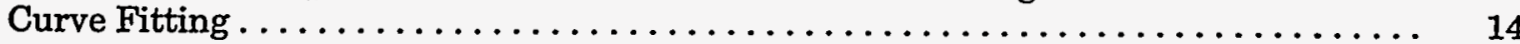

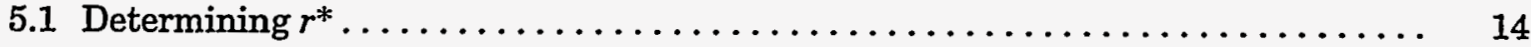

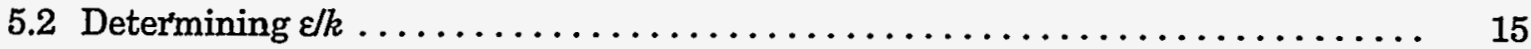

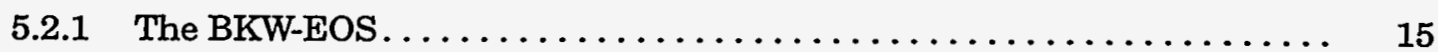

5.2.2 The BKWR Parameterization. ....................... 16

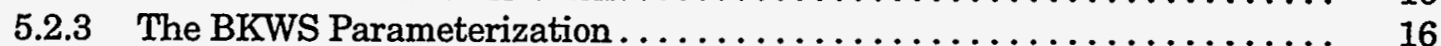

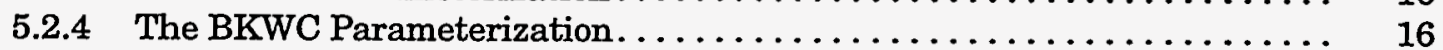

5.2.5 Using the BKWS-EOS to Determine $\varepsilon / k \ldots \ldots \ldots \ldots \ldots \ldots \ldots \ldots . \ldots \ldots$

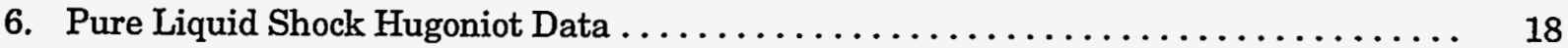

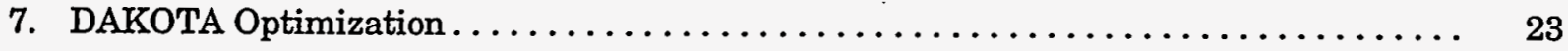

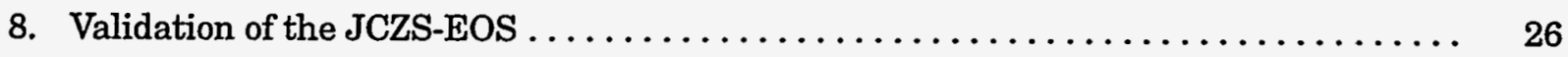

8.1 Explosive Performance.............................. 27

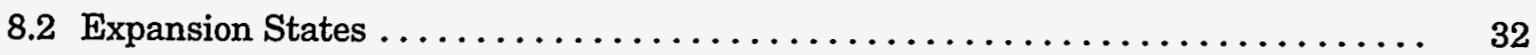

8.3 Detonation in Condensed Explosives with Low Initial Densities . . . . . . . . 32

8.4 High Pressure Gas Detonations $\ldots \ldots \ldots \ldots \ldots \ldots \ldots \ldots \ldots \ldots \ldots \ldots \ldots \ldots$

9. Summary and Conclusions $\ldots \ldots \ldots \ldots \ldots \ldots \ldots \ldots \ldots \ldots \ldots \ldots \ldots \ldots \ldots \ldots$

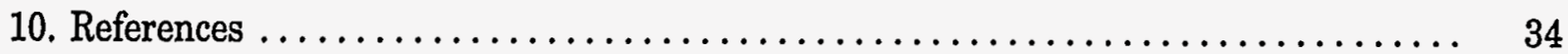

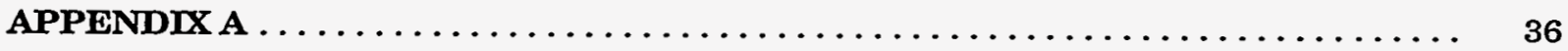

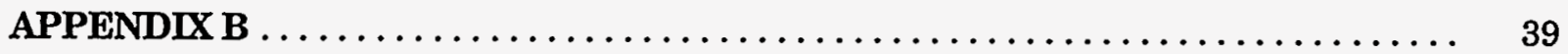

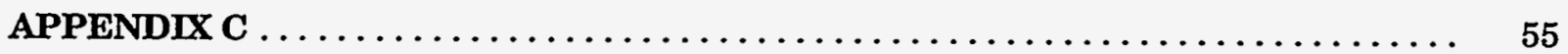




\section{List of Figures}

Figure 1. Plot of the normalized exponential 6 potential function for Argon (solid line) with an $r^{*}$ and $\varepsilon / k$ of $3.85 \AA$ and $122 \mathrm{~K}$, respectively. The repulsive (dotted line) and attractive (dashed line) energy terms are also shown.

Figure 2. Plot of the normalized Lennard-Jones potential function for Argon (solid) with an $\sigma$ and $\varepsilon / k$ of $3.43 \AA$ and $122 \mathrm{~K}$, respectively. The repulsive (dotted line) and attractive (dashed line) energy terms are also shown. ........

Figure 3. Plot of the $\mathrm{LJ}$ potential function for $\mathrm{AlCl}_{3}$ (solid line). The EXP 6 potential functions are plotted with the LJ characteristic diameter (dashed) and the corrected characteristic diameter (dash dotted) . . . . . . . . . . . . . . .

Figure 4. Plot of the $r^{*} \mathrm{SCS}$ versus $r_{4 \mathrm{~B}}^{*}$ for 103 different molecules.

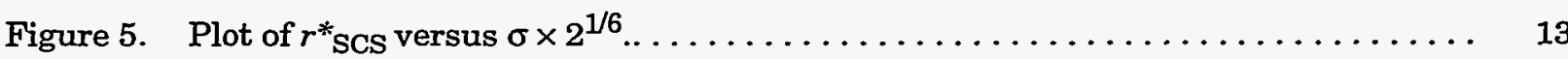

Figure 6. Plot of $(\varepsilon / k)_{S C}$ versus $(\varepsilon / k)_{L J} \ldots \ldots \ldots \ldots \ldots \ldots \ldots \ldots \ldots \ldots \ldots \ldots$

Figure 7. Plot of the exponential 6 potential function for $\mathrm{AlCl}_{3}$ using the SCS parameters $\left(r^{*}=5.84 \AA, \varepsilon / k=509 \mathrm{~K}\right)$ and the LJ corrected parameters

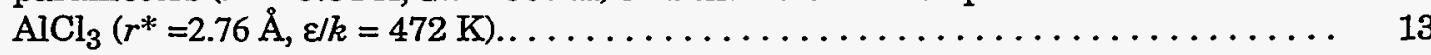

Figure 8. Geometrical representation of $\mathrm{CH}_{2} \mathrm{O} \ldots \ldots \ldots \ldots \ldots \ldots \ldots \ldots \ldots \ldots \ldots$

Figure 9. Correlation between molecular volume and A) $r^{*}$ SCS for 95 species and B) $\sigma \times 2^{1 / 6}$ for 195 species. The linear correlation in $A$ is replotted in $B$ and labeled as Eq. (5). . . . . . . . . . . . . . . . . . . . . . . .

Figure 10. Plot of poor correlation between LJ potential well depths and the electron density for $\mathbf{2 1 5}$ molecules. The monatomic species are shown as open circles.

Figure 11. Formyl fluoride, $\mathrm{CHFO}, 298 \mathrm{~K}$ and $3000 \mathrm{~K}$ isentrope predictions using the ideal gas EOS, the BKWS-EOS, and the JCZS-EOS. Parameters for the JCZS-EOS were chosen to be $\mathrm{r}^{*}=4.50 \AA$ and $\varepsilon / k=150 \mathrm{~K}$ using Eq. (5) for $\mathrm{r}^{*}$ and fitting $\varepsilon / k$ to match the high pressure $298 \mathrm{~K}$ isentrope.

Figure 12. Carbon subnitride, $\mathrm{C}_{4} \mathrm{~N}_{2}, 298 \mathrm{~K}$ isentrope predictions using the ideal gas EOS, BKWS-EOS, and the JCZ3-EOS. The JCZ prediction labeled "Fit" uses $r^{*}$ from Eq. (12) and the prediction labeled "Special Fit" used $r^{*}$ to best fit the BKWS isentrope. . . . . . . . . . . . . . . . . . . . . . .

Figure 13. Comparison of measured (symbols) liquid shock Hugoniot to predicted liquid shock Hugoniot (lines) using the BKWS-EOS, BKWC-EOS, and JCZS-

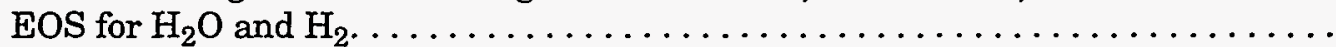

Figure 14. Comparison of measured (symbols) liquid shock Hugoniot to predicted liquid shock Hugoniot (lines) using the BKWS-EOS, BKWC-EOS, and JCZSEOS for A) $\left.\mathrm{CH}_{3} \mathrm{OH}, \mathrm{B}\right) \mathrm{CH}_{4}$, and C) $\mathrm{CO}_{2} \ldots \ldots \ldots \ldots \ldots \ldots \ldots \ldots \ldots \ldots \ldots \ldots \ldots \ldots$ 
Figure 15. Comparison of measured (symbols) liquid shock Hugoniot to predicted liquid shock Hugoniot (lines) using the BKWS-EOS, BKW.C-EOS, and JCZS-

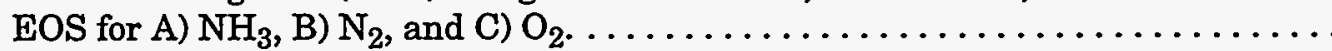

Figure 16. Comparison of measured (symbols) liquid shock Hugoniot to predicted liquid shock Hugoniot (lines)using the BKWS-EOS, BKWC-EOS, and JCZS-

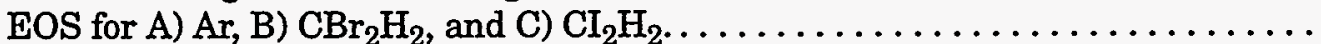

Figure 17. CHEETAH interface with DAKOTA.

Figure 18. Comparison of measured (symbols) detonation velocity and pressure for PETN to predictions using the BKWS-EOS (dashed lines) and the JCZS-

EOS (solid lines).

Figure 19. Predicted (lines) and measured (symols) detonation velociteis for high pressure gases.

\section{List of Tables}

Table 1. EXP 6 parameters used with JCZ3-EOS to best match liquid shock Hugoniot data

Table 2. DAKOTA optimized $r^{*}$ values for major $\mathrm{C}, \mathrm{H}, \mathrm{N}, \mathrm{O}, \mathrm{Cl}$, and $\mathrm{F}$ species $\ldots \ldots \ldots$

Table 3. Measured and predicted detonation velocities and pressures ........... 25

Table 4. $\quad$ RMS percent errors - optimization $\ldots \ldots \ldots \ldots \ldots \ldots \ldots \ldots \ldots \ldots \ldots \ldots \ldots \ldots$

Table 5. RMS percent errors - optimization $\ldots \ldots \ldots \ldots \ldots \ldots \ldots \ldots \ldots \ldots \ldots \ldots \ldots$

Table 6. Overall percent RMS errors for $\mathrm{D}$, $\mathrm{P}$, and $\mathrm{T} \ldots \ldots \ldots \ldots \ldots \ldots \ldots \ldots \ldots \ldots \ldots \ldots$

Table 7. Measured and predicted detonation temperatures using CHEETAH $1.4 \ldots \ldots \ldots \quad 27$

Table 8. Measured and predicted detonation velocities and pressure with \%RMS errors... 28

Table 9. Percent RMS errors for $\mathrm{E}, \mathrm{E}_{2.2}, \mathrm{E}_{4.1}, \mathrm{E}_{6.5} \ldots \ldots \ldots \ldots \ldots \ldots \ldots \ldots \ldots \ldots \ldots$

Table A.1 Species with known critical volumes.................... 36

Table A.2 Species with known critical temperatures $\ldots \ldots \ldots \ldots \ldots \ldots \ldots \ldots \ldots \ldots$

Table A. 3 Specieswith known Lennard-Jones parameters ................. 38

Table B.1 The complete JCZS database of $r^{*}$ and $\varepsilon / k$ values $\ldots \ldots \ldots \ldots \ldots \ldots \ldots \ldots$ 
(Intentionally left blank) 


\section{Executive Summary}

Determination of product species and associated equations-of-state (EOS) for energetic materials with complex elemental compositions remains a major unsolved problem. A simple EOS model is needed to predict thermochemical behavior of product species for conditions ranging from high pressure detonation states to low pressure ideal conditions. Such an EOS model should be based on physical arguments, rather than excessive curve fittings to a limited set of specific conditions. The JacobsCowperthwaite-Zwisler-3 EOS $^{1}$ (JCZ3-EOS) uses exponential 6 (EXP 6) intermolecular potentials to describe the P-V-T relationship of the gaseous product species resulting from detonation of energetic materials.

The primary disadvantage of using the JCZ3-EOS for equilibrium calculations of energetic materials is that only 20 species have known JCZ3 molecular potential force constants. Realistic thermochemical equilibrium calculations require an EOS with a large species database to encompass all possible product species in a detonation event. In this work, a new database for use with the JCZ3EOS has been developed. This new database will be referred to as the JCZS (where the $S$ refers to Sandia) EOS database. A methodology has been established to increase the size of the JCZS database to approximately 750 species. Among these species are all the gases in the JANNAF ${ }^{2}$ database. For each species, force constants are obtained to parameterize an EXP 6 potential function. One technique of obtaining these constants relates Lennard-Jones (LJ) potential function parameters to the EXP 6 potential function parameters. Another technique uses a simple corresponding states (SCS) theory (SCS) that relates the unknown molecular potential force constants of a molecule to the constants of a corresponding states molecule, argon, through use of critical properties. This method was used by Ross and $\operatorname{Re}^{3}$ for simple molecules. The remaining constants are obtained in the present work from a series of correlation and estimation techniques that are presented later. In addition to these techniques, a few important species constants were obtained by matching liquid shock Hugoniot data.

Hugoniot calculations with the JCZS-EOS are shown to adequately replicate Hugoniot data for various molecules. Various detonation and cylinder expansion calculations using the JCZS-EOS also compare favorably to experimental data. The JCZS-EOS is shown to adequately predict high pressure states from $500 \mathrm{kbar}$ to expansion states near atmospheric pressure.

\section{JCZ3-EOS Background} EOS: ${ }^{4}$

The JCZ3-EOS uses an equation based on P-V-T relationships similar to the Mie-Grüneisen

$$
P=\frac{G(V, T) n R T}{V}+P_{0}(V)
$$

where $P, n, R, T$, and $V$ represent the pressure, number of moles, universal gas constant, and volume, respectively. The form of the Grüneisen function, $G$, and the volume dependent internal pressure function, $P_{0}$, is documented (e.g., Ref. 1). Both the internal pressure function, $P_{0}$, and the Grüneisen function are composed of the EXP 6 potential function:

$$
\varphi(r)=\varepsilon\left[\left(\frac{6}{\eta-6}\right) \exp \left[\eta\left(1-r / r^{*}\right)\right]-\left(\frac{\eta}{\eta-6}\right)\left(\frac{r^{*}}{r}\right)^{6}\right]
$$


where $\varepsilon$ is the well depth for the pair potential and $r^{*}$ is the radius of the minimum pair potential energy. The molecular force parameters $\varepsilon, \eta$, and $r^{*}$ are required for each product species. The force constant, $\varepsilon$, is often given as $\varepsilon / k$, where $k$ is Boltzmann's constant. The explicit dependence of the Grüneisen function, $G$, and the internal pressure function, $P_{o}$, on the potential function, $\varphi$, is not obvious and the interested reader is referred to Ref. [1] for more information. Hobbs and Baer ${ }^{5}$ have shown that the investigators using $\eta=13$ give the best agreement between measured and predicted pure liquid shock Hugoniots than other values of $\eta$. Therefore this study also assumes that $\eta$ is 13 for all molecules, leaving $r^{*}$ and $\varepsilon / k$ to be determined for each molecule.

Figure 1 shows a plot of the repulsive and attractive energy terms in the EXP 6 potential function for Argon with $r^{*}=3.85 \AA, \varepsilon / k=122 \mathrm{~K}$. Molecules attract each other when they are separated by distances greater than $r^{*}$. As the molecules come closer together than $r^{*}$, the molecules repel one another as modeled by the repulsive term.

\section{Obtaining the Exponential 6 Potential Force Con- stants from Lennard-Jones Potential Parameters}

Similar to the EXP 6 potential function, the Lennard-Jones (LJ) potential function describes the repulsion and attraction between spherical molecules as shown in Fig. 2 with characteristic diameter, $\sigma$, set equal to $3.43 \AA$, and the well depth, $\varepsilon / k$, being set to $122 \mathrm{~K}$. The value of the two potential func-

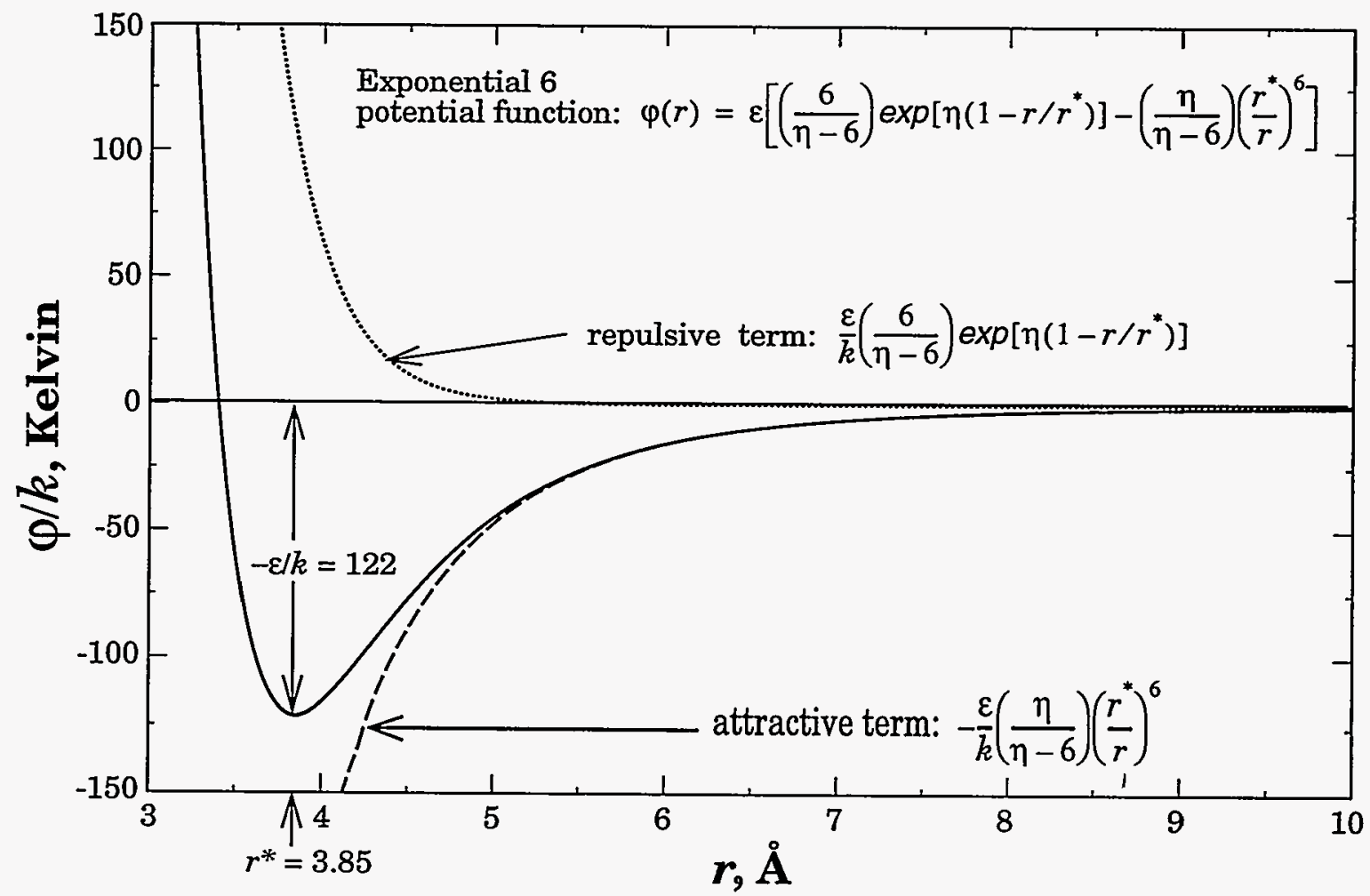

Fig. 1. Plot of the normalized EXP 6 potential function for Argon (solid line) with an $r^{*}$ and $\varepsilon / k$ of $3.85 \AA$ and $122 \mathrm{~K}$, respectively. The repulsive (dotted line) and attractive (dashed line) terms are also shown. 


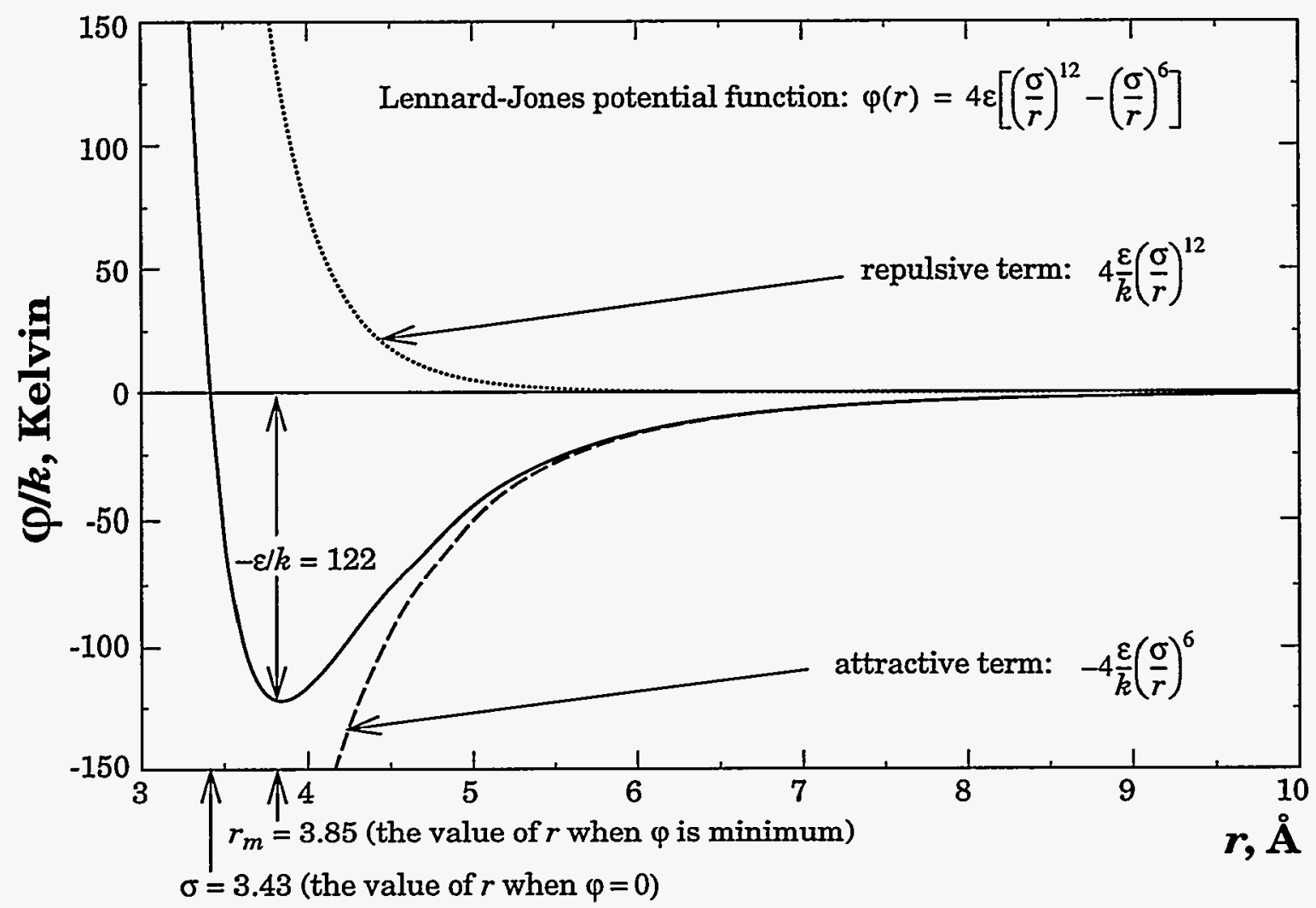

Fig. 2. Plot of the normalized LJ potential function for Argon (solid line) with an $\sigma$ and $\varepsilon / k$ of $3.43 \AA$ and $122 \mathrm{~K}$, respectively. The repulsive (dotted line) and attractive (dashed line) terms are also shown.

tions in Fig. 1 and 2 using the EXP 6 function and the LJ function are essentially identical. The primary difference between the two function is the location of the characteristic diameter depicted as $r^{*}$ for the EXP 6 function and $\sigma$ for the LJ function.

The LJ characteristic diameter, $\sigma$, is related to $r^{*}$ of the EXP 6 potential function by: ${ }^{6} \sigma / r^{*}=0.8909$ or $r^{*}=\sigma \times 2^{1 / 6}$. The constant $2^{1 / 6}$ was determined by finding the minimum of the LJ potential function. As shown in Fig. $2, \sigma$ is the value of $r$ when $\varphi=0$. But, $r^{*}$ in the EXP 6 potential function is at the bottom of the potential well when $\varphi$ is minimum. By taking the derivative of the LJ potential function, $r_{m}$, the value of $r$ at the bottom of the potential well, can be determined. This value, $r_{m}$, is equivalent to the EXP 6 force constant $r^{*}$. Figure 3 demonstrates the method of obtaining EXP6 parameters from $\mathrm{LJ}$ parameters for $\mathrm{AlCl}_{3}$. The

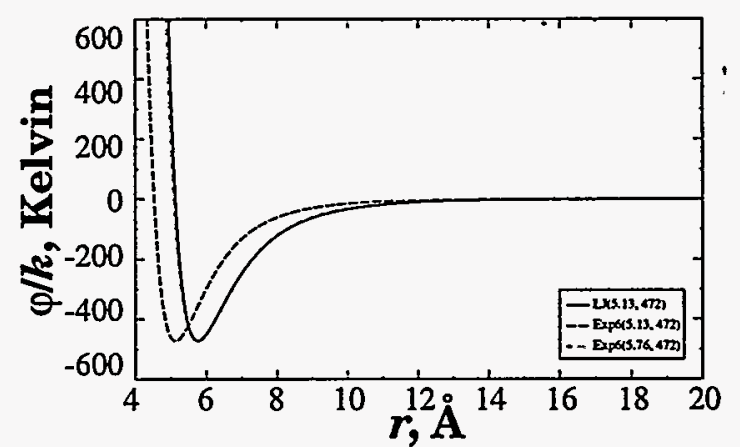

Fig. 3. Plot of the $\mathrm{LJ}$ potential function for $\mathrm{AlCl}_{3}$ (solid line). The EXP 6 potential functions are plotted with the LJ characteristic diameter (dashed) and the corrected characteristic diameter (dash dotted). 
solid curve represents the $\mathrm{LJ}$ potential function with the accepted experimental values of $\sigma=5.13, \varepsilon / k$ $=472$. The dashed curve represents the EXP 6 potential function with the LJ force parameters used directly. The dashed curve is shifted to the left of the LJ potential function. The dash-dotted curve represents the EXP 6 potential using the adjusted LJ parameters $\left(r^{*}=5.76=\sigma \times 2^{1 / 6}\right)$ while retaining the value of $\varepsilon / k=472$. The dash-dotted curve is an acceptable fit to the original $\mathrm{LJ}$ potential function curve.

Of the 750 species listed in the JANNAF ${ }^{2}$ tables, 200 have LJ parameters. References for LJ values used in this study are listed in Appendix A in Table A.3. EXP 6 parameters obtained from LJ data are assumed to be the most accurate since experimental data were used in obtaining most of these values.

\section{Estimating the Exponential 6 Potential Force Con- stants from Critical Properties}

At the beginning of this study, JCZS-EOS force constants were initially determined by the following four parameter corresponding states (4PCS) equation set: ${ }^{5}$

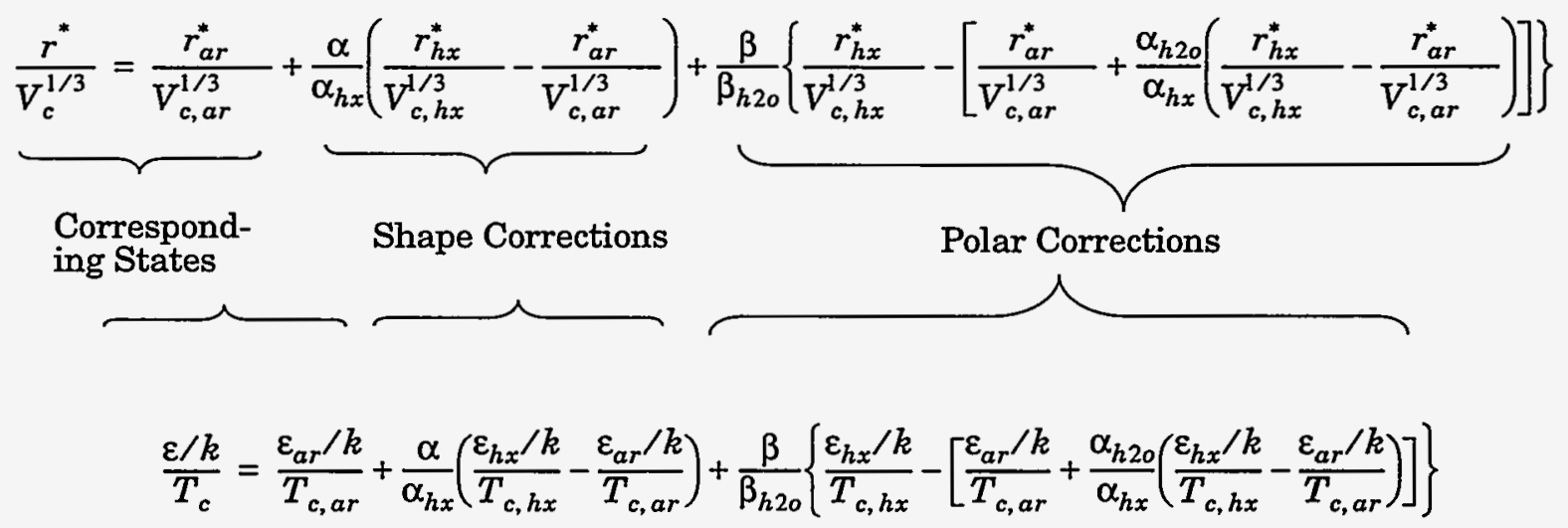

The first term of Eq. (3) and (4) represent the simple corresponding states (SCS) law used by Ross and $\mathrm{Re}^{3}$ to determine force constants as proposed originally by Hirschfelder et al. ${ }^{7}$ The second and third terms of each equation represent shape and polar corrections obtained by the ELK method. ${ }^{8-9}$ The values $r^{*}$ and $\varepsilon / k$ were calculated using the critical temperature, critical volume, $\alpha$ and $\beta$ values. $\alpha$ was calculated from the acentricity factor, $\beta$ was calculated from polarity, and $\beta_{h}$ was calculated from the heat of vaporization. Pure shock Hugoniot calculations with the JCZ3-EOS, using potential parameters determined with the SCS method yielded comparable results to JCZ3 Hugoniot estimates using parameters determined with the 4PCS method. The shape and polar corrections in Eq. (3) and (4) may not be necessary for Hugoniot calculations using the JCZ3-EOS.

The EXP 6 potential function implicitly assumes that molecules are both spherical and nonpolar. Including shape and polar effects are typically addressed by adding terms to the potential function, rather than changing $r^{*}$ and $\varepsilon / k$, as in the 4PCS method. Figures 4 show that shape and polar corrections do not significantly influence $r^{*}$. Figure 4 shows a plot of $r^{*}$ SCS versus $r_{4 \mathrm{P}}^{*}$ The subscripts SCS and 4PCS denote that $r^{*}$ was calculating using the SCS technique and the 4PCS technique, respectively. Figure 4 shows that the difference between the two methods is minimal. In the present work, the SCS technique, without the shape or polar correction, is used to estimate $r^{*}$ and $\varepsilon / k$. 


\section{Estimating the Exponential 6 Potential Force Constants from Critical Properties}

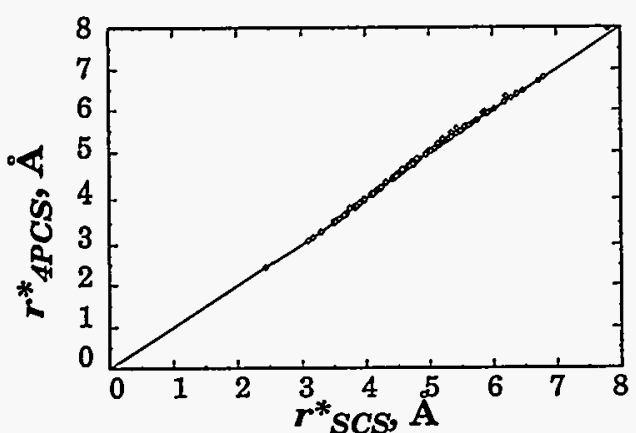

Fig. 4. Plot of the $r^{*}$ SCS versus $r_{4 \mathrm{PCS}}^{*}$ for 103 different molecules.

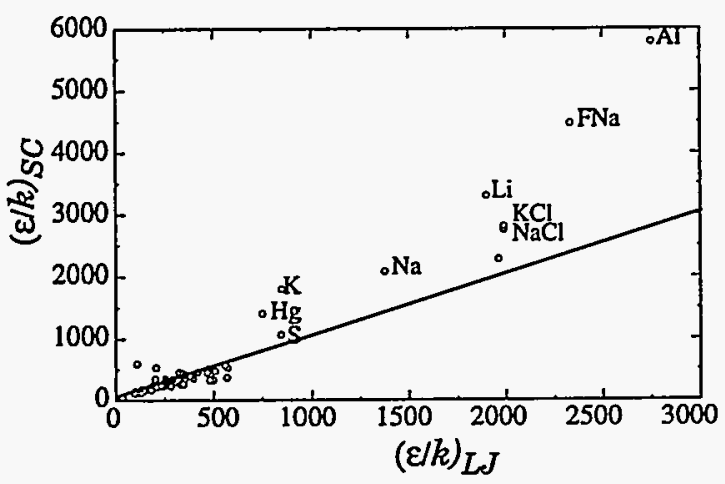

Fig.6. Plot of $(\varepsilon / k)_{S C}$ versus $(\varepsilon / k)_{L J}$.

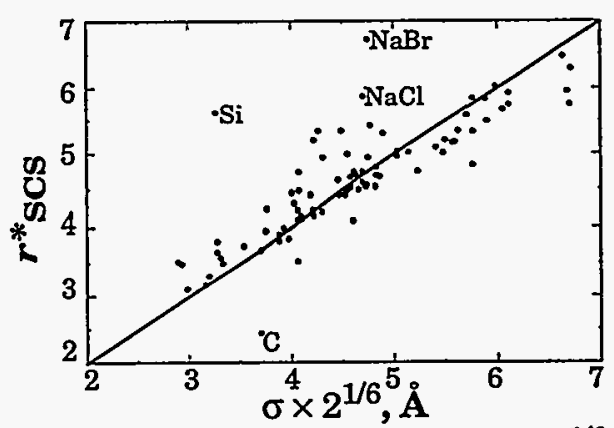

Fig. 5. Plot of $r^{*}$ SCS versus $\sigma \times 2^{1 / 6}$.

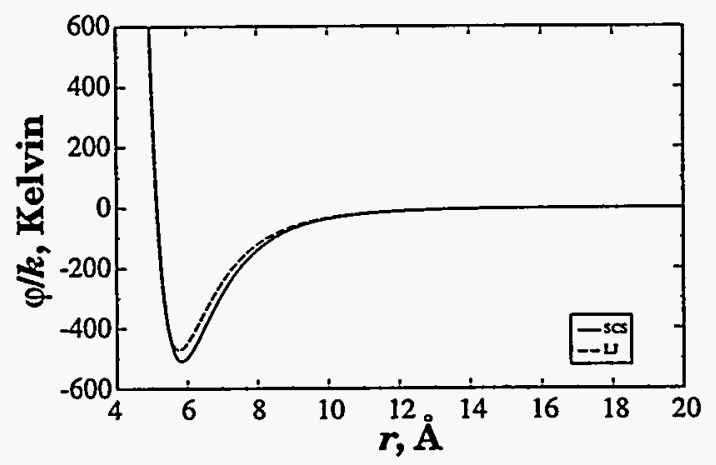

Fig. 7. Plot of the EXP 6 potential for $\mathrm{AlCl}_{3}$ using the SCS method $\left(r^{*}=5.84, \varepsilon / k=509\right)$ and the LJ method $\left(r^{*}=\sigma \times 2^{1 / 6}=5.13 \times 2^{1 / 6}=2.76, \varepsilon / k=472\right)$.

Figure 5 shows the agreement between the corrected LJ characteristic diameter as discussed in Section $3, \sigma \times 2^{1 / 6}$, and $r^{*}$ SCS. The correlation is especially good for covalently bonded species. The species with poor correlation are either monatomic species or ionically bonded species. Table A.1 in Appendix A gives the literature reference to each critical volume found. Table A.2 in Appendix A gives the references for each critical temperature. Figure 6 shows a plots of $(\varepsilon / k)_{L J}$ versus $(\varepsilon / k)_{S C S}$. Good correlation exists between the SCS technique and the experimentally determined values of $\varepsilon / k$. Large deviations exist for monatomic species and ionically bonded molecules as shown in Fig. 6 .

Figure 7 shows the EXP 6 function for a typical molecule in the JANNAF database, $\mathrm{AlCl}_{3}$, determined using the SCS method and the LJ method. Both methods give similar predictions of the intermolecular potential. Unfortunately, not all chemical species have critical properties. Critical properties of unstable species are rare, and for free radical species, non-existent. For heavy metals and many ionic compounds, reported values are typically calculated with questionable accuracy. Out of the database of 750 species, 150 species have both the critical temperature and critical volume. Of these 150 species, 93 also have LJ parameters. Thus, the EXP 6 parameters for approximately 250 out of 750 JANNAF species can be obtained using either the SCS technique or can be estimated with known LJ constants. 


\section{Estimating the Exponential 6 Potential Force Con- stants through Correlation and Curve Fitting}

This section describes the method used to obtain the remaining EXP 6 potential parameters for species without critical properties or LJ parameters. Some judgement was also required to determine whether these values could be used in the JCZS database. The methodology of achieving the values of the near 500 remaining species plus those uncertain cases is explained in Sections 5.1 and 5.2. The methods used to select the JCZS parameters, when more than one value exists, are discussed in Section 5.3.

\subsection{Determining $r^{*}$}

The BKWS study ${ }^{10}$ required the calculation of molecular volume of each species to estimate covolumes. Molecular volume is calculated from known and predicted van der Waals radii. Figure 8 shows a geometrical representation of $\mathrm{CH}_{2} \mathrm{O}$. When calculating the molecular volume of a species such as $\mathrm{CH}_{2} \mathrm{O}$, the volume of each atom is assumed to be represented by a sphere with the radius equal to van der Waals radius. When atoms overlap in a molecule, the volume is only represented once. Therefore the molecular volume is the same as the volume of a space-filling model with the appropriate units.

A strong correlation exists between the actual volume of a gas molecule calculated using van der Waals radii and the radius of the minimum pair potential energy, $r^{*}$. Figure 9.A shows the correlation between $r^{*}$ scs and molecular volume to the third power for 93 species calculated with known critical volumes.

Most of the species that stray farthest from the linear correlation in Figure 9.A are monatomic. Because almost all of these have LJ potential parameters for use in the EXP 6 potential function anyway, the monatomic species were eliminated from the least squares fit to obtain an improved correlation. The least squared linear correlation of the polyatomic species in Fig. 9.A can be used to estimate $r^{*}$ from molecular volumes:

$$
r^{*}=1.19(\text { MoleculärVolume })^{(1 / 3)}+0.68
$$
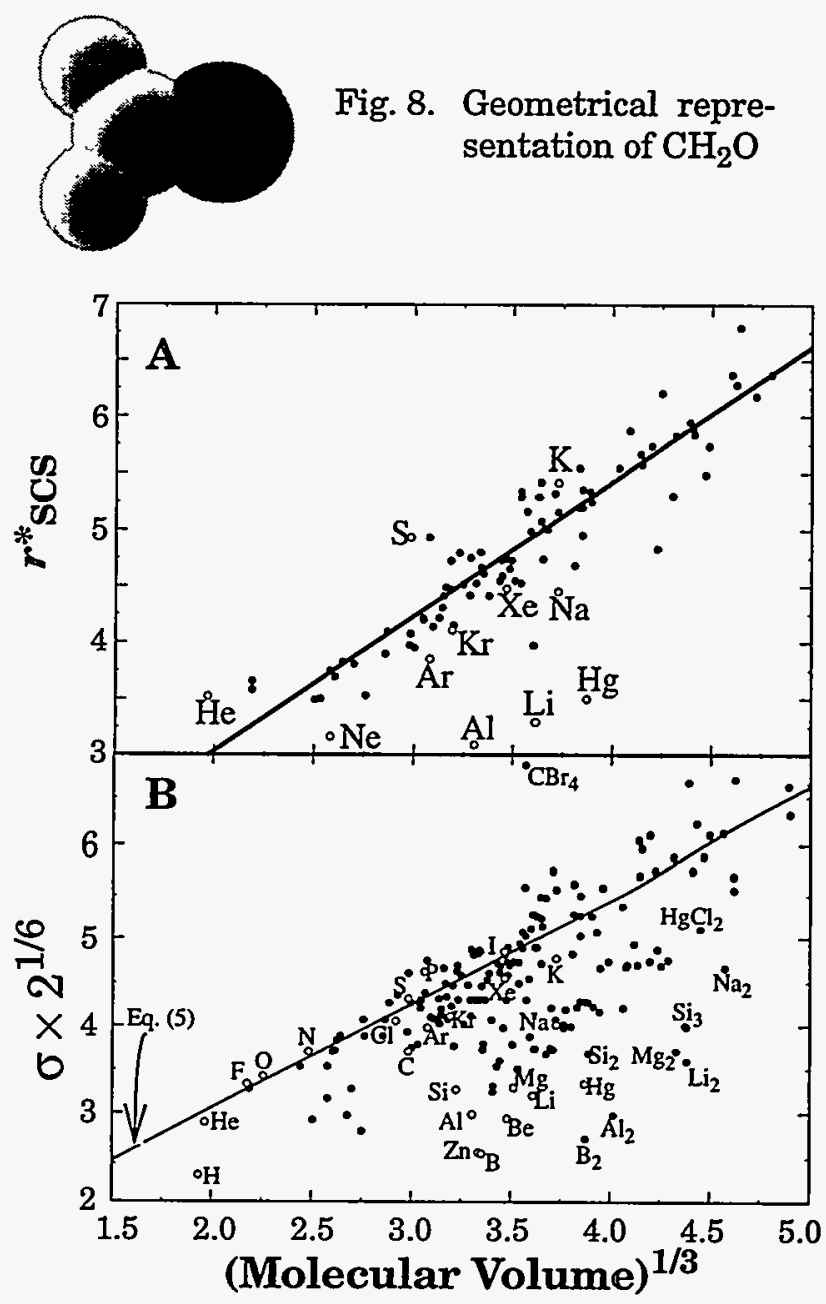

Fig. 9. Correlation between molecular volume and A) $r^{*}$ SCs for 95 species and B) $\sigma \times 2^{1 / 6}$ for 195 species. The linear correlation in $A$ is replotted in B and labeled as Eq. (5). 
As shown previously in Fig. 5, the corrected LJ characteristic diameter, $\sigma \times 2^{1 / 6}$, correlated adequately with $r^{*}$ calculated using SCS theory. Thus, the $\sigma \times 2^{1 / 6}$ should also be correlated to (Molecular Volume) $)^{1 / 3}$ as shown in Fig. 9.B. Again, most of the scatter in Fig. 9.B is attributed to monatomic species.

\subsection{Determining $\varepsilon / k$}

A similar correlation for $\varepsilon / k$ with molecular volume was sought. Electron density can be calculated readily from the molecular volume and was initially thought to be correlated to the potential well depth. Unfortunately, Fig. 10 there is a poor relationship between the 215 LJ potential well depths, $\varepsilon / k$, and the electron density represented as the number of electrons, $Z$, divided by the molecular volume as shown in Fig. 10. References for the LJ potential well depths can be found in Appendix A Table A.3. The potential well depths determined with corresponding states methods are also poorly correlated with electron density. Unfortunately, an adequate correlation of $\varepsilon / k$ was not found in this study. An alternative method for determining $\varepsilon / k$ was developed. This method involves choosing $\mathrm{r}^{*}$

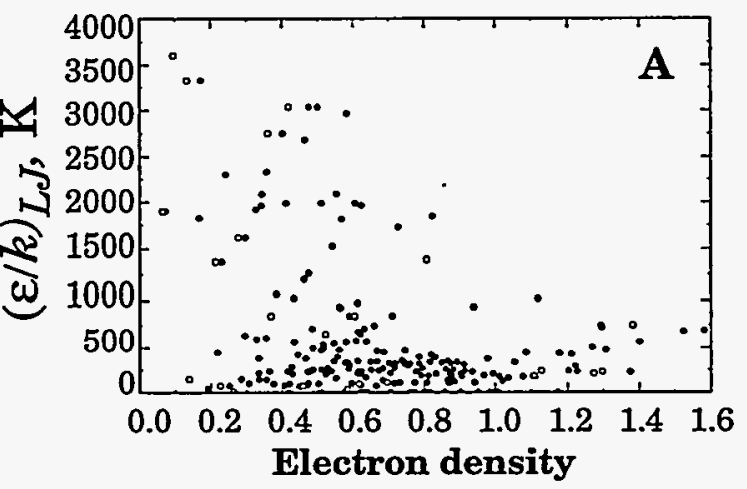

Fig. 10. Plot of poor correlation between LJ potential well depths, $\varepsilon / k$, and the electron density for 215 molecules. The monatomic species are shown as open circles. hich high pressure, pure species, isentropes calculated with the BKWS-EOS which is described subsequently.

\subsubsection{The BKW-EOS}

The Becker-Kistiakowsky-Wilson equation-of-state (BKW-EOS) is used extensively to calculate detonation properties. Hobbs and $\mathrm{Baer}^{10}$ give the historical background and molecular covolumes for the BKW-EOS:

$$
\frac{P V}{R T}=1+X e^{\beta X} \quad \text { with } \quad X=\frac{\kappa \sum n_{i} k_{i}}{V(T+\theta)^{\alpha}}
$$

where $\mathrm{P}, \mathrm{V}, \mathrm{R}, \mathrm{T}$, and $\mathrm{n}_{\mathrm{i}}$ represent pressure, molar gas volume, gas constant, absolute temperature, and mole fraction of the $\mathrm{i}^{\text {th }}$ gaseous component, respectively. The summation extends over all components of the gaseous mixture. The covolume factors, $k_{i}$, representing excluded volume, are discussed subsequently. The parameters $\alpha, \beta, \kappa$, and $\theta$ are empirical constants. The quantity $\theta$ was added to the equation to prevent $P$ from approaching infinity as $T$ approaches zero. ${ }^{11}$ Typically, the parameters $\alpha, \beta, \kappa, \theta$, and $\mathrm{k}_{\mathrm{i}}$ are adjusted to fit measured detonation properties. Three different parameterizations of the BKW-EOS are in use: BKWC, ${ }^{12}$ BKWR, ${ }^{13}$ and BKWS. ${ }^{10}$ The C, R, and $S$ represent CHEETAH reparameterization, Finger et al. ${ }^{13}$ Reparameterization, and S Sandia reparameterization, respectively. The BKWS parameterization with covolumes based on physical arguments should give better predictions of detonation properties than the empirical BKW parameterizations (BKWC and BKWR) with covolumes used as fitting parameters. 


\subsubsection{The BKWR Parameterization}

Parameters optimized in the BKWR-EOS included three BKW constants $(\beta, \kappa$, and $\theta)$ and 10 covolumes. The constants were calibrated using 10 measured detonation velocities (D), 10 measured detonation pressures (P), and 4 measured detonation temperatures (T). The BKWR-EOS produces adequate detonation velocities and pressures. However, the predicted detonation temperatures are about a thousand degrees too low and the energies of detonation are uniformly about $10 \%$ too high. ${ }^{14}$ To correct for these deficiencies, BKWR energies are corrected by normalizing with $1.62 \mathrm{~g} / \mathrm{cc}$ PETN as a standard. The BKWR-EOS (13 gas and I condensed species) is only applicable to energetic materials consisting of $\mathrm{C}, \mathrm{H}, \mathrm{N}, \mathrm{O}$, and $\mathrm{F}$. Thus the BKWR-EOS is inadequate to determine all the parameters for the JCZS-EOS with 750 species containing a variety of elements.

\subsubsection{The BKWS-EOS Parameterization}

Parameters optimized in the BKWS-EOS only include the three BKW constants $(\beta, \kappa$, and $\theta)$. Unlike the BKWR-EOS and BKWC-EOS, covolumes used in the BKWS-EOS were assumed to be invariant and based on the molecular structure of the product species. Covolumes were obtained using measured van der Waal radii, bond lengths, and bond angles. The three BKW constants were calibrated using a density weighted cost function comprised of 103 detonation velocities, 64 detonation pressures, and 14 detonation temperature measurements. The BKWS-EOS predicts higher detonation temperatures leading to lower detonation energies allowing calculated energies of detonation to be used without correction. Since covolumes are not used as adjustable constants, the BKWS-EOS can be applied to a large number of product species. Currently the BKWS library considers approximately 750 gaseous products and 400 condensed reaction products found in the JANNAF tables ${ }^{2}$ and can be used to parameterize $\varepsilon / k$ for the JCZS-EOS.

A thermal-elastic $\operatorname{EOS}^{15}$ was used for condensed reaction products. However, thermal expansion and compressibility data were not available for all 400 condensed species. In the BKWS database, most condensed phase species were assumed to be incompressible, although temperature and pressure dependent compressibility can be easily added when such information becomes available. Condensed $\mathrm{Al}, \mathrm{AlN}, \mathrm{Al}_{2} \mathrm{O}_{3}, \mathrm{Al}_{4} \mathrm{C}_{3}, \mathrm{C}$ and $\mathrm{H}_{2} \mathrm{O}$ were included as compressible species.

\subsubsection{The BKWC Parameterization}

The success of the BKWS-EOS prompted Fried et al. ${ }^{12}$ to optimize the BKW parameters again, including covolumes, freeze-out temperature, and condensed phase compressibility constants using a smaller product species database ( 23 gaseous products and 2 condensed products) determined from major species predicted using the BKWSEOS. Parameters optimized in the BKWC-EOS include four BKW constants $(a, \beta, \kappa$, and, $\theta$ ), the freezing temperature used in cylinder expansion $\left(T_{f}\right)$, three parameters in the condensed-phase carbon EOS $\left(V_{o}, a\right.$, and $\left.b\right)$, and 23 covolumes. The $31 \mathrm{BKW}$ constants were calibrated using an estimated error weighted cost function comprised of 32, 30, and $132 \mathrm{D}, \mathrm{P}$, and expansion energies, respectively. With the large number of adjustable parameters, the BKWC-EOS was used to improve the prediction of detonation velocity and pressure over BKWS by about $1 \%$ for energetic materials composed of $\mathrm{C}, \mathrm{H}, \mathrm{N}$, and $\mathrm{O}$. However, improvement in detonation property prediction is not justified when experimental variability $(5-10 \%)$ is considered. Also, the BKWC optimization was not constrained to consider measured properties such as $\mathrm{H}$ and $\mathrm{O}$ van der. Waal radii. The optimized covolume of $\mathrm{H}_{2}$ became larger than $\mathrm{H}_{2} \mathrm{O}$ in the BKWC-EOS which is physically impossible. Significant errors are shown in Section 6 when the BKWC-EOS is used to predict shock Hugoniot data. Furthermore, with only a small set of product species, the BKWC-EOS cannot be used to parameterize the JCZS-EOS with 750 gaseous species. 


\subsubsection{Using the BKWS-EOS to Determine $\varepsilon / k$}

Because the BKWS database provides acceptable results for high pressure detonation states and the ideal gas law provides accurate results for low pressure states, $\varepsilon / k$ can be estimated by matching isentropes at high pressure and low pressure states using the calculated $r^{*}$ from molecular volume data. In this study, the standard temperature and pressure (298 $\mathrm{K}$ and $1 \mathrm{~atm}$ ) isentrope was chosen for fitting $\varepsilon / k$. Figure 11 shows the $298 \mathrm{~K}$ and $3,000 \mathrm{~K}$ isentrope for Formyl fluoride. Parameters for the JCZS-EOS were chosen to be $r^{*}=4.50 \AA$ and $\varepsilon / k=150 \mathrm{~K}$ using Eq. (5) for $\mathrm{r}^{*}$ and fitting $\varepsilon / k$ to match the high pressure $298 \mathrm{~K}$ isentrope. The agreement between the JCZS-EOS and BKWS-EOS at high pressure for the $3,000 \mathrm{~K}$ isentrope in Fig. 11 indicates that fitting the $298 \mathrm{~K}$ isentrope is sufficient to match isentropes at significantly different conditions.

Not all values of $r^{*}$ predicted with Eq. (5) were adequate to match the BKWS isentropes. For such species, $r^{*}$ was adjusted to match the BKWS isentrope as shown in Fig. 12 for carbon subnitride, $\mathrm{C}_{4} \mathrm{~N}_{2}$. For such cases, Eq. (5) is used as an initial estimate of $r^{*}$ and the both $\mathrm{r}^{*}$ and $\varepsilon / k$ are fit to the BKWS isentrope. The force parameters for these "specially fit" molecules are not unique and various combinations of parameters will give an adequate match to the BKWS isentrope.

As shown in Figures 11 and 12, the JCZS isentrope deviates from the BKWS isentrope at intermediate pressures. The JCZS isentropes matches the BKWS isentrope at high pressures. At intermediate pressures, the JCZS isentrope approaches the ideal gas isentrope whereas the BKWS isentrope remains at higher values. At low pressures, all three isentropes converge. As shown in the evaluation section, the JCZS-EOS model gives better predictions in this intermediate pressure regime giving better predictions of low density explosives and expansion states than the BKW-EOS. The intermediate pressure regimes in Fig. 11 and 12 show characteristics of the potential well described by the EXP 6 potential function.

Caution must be used when using the JCZS-EOS for molecules with $\varepsilon / k$ estimated from BKWS predictions. The parameters for these molecules are only as good as the BKWS predictions. Because the BKWS-EOS was calibrated at high pressures with explosives composed primarily of C, H, N, O, F, and $\mathrm{Cl}$, species with substantially different atomic compositions may be in error. One method to determine the accuracy of the BKWS and JCZS predictions would be to compare Hugoniot predictions to pure liquid shock Hugoniot data as discussed further in Section 6.

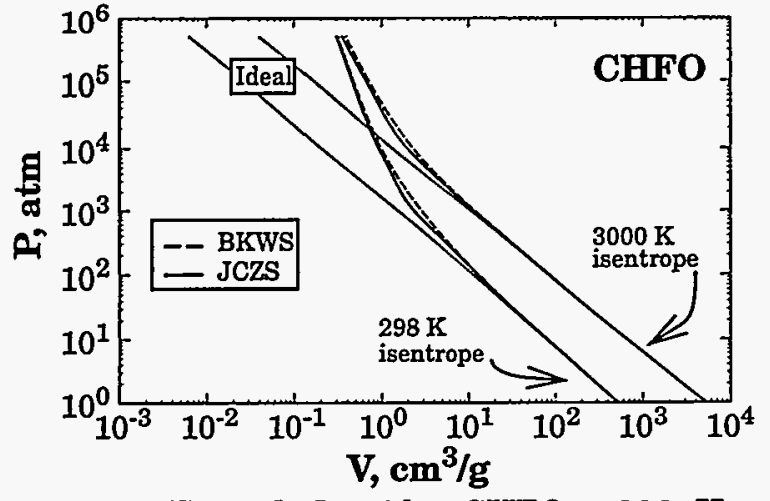

Fig. 11. Formyl fluoride, CHFO, $298 \mathrm{~K}$ and $3000 \mathrm{~K}$ isentrope predictions using the ideal gas EOS, BKWS-EOS, and the JCZS-EOS. Parameters for the JCZS-EOS were chosen to be $r^{*}=4.50$ $\AA$ and $\varepsilon / k=150 \mathrm{~K}$ using Eq. (5) for $\mathrm{r}^{*}$ and fitting $\varepsilon / k$ to match the high pressure $298 \mathrm{~K}$ isentrope.

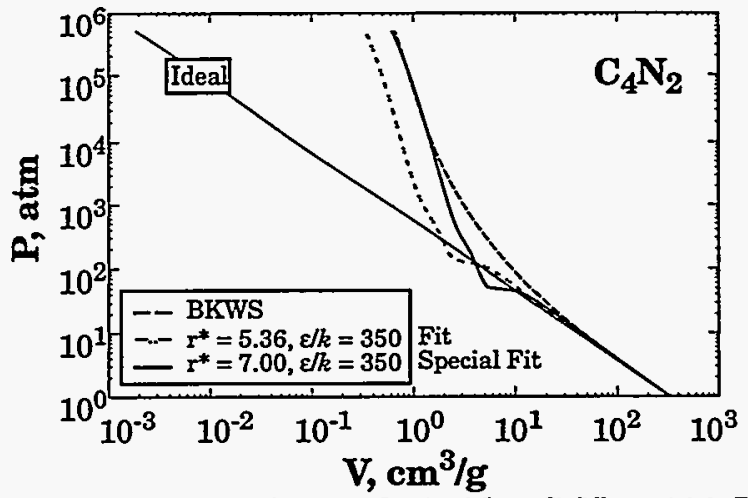

Fig. 12. Carbon subnitride, $\mathrm{C}_{4} \mathrm{~N}_{2}, 298 \mathrm{~K}$ isentrope predictions using the ideal gas EOS, BKWS-EOS, and the JCZ3-EOS. The JCZ prediction labeled "Fit" uses $r^{*}$ from Eq. (5) and the prediction labeled "Special Fit" used $r^{*}$ to best fit the BKWS isentrope. 


\section{Pure Liquid Shock Hugoniot Data}

The accuracy of an EOS can be tested by comparing predictions to data of pure liquid shock Hugoniots. Some caution must be used when using pure liquid shock Hugoniot data since the species may break into smaller fragments at elevated temperatures and pressures. Sheffield ${ }^{17}$ suggests that if the Hugoniot deviates from the "universal" liquid Hugoniot ${ }^{18}$ the species is likely breaking into smaller fragments. Figures 13 through 16 show a comparison between liquid shock Hugoniot data and predicted liquid shock Hugoniot using the BKWS-EOS, BKWC-EOS, and the JCZ-EOS for water, hydrogen, methanol, methane, carbon dioxide, ammonia, nitrogen, oxygen, carbon tetrachloride, and trichloromethane, respectively. The source of the EXP 6 parameters is given in Table 1. Three of the JCZS parameters were obtained by the SCS method $\left(\mathrm{CH}_{4}, \mathrm{~N}_{2}\right.$, and $\left.\mathrm{O}_{2}\right)$, three parameters were obtained by the $\mathrm{LJ}$ method $\left(\mathrm{CO}_{2}, \mathrm{NH}_{3}\right.$, and $\left.\mathrm{CHCl}_{3}\right)$, one parameter set was obtained by the 4PCS method, two parameter sets were obtained from literature values $\left(\mathrm{H}_{2} \mathrm{O}\right.$ and $\mathrm{Ar}$ ), one parameter set was obtained by slightly adjusting the LJ value of $r^{*}\left(\mathrm{H}_{2}\right)$, and one parameter set was obtained by a combination of the SCS and LJ methods $\left(\mathrm{CH}_{3} \mathrm{OH}\right)$.

Table 1. EXP 6 parameters used with JCZ3-EOS to best match liquid shock Hugoniot data

\begin{tabular}{|c|c|c|c|}
\hline Species & $\boldsymbol{r}^{*}$ & $\varepsilon / k$ & Source for JCZS Hugoniot fit \\
\hline $\mathrm{H}_{2} \mathrm{O}$ & 3.06 & 356 & Ref. 16 \\
\hline $\mathbf{H}_{\mathbf{2}}$ & 2.85 & 38 & $\mathrm{r}^{*}$ constrained so that $\mathrm{r}_{\mathrm{H} 2}^{*}<\mathrm{r}_{\mathrm{H} 2 \mathrm{O}}, \varepsilon / k$ selected from Ref. 34 \\
\hline $\mathrm{CH}_{3} \mathrm{OH}$ & 4.23 & 482 & $r^{*}$ taken as the average of SCS and LJ, $\varepsilon / k$ taken from $\mathrm{LJ}$ \\
\hline $\mathbf{C H}_{4}$ & 4.23 & 154 & SCS values \\
\hline $\mathrm{CO}_{2}$ & 4.22 & 244 & LJ values \\
\hline $\mathrm{NH}_{3}$ & 3.33 & 481 & LJ values \\
\hline $\mathbf{N}_{2}$ & 4.00 & 102 & SCS values \\
\hline $\mathbf{O}_{2}$ & 3.86 & 125 & SCS values \\
\hline Ar & 3.85 & 122 & Ref. 3 (Argon is used as the corresponding molecule for all SC molecules) \\
\hline $\mathbf{C C l}_{4}$ & 5.98 & 631 & 4PCS (Ref. 5) used instead of SCS because of the better fit \\
\hline $\mathrm{CHCl}_{3}$ & 6.05 & 340 & LJ values \\
\hline
\end{tabular}

The JCZS-EOS adequately predicts liquid shock Hugoniot data as shown in Figures 13-16. The better results of the BKWS predictions compared to the BKWC predictions are likely due to the values of the covolumes. Finger et al., ${ }^{13}$ Mader, ${ }^{11}$ and Cowan and Fickett ${ }^{29}$ report covolume factors calibrated with shock Hugoniot data for $\mathrm{CO}_{2}, \mathrm{H}_{2} \mathrm{O}, \mathrm{N}_{2}$, and $\mathrm{O}_{2}$ as $670,360,380$, and 325, respectively. The geometrical covolumes calculated by Hobbs and $\mathrm{Baer}^{30}$ are 70.3,39.9, 39.9, and 33.5, respectively. The covolume factors divided by the geometric covolume for these species are 9.53, 9.02, 9.52, and 9.70, respectively, giving an average value of 9.43. The covolumes reported in Figures 13-16, are the geometrical covolumes multiplied by 9.43 ; the BKWS covolume factors for $\mathrm{CO}_{2}, \mathrm{H}_{2} \mathrm{O}, \mathrm{N}_{2}$, and $\mathrm{O}_{2}$ are $663,376,376$, and 316. Even though the geometrical covolumes are similar to the values used in the 


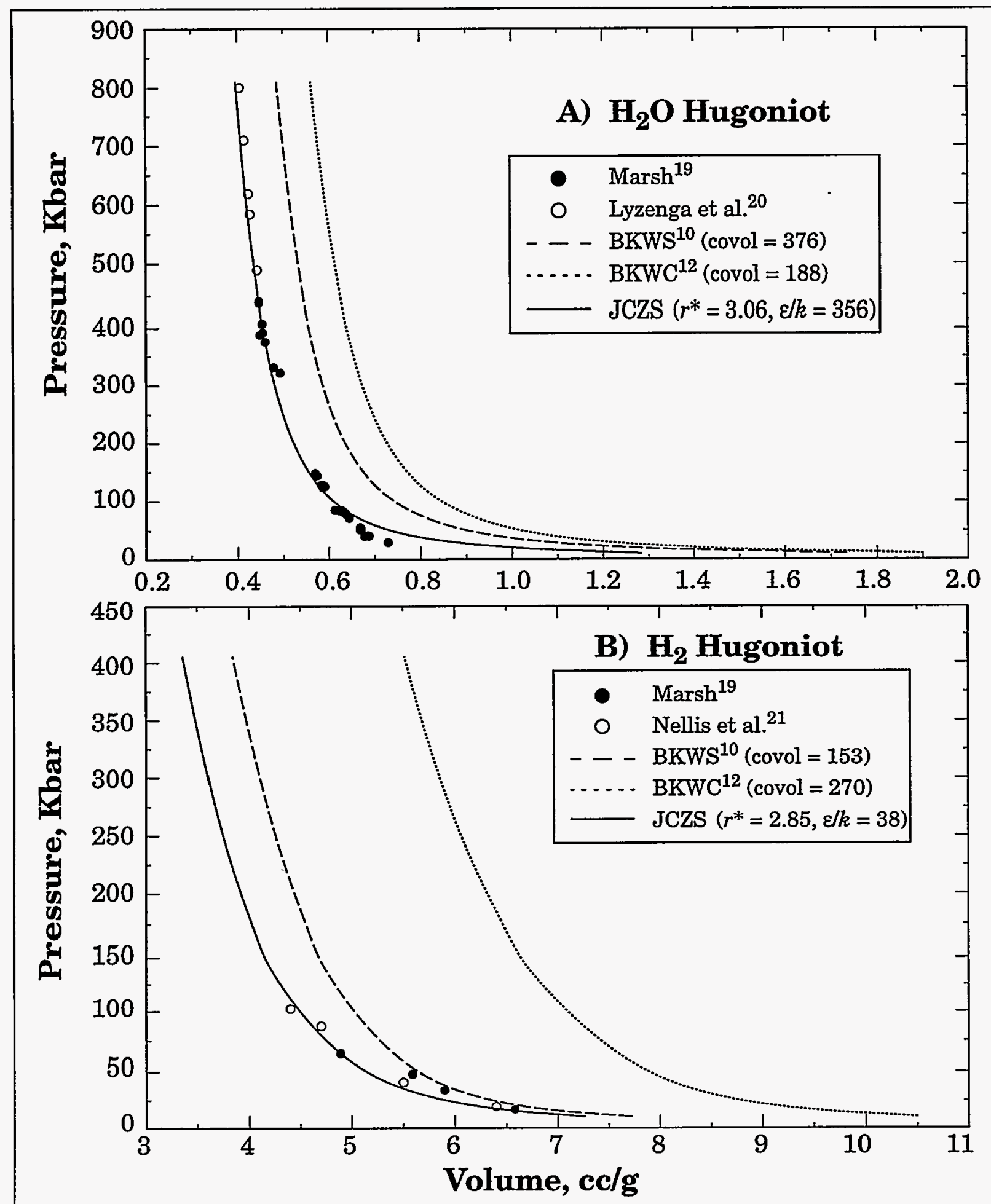

Fig. 13. Comparison of measured (symbols) liquid shock Hugoniot to predicted liquid shock Hugoniot using the BKWS-EOS, BKWC-EOS, and JCZS-EOS for $\mathrm{H}_{2} \mathrm{O}$ and $\mathrm{H}_{2}$. 


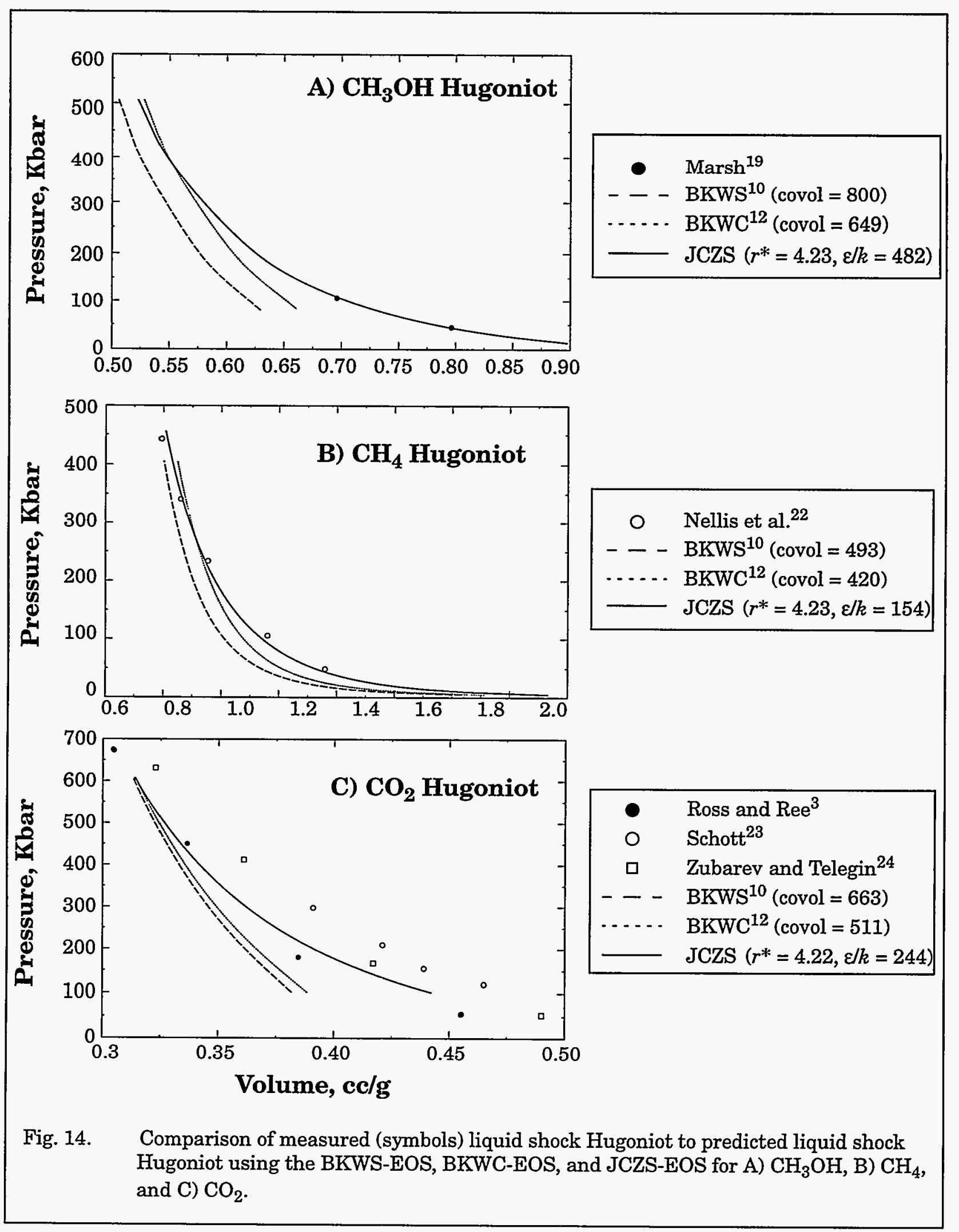




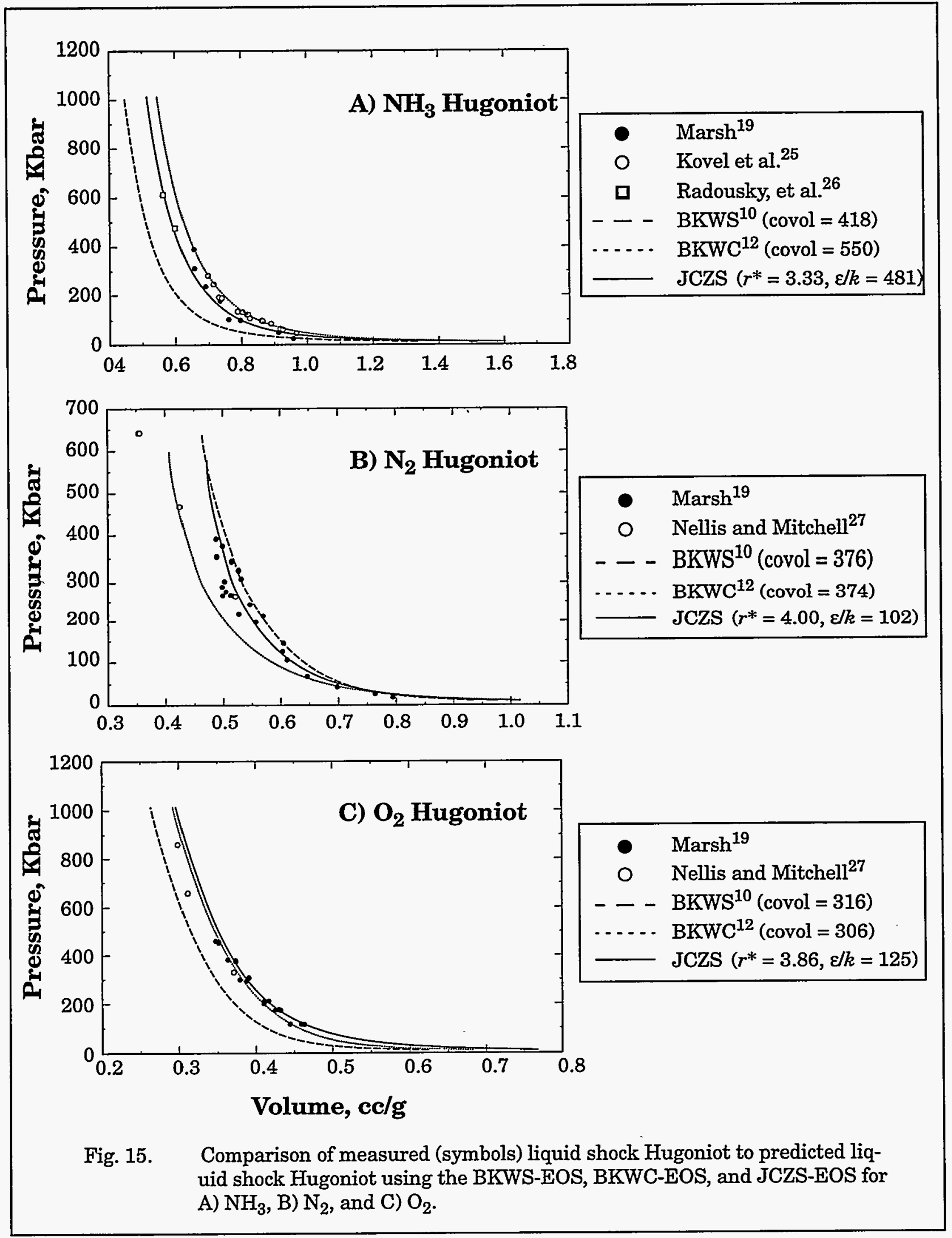


Pure Liquid Shock Hugoniot Data

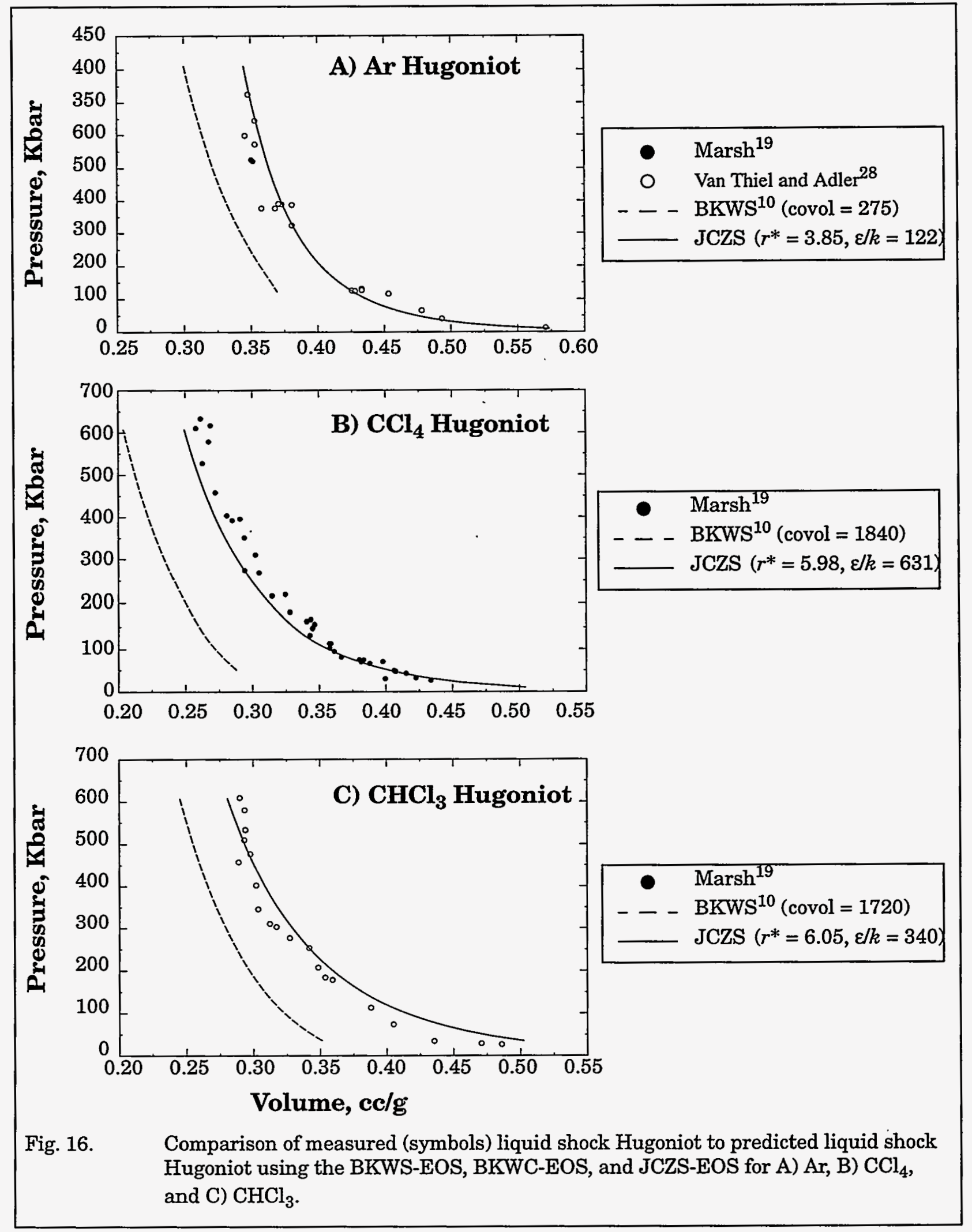


literature to predict Hugoniot data, the coefficients in the BKWS-EOS $(\beta, \kappa$, and $\theta)$ are different than the coefficients used in the literature and give slightly different results. Hugoniot calculations using the BKWC-EOS are not acceptable. The BKWC-EOS was developed by adjusting covolumes to match detonation states without regard to the physical significance of the covolume factors as discussed in Section 5.2.4. Although the BKWS covolumes were used as an initial estimate for the BKWC covolumes, the BKWC optimization was not constrained to consider measured properties such as $\mathrm{H}$ and $\mathrm{O}$ van der Waal radii. The optimized covolume of $\mathrm{H}_{2}$ became larger than $\mathrm{H}_{2} \mathrm{O}$ in the BKWC-EOS which is physically impossible. Such parameters lead to spurious results as shown in Fig. 13 for $\mathrm{H}_{2} \mathrm{O}$ and $\mathrm{H}_{2}$. Caution must be used when using the BKWC-EOS.

\section{DAKOTA Optimization}

To avoid an unconstrained reparameterization of the JCZS-EOS, similar to the BKWC reparameterization of the BKWS-EOS, the JCZS parameters for major species were slightly adjusted using constrained optimization to obtain optimal agreement with detonation velocity measurements. The species chosen for this constrained optimization are listed in Table 2 with the initial values of $r^{*}$ and the final optimized values of $r^{*}$. The initial $r^{*}$ values are either from the $\mathrm{LJ}$ values $(\mathrm{lj})$, isentrope fit values (fit), or the corresponding states values (cs). The source of the $r^{*}$ values are labeled in the superscript of $r^{*}$ initial. During the fitting process, $r^{*}$ was found to be more sensitive than $\varepsilon / k$ when fitting BKWS isentropes. The $\varepsilon / k$ values were left as the original lj, fit, or cs values. The complete JCZS database is given in Appendix $B$.

Table 2. DAKOTA optimized $r^{*}$ values for major $\mathrm{C}, \mathrm{H}, \mathrm{N}, \mathrm{O}, \mathrm{Cl}$, and $\mathrm{F}$ species

\begin{tabular}{|c|c|c|c|c|c|c|c|c|c|c|c|}
\hline Species & $\underset{\text { initial }}{r^{*}}$ & $\begin{array}{c}r^{*} \\
\text { opt. }\end{array}$ & Species & $\underset{\text { initial }}{r^{*}}$ & $\begin{array}{l}r^{*} \\
\text { opt. }\end{array}$ & Species & $\underset{\text { initial }}{\boldsymbol{r}^{*}}$ & $\begin{array}{l}r^{*} \\
\text { opt. }\end{array}$ & Species & $\underset{\text { initial }}{r^{*}}$ & opt. $^{*}$ \\
\hline $\mathrm{CClF}_{3}$ & $5.16^{\mathrm{lj}}$ & 4.71 & $\mathrm{CH}_{2} \mathrm{O}$ & $4.31^{\mathrm{cs}}$ & 4.40 & $\mathrm{CO}$ & $4.10^{\mathrm{j}}$ & 3.88 & $\mathbf{H}$ & $2.30^{\mathrm{lj}}$ & 2.00 \\
\hline CClFO & $5.07^{\text {fit }}$ & 5.06 & $\mathrm{CH}_{2} \mathrm{O}_{2}$ & $4.56^{\text {fit }}$ & 4.46 & $\mathrm{CO}_{2}$ & $4.22^{! j}$ & 4.22 & $\mathbf{H}_{2}$ & $3.28^{l j}$ & 2.85 \\
\hline $\mathbf{C F}_{2}$ & $4.08^{\mathrm{jj}}$ & 4.87 & $\mathbf{C H}_{3}$ & $4.27^{\mathrm{j}}$ & 4.15 & $\mathbf{C}_{2} \mathbf{F}_{3} \mathbf{N}$ & $5.36^{c s}$ & 5.83 & $\mathrm{H}_{2} \mathrm{O}$ & $2.92^{\mathrm{jj}}$ & 3.06 \\
\hline $\mathrm{CF}_{2} \mathrm{O}$ & $4.75^{c s}$ & 5.59 & $\mathrm{CH}_{3} \mathrm{~F}$ & $4.42^{\text {cs }}$ & 4.93 & $C_{2} F_{4}$ & $5.08^{c s}$ & 6.03 & $\mathrm{H}_{3} \mathrm{~N}$ & $3.28^{\mathrm{jj}}$ & 3.33 \\
\hline $\mathrm{CF}_{3}$ & $4.85^{\mathrm{lj}}$ & 5.65 & $\mathrm{CH}_{3} \mathrm{OH}$ & $4.07^{\mathrm{j}}$ & 4.23 & $\mathrm{C}_{2} \mathrm{~F}_{6}$ & $5.55^{\mathrm{es}}$ & 7.36 & HO & $3.53^{\mathrm{lj}}$ & 3.29 \\
\hline $\mathrm{CF}_{4}$ & $5.23^{\mathrm{lj}}$ & 6.40 & $\mathrm{CH}_{4}$ & $4.22^{\mathrm{cs}}$ & 4.23 & $\mathrm{C}_{2} \mathrm{H}_{4}$ & $4.46^{\mathrm{lj}}$ & 4.50 & $\mathbf{N}_{2}$ & $4.10^{c s}$ & 4.00 \\
\hline $\mathrm{CF}_{4} \mathrm{O}$ & $4.86^{\text {fit }}$ & 6.40 & $\mathrm{CHF}_{3}$ & $4.67^{\mathrm{cs}}$ & 5.71 & $\mathrm{C}_{2} \mathrm{H}_{6}$ & $4.8 / 3^{l j}$ & 4.01 & $\mathrm{~N}_{2} \mathrm{O}$ & $4.30^{\mathrm{j}}$ & 5.18 \\
\hline CFO & $4.51^{\text {fit }}$ & 4.72 & CHFO & $4.50^{\text {fit }}$ & 4.50 & $\mathrm{C}_{3} \mathrm{O}_{2}$ & $4.72^{c s}$ & 5.22 & No & $3.92^{\mathrm{j}}$ & 4.15 \\
\hline $\mathrm{CH}_{2} \mathrm{ClF}$ & $5.03^{\mathrm{lj}}$ & 4.86 & CENO & $4.30^{\mathrm{j}}$ & 4.80 & CLH & $3.95^{\mathrm{cs}}$ & 3.35 & $\mathrm{NO}_{2}$ & $3.98^{\mathrm{sc}}$ & 4.77 \\
\hline $\mathrm{CH}_{2} \mathrm{~F}_{2}$ & $4.58^{\mathrm{lj}}$ & 4.36 & CNO & $4.30^{\mathrm{j}}$ & 4.89 & FH & $3.53^{\mathrm{lj}}$ & 3.70 & $\mathrm{O}_{2}$ & $3.82^{\mathrm{sc}}$ & 3.86 \\
\hline
\end{tabular}




\section{DAKOTA Optimization}

CHEETAH, ${ }^{12}$ a $\mathrm{C}$ version of the FORTRAN equilibrium code TIGER, ${ }^{15}$ was chosen as the analysis code to solve the CJ detonation problem for the 32 explosives listed in Table 3. Formation enthalpies can be found in Ref. 12. Starting with the initial $r^{*}$ values listed in Table 2, an objective function was minimized using DAKOTA ${ }^{31}$ (Design Analysis Kit for OpTimizAtion). The objective function was the root mean square error $(r m s)$ between calculated $\left(D_{i, c}\right)$ and measured $\left(D_{i, c}\right)$ detonation velocities

$$
r m s=\sqrt{\frac{1}{N} \sum_{i=1}^{N}\left(\frac{D_{i, m}-D_{i, c}}{D_{i, m}}\right)^{2}}
$$

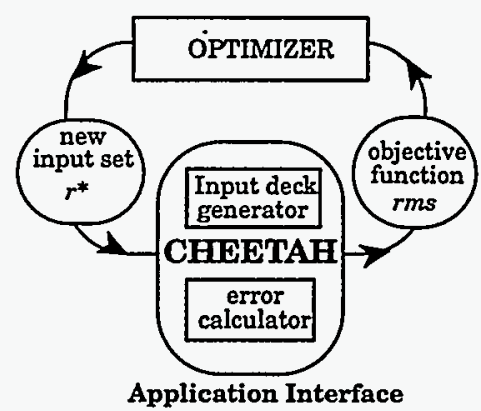

(7) Fig. 17. CHEETAH interface with DAKOTA.

where the subscripts $i, m$, and $c$ represent the $i^{t h}$ explosive in Table 3, measured, and calculated, respectively. $N$ represents the number of detonation velocity measurements, 32 . Figure 17 shows the conceptualized CHEETAH interface with the DAKOTA ${ }^{31}$ toolkit which utilizes object-oriented design to interface analysis codes to various optimization techniques. The input deck generator is based on an algebraic preprocessor, APREPRO. ${ }^{32}$ The error calculator is a FORTRAN code used to read CHEETAH output and compute the error function given in Eq. (7). The input generator and error calculator are controlled by a C-shell script.

Table 4 shows the overall percent RMS error for predicted detonation velocity and detonation pressure for the explosives listed in Table 2 for the BKWS-EOS, BKWC-EOS, JCZS-40 EOS, and JCZS-132 EOS. The predictions were made using CHEETAH 1.40. During the course of this study, CHEETAH 2.0 was released. Predictions made using CHEETAH 2.0 are given in Table 5. The format of the libraries and formula cards were changed in CHEETAH 2.0. The discepancy in Tables 4 and 5 are probably related to roundoff error in translating heats of formation for products and reactants to SI units. The JCZS-40 database only considered the 40 species listed in Table 2 for the detonation calculations. The JCZS-132 predictions considered all 132 species in the JANNAF tables composed of species containing $\mathrm{C}, \mathrm{H}, \mathrm{N}, \mathrm{O}, \mathrm{Cl}$, or $\mathrm{F}$. Since the RMS percent errors for both the JCZS40 and JCZS-132 are similar, the JCZS-40 database is probably sufficient for energetic materials composed of $\mathrm{C}, \mathrm{H}, \mathrm{N}, \mathrm{O}, \mathrm{Cl}$, or $\mathrm{F}$. The CHEETAH input deck, DAKOTA input deck, C-shell script, and FORTRAN rms error program are given in Appendix $\mathrm{C}$ for reference.

Table 4 also shows the overall percent RMS error for predicted detonation velocities and detonation pressure for the explosives listed in Table 2 excluding the nonideal explosives HNB and TATB containing explosives (HNB, TATB, RX26, and IX17). These nonideal explosives may not reach complete equilibrium and probably should not be considered in the RMS percent error calculation. A more complete set of explosives will be used for validation of the JCZS-EOS in Section 8.

The 31 BKWC constants were optimized as discussed in Section 5.2.4 using the detonation velocities, detonation pressures, and expansion energies for the explosives shown in Table 3. Only detonation velocities were used in the DAKOTA optimization. Detonation velocities are thought to be the most accurate performance measurement provided a steady velocity has been reached. Detonation pressures, $P_{c j}$, are directly related to the detonation velocity D:

$$
P_{c j}=\rho_{o} D u
$$

where $\rho_{0}$ and $u$ represent the initial density and particle velocity, respectively. The detonation pressures are typically inferred from the detonation velocity and particle velocity. Since the JCZS-EOS predicts accurate detonation velocities, detonation pressure predictions are likely adequate. 


\section{DAKOTA Optimization}

Table 3. Measured ${ }^{12}$ and predicted detonation velocities and pressures*

\begin{tabular}{|c|c|c|c|c|c|c|c|c|c|}
\hline $\begin{array}{l}\text { Explosive and } \\
\text { density, } \mathrm{g} / \mathrm{cm}^{3} \text {. }\end{array}$ & $\begin{array}{c}D_{\mathrm{m}} \\
\mathrm{km} / \mathrm{s}\end{array}$ & $\begin{array}{l}\mathbf{P}_{\mathrm{m}} \\
\mathrm{kbar}\end{array}$ & $\begin{array}{c}\mathrm{D}_{\mathrm{BKWS}} \\
\mathrm{km} / \mathrm{s}\end{array}$ & $\begin{array}{c}D_{B K W C} \\
\mathrm{~km} / \mathrm{s}\end{array}$ & $\begin{array}{c}D_{J \text { JC2s-small }} \mathrm{km} / \mathrm{s}\end{array}$ & $\begin{array}{c}D_{\text {JczS-large }} \\
\mathrm{km} / \mathrm{s}\end{array}$ & $\begin{array}{c}\text { P }_{\text {BKwS }} \\
\text { kbar }\end{array}$ & $\begin{array}{c}P_{J C Z S-\text { small }} \\
\text { kbar }\end{array}$ & $\begin{array}{c}\text { PJCZs-large } \\
\cdot \text { kbar }\end{array}$ \\
\hline btf, 1.85 & 8.49 & 340. & $8.12(4.32)$ & $8.57(0.94)$ & $8.57(0.92)$ & $8.55(0.73)$ & 307. (9.77) & $327 .(3.94)$ & 327. (3.93) \\
\hline hmx, 1.89 & 9.10 & 405. & $9.35(2.74)$ & $9.24(1.58)$ & $9.11(0.15)$ & $9.11(0.09)$ & 374. (7.64) & 399. (1.52) & 399.(1.55) \\
\hline hmx, 1.18 & 6.67 & 165. & $6.72(0.68)$ & $6.73(0.90)$ & $6.61(0.91)$ & $6.61(0.92)$ & 147. (5.28) & 138. (11.04) & 138. (11.03) \\
\hline hnb, 1.97 & 9.34 & 430. & $8.86(5.14)$ & $9.25(0.87)$ & $8.76(6.14)$ & $8.71(6.74)$ & 373. (13.28) & 348. (18.99) & , 347. (19.33) \\
\hline hng, 1.66 & 7.08 & 215. & $7.08(0.70)$ & $7.00(0.39)$ & $7.07(0.63)$ & $7.07(0.62)$ & 203. (5.56) & 204. (4.94) & 204. (4.95) \\
\hline hns, 1.40 & 6.34 & 160. & $6.26(1.30)$ & $6.27(1.12)$ & $6.26(1.27)$ & $6.26(1.27)$ & 143. (10.42) & 140. (12.40) & $140 .(12.41)$ \\
\hline hns, 1.20 & 5.74 & 115. & $5.73(0.23)$ & $5.71(0.59)$ & $5.69(0.88)$ & $5.69(0.88)$ & 109. (4.81) & 103. (10.55) & 103. (10.55) \\
\hline hns, 1.00 & 5.10 & 73. & $5.27(3.39)$ & $5.15(1.00)$ & $5.13(0.66)$ & $5.13(0.65)$ & 81. (11.38) & 71. (2.16) & 71. (2.17) \\
\hline $\mathrm{nm}, \mathbf{1 . 1 3}$ & 6.28 & 120. & $6.59(4.88)$ & $6.03(4.02)$ & $6.17(1.70)$ & $6.17(1.70)$ & 130. (8.62) & 115. (3.77) & 115. (3.77) \\
\hline petn, 1.76 & 8.27 & 310. & $8.68(4.86)$ & $8.50(2.74)$ & $8.40(1.52)$ & $8.40(1.46)$ & $312 .(0.71)$ & 296. (4.52) & 296. (4.52) \\
\hline petn, $\mathbf{1 . 5 0}$ & 7.48 & 240. & $7.66(2.43)$ & $7.64(2.15)$ & $7.36(1.59)$ & $7.36(1.59)$ & 223. (7.22) & 202. (16.01) & 202.(16.01) \\
\hline petn, 1.26 & 6.59 & 160. & $6.85(3.98)$ & $6.63(0.61)$ & $6.49(1.57)$ & $6.49(1.56)$ & $160 .(0.17)$ & 139. (12.84) & 139. (12.82) \\
\hline rx23, 1.42 & 8.64 & 258. & $8.68(0.48)$ & $8.71(0.82)$ & $8.31(3.82)$ & $8.31(3.82)$ & 236. (8.69) & 210. (18.44) & 210. (18.44) \\
\hline tatb, 1.83 & 7.58 & 260 & $8.00(5.48)$ & $7.75(2.18)$ & $8.02(5.75)$ & $8.02(5.75)$ & 266. (2.19) & $280 .(7.88)$ & 280. (7.87) \\
\hline $\operatorname{tnm}, 1.65$ & 6.45 & 155. & $5.53(14.32)$ & $6.36(1.42)$ & $6.27(2.72)$ & $6.27(2.72)$ & 116. (25.19) & 148. (4.42) & 144. (7.37) \\
\hline tnt, 1.63 & 7.07 & 205. & $7.15(1.12)$ & $6.81(3.63)$ & $6.99(1.10)$ & $6.99(1.10)$ & $200 .(2.30)$ & 192. (6.10) & 192. (6.11) \\
\hline $\mathrm{Lx} 14,1.83$ & 8.80 & 370. & $9.00(2.22)$ & $8.78(0.22)$ & $8.75(0.55)$ & $8.75(0.57)$ & $341 .(7.96)$ & 347. (6.15) & $347 .(6.16)$ \\
\hline $\mathrm{rx} 26,1.84$ & 8.24 & 340. & $8.54(3.67)$ & $8.25(0.07)$ & $8.39(1.87)$ & $8.39(1.86)$ & $307 .(9.59)$ & $321 .(5.71)$ & 321. (5.71) \\
\hline anfo, 0.80 & 4.70 & - & $5.14(9.46)$ & $4.56(2.93)$ & $4.71(0.19)$ & $4.71(0.19)$ & 56. (-) & $47 .(-)$ & 47. (-) \\
\hline qm100, 1.51 & 7.70 & - & $8.08(4.98)$ & $7.17(6.84)$ & $7.56(1.81)$ & $7.56(1.81)$ & 217. (--) & 188. $(-\rightarrow)$ & 188. (-) \\
\hline $\mathrm{dp} 12,1.26$ & 5.97 & 125. & $5.88(1.53)$ & $6.11(2.35)$ & $5.93(0.60)$ & $5.93(0.60)$ & 166. (32.58) & 154. (23.47) & 155. (23.72) \\
\hline af $x 902,1.74$ & 8.34 & 290. & $8.11(2.77)$ & $8.08(3.22)$ & $8.38(0.40)$ & $8.38(0.40)$ & 249. (14.12) & 257. (11.34) & 257. (11.31) \\
\hline fefo, 1.61 & 7.45 & 245. & $7.36(1.25)$ & $7.36(1.22)$ & $7.41(0.62)$ & $7.40(0.65)$ & 227. (7.30) & 248. (1.38) & $240 .(1.98)$ \\
\hline fm1, 1.51 & 6.57 & 190. & $7.23(10.09)$ & $6.91(5.24)$ & $6.99(6.39)$ & $6.99(6.39)$ & 204. (7.60) & 189. $(0.70)$ & 189. $(0.61)$ \\
\hline pf, 1.83 & 7.29 & 270. & $7.28(0.15)$ & $7.33(0.55)$ & $7.40(1.48)$ & $7.40(1.48)$ & 237. (12.10) & 237. (12.30) & 237. (12.20) \\
\hline $\mathbf{r x 3 6 , 1 . 8 3}$ & 8.51 & 335. & $8.37(1.60)$ & $8.52(0.16)$ & $8.32(2.21)$ & $8.32(2.24)$ & 312. (6.96) & $313 .(6.63)$ & 313. $(6.60)$ \\
\hline $\operatorname{rx} 41,1.86$ & 8.81 & 850. & $8.64(1.99)$ & $8.90(0.94)$ & $8.67(1.68)$ & $8.66(1.74)$ & $324 .(7.32)$ & 333. (4.93) & $332 .(5.16)$ \\
\hline $1 \times 17,1.91$ & 7.63 & 260. & $7.94(4.12)$ & $7.72(1.13)$ & $7.90(3.53)$ & $7.90(3.53)$ & $280 .(7.59)$ & 281. (8.10) & 281. (8.12) \\
\hline$r \times 27,1.64$ & 6.93 & 200. & $6.69(3.38)$ & $6.69(3.47$ & $6.67(3.67)$ & $6.67(3.67)$ & 182. (8.79) & 182. (8.96) & 182. (8.89) \\
\hline $\mathrm{rx} 45,1.75$ & $7: 71$ & 250. & $7.66(0.62)$ & $7.79(1.05)$ & $7.72(0.11)$ & $7.72(0.11)$ & 236. (5.46) & 249. (0.27) & 249. (0.25) \\
\hline $1 \times 47,1.82$ & 7.66 & 260. & $7.68(0.33)$ & $7.67(0.22)$ & $7.58(0.99)$ & $7.58(0.99)$ & $258,(0.82)$ & 256. (1.47) & 256. (1.44) \\
\hline $\operatorname{rx48,1.85}$ & 7.76 & 263. & $7.74(0.19)$ & $7.77(0.15)$ & $7.66(1.27)$ & $7.66(1.28)$ & 269. (2.20) & $267 .(1.56)$ & 267. (1.58) \\
\hline
\end{tabular}

* Percent RMS errors are given in parenthesis 
Validation of the JCZS-EOS

Table 4. RMS \% errors - optimization*

\begin{tabular}{|l|c|c|c|c|}
\hline EOS - \# gases & $\mathbf{D},{ }^{\dagger} \%$ & $\mathbf{D},{ }^{\ddagger} \%$ & $\mathbf{P}^{\dagger} \%$ & $\mathbf{P}^{\ddagger} \%$ \\
\hline BKWS - 132 & 4.52 & 4.21 & 10.7 & 10.9 \\
\hline BKWC - 22 & 2.32 & 2.28 & 8.01 & 7.96 \\
\hline JCZS - 40 & 2.45 & 1.83 & 9.82 & 9.52 \\
\hline JCZS - 132 & 2.48 & 1.85 & 9.72 & 9.43 \\
\hline
\end{tabular}

* Calculated using CHEETAH 1.40

$\uparrow$ All explosives in Table 3

$\doteqdot$ All explosives in Table 3 excluding nonideal explosives containing TATB and HNB
Table 5. RMS \% errors - optimization*

\begin{tabular}{|l|c|c|c|c|}
\hline EOS - \# gases & $\mathbf{D},{ }^{\dagger} \%$ & $\mathbf{D}, \%$ & $\mathbf{P}, \dagger$ & $\mathbf{P} \ddagger \%$ \\
\hline BKWS - 132 & 5.12 & 5.18 & 9.47 & 9.54 \\
\hline BKWC - 22 & 2.34 & 2.45 & 8.15 & 8.16 \\
\hline JCZS - 40 & 2.61 & 2.12 & 8.48 & 8.13 \\
\hline JCZS - 132 & 2.64 & 2.16 & 8.34 & 7.99 \\
\hline
\end{tabular}

Experimental Chapman-Jouguet (C-J) detonation velocity, pressure, and temperature depend on composition, density, and size of the initial explosive charge. Detonation velocities are measured at various charge diameters and extrapolated to an "infinite diameter" for comparison with equilibrium calculations. Detonation velocities can typically be measured to within a few percent. ${ }^{11}$ The RMS percent error for the JCZS-EOS is within experimental error. Detonation pressures determined by various indirect methods span a range of $10-20 \%$ (e.g. see Davis and Venable ${ }^{33}$ ). The JCZS-EOS is 9.8\% as shown in Tables 4 and 5. The lower percent RMS error for the BKWC-EOS was probably obtained at the cost of a larger percent error for detonation velocities.

\section{Validation of the JCZS-EOS}

Accuracy of detonation velocity and detonation pressure measurements were discussed in Section 7 . Detonation velocity measurements are probably good to within $2 \%$. Detonation pressure measurements are probably good to within $20 \%$. Similar to detonation pressure measurements, detonation temperature measurements are probably good to within $20 \%$. Detonation temperatures are measured by the brightness of the detonation front interacting with a detector. Void free systems such as liquid explosives or single crystal systems are believed to be more accurate. Measurements in porous systems include the effects of shocked air or perhaps low-density explosive material jetting into the voids rather than the brightness of the pure detonation products. Comparisons of measured detonation temperatures to calculated detonation temperatures should be done with caution.

Fried and Souers ${ }^{12}$ estimated the accuracy of the total energy of detonation measured by bomb calorimetry to be within 5\%. Fried also estimated the error in predicted adiabat energies at relative volumes of $2.2,4.1$, and 6.5 to be $5 \%$. The total energy of detonation and the various adiabat energies can be calculated with CHEETAH using the "standard run" command. Experimental measurements for explosives within the Lawrence Livermore National Laboratories (LLNL) explosives database were reported by Fried and Souers. ${ }^{12}$ These are the same explosives listed in Table 3 (excluding ANFO and QM100R).

Validation of the JCZS-EOS includes comparisons of predictions to measured detonation velocities, detonation pressures, detonation temperatures, total energy of detonation, and expansion energies at relative volumes of $2.2,4.1$, and 6.5. Hobbs and Baer ${ }^{10}$ presented an extensive table of explosives performance data from a large number of investigators. Hobbs and Baer's ${ }^{10}$ explosive performance database covers a broad range of materials that include 111 detonation velocities, 67 deto- 
nation pressures, and 14 detonation temperature measurements. The 32 detonation velocity measurements and 31 detonation pressure measurements in the LLNL performance database were compared previously in Tables 3-5 discussed in Section 7. The LLNL performance database will be used in Section 8.2 to examine total energy of detonation and expansion energies.

\subsection{Explosive Performance}

Table 6 shows the overall percent RMS error for the BKWS, BKWC, and JCZS-132 predictions of detonation velocity, detonation pressure, and detonation temperature for 62 various explosives which contain $\mathrm{C}, \mathrm{H}, \mathrm{N}, \mathrm{O}$, $\mathrm{Cl}$, and $\mathrm{F}$ at various densities. The predictions were made using $\mathrm{CHEE}$ TAH 1.4 and CHEETAH 2.0. The detonation temperatures predicted with CHEETAH 1.4 are shown in Table 7. Specific information regarding the composition and heat of formation of each explosive can be found in Ref. 10 or in Appendix C. Table 8 lists the percent RMS error between the calculated and measured performance for 111 detonation velocities and 67 detonation pressures using CHEETAH 1.4. The JCZS- 40 only considered the 40 species listed in Table 2 for the detonation calculations. The JCZS-132 predictions considered 132 species as possible detonation products. Since the RMS percent errors for both the JCZS-40 and JCZS-132 are similar, the JCZS-40 data set is probably sufficient for energetic materials composed of $\mathrm{C}, \mathrm{H}, \mathrm{N}, \mathrm{O}, \mathrm{Cl}$, or $\mathrm{F}$.

Table 6 shows that the overall percent RMS error in predicted detonation velocity is almost a percent better using the JCZS-EOS than the BKWC-EOS. The better agreement with data is consistent with the results from the LLNL performance database given in Table 5 . The overall percent RMS error in the detonation pressures are consistent between the JCZS-EOS and the BKWC-EOS. The overall percent RMS error in the predicted detonation temperatures is higher for the JCZS-EOS than the BKWC-EOS. However, the predicted RMS error is within the expected accuracy of the opti-

Table 7. Measured and predicted detonation temperatures using CHEETAH 1.4.

\begin{tabular}{|l|c|c|c|c||l|l|l|l|l|}
\hline EM, g/cm & Exp. & BKWS & BKWC & JCZS & EM, g/cm & Exp. & BKWS & BKWC & JCZS \\
\hline HMX, 1.60 & 4300 & 4266 & 4281 & 3986 & RDX, 1.00 & 4600 & 4489 & 4323 & 4339 \\
\hline NG, 1.60 & 4260 & 4568 & 4523 & 4575 & Tetryl, 1.61 & 4200 & 4269 & 4208 & 3792 \\
\hline NM, 1.13 & 3430 & 3583 & 3617 & 3394 & Tetryl, 1.40 & 4130 & 4348 & 4201 & 3806 \\
\hline PETN, 1.60 & 4400 & 4395 & 4391 & 4378 & Tetryl, 1.20 & 4300 & 4379 & 4153 & 3765 \\
\hline RDX, 1.66 & 4320 & 4234 & 4270 & 3943 & Tetryl, 1.00 & 4390 & 4340 & 4076 & 3678 \\
\hline RDX, 1.40 & 4610 & 4387 & 4343 & 4146 & TNT, 1.00 & 3400 & 3747 & 3558 & 3235 \\
\hline RDX, 1.20 & 4610 & 4463 & 4351 & 4257 & TNM, 1.64 & 2800 & 2870 & 2723 & 2538 \\
\hline
\end{tabular}


Table 8. Measured ${ }^{10}$ and predicted detonation velocities and pressures with \%RMS errors.

\begin{tabular}{|c|c|c|c|c|c|c|c|c|c|}
\hline $\begin{array}{l}\text { Explosive and } \\
\text { density, } g / \mathrm{cm}^{3}\end{array}$ & $\begin{array}{l}\mathrm{D}_{\mathrm{m}} \\
\mathrm{km} / \mathrm{s}\end{array}$ & $\begin{array}{l}P_{\mathrm{mp}} \\
\mathrm{kbar}\end{array}$ & $\begin{array}{c}\mathrm{D}_{\mathrm{BKWS}}, \\
\mathrm{km} / \mathrm{s}\end{array}$ & $\begin{array}{c}\mathrm{D}_{\mathrm{BKWWC}} \\
\mathrm{km} / \mathrm{s}\end{array}$ & $\begin{array}{c}D_{\text {JCZS-small }} \\
\mathrm{km} / \mathrm{s}\end{array}$ & $\begin{array}{c}D_{\text {JCZs-large }} \\
\mathrm{km} / \mathrm{s}\end{array}$ & $\begin{array}{l}\mathrm{P}_{\mathrm{BKWS}} \\
\ldots \mathrm{kbar}\end{array}$ & $\underset{\mathrm{kbar}}{P_{\text {fczs-small }}}$ & $\underset{\text { kbas }}{\text { PJczS-large }}$ \\
\hline abh, 1.64 & 7.20 & $\cdots$ & $7.14(0.78)$ & $7.36(2.18)$ & $7.28(1.09)$ & $7.28(1.09)$ & 211. (--) & 216. (-- & 216. (-) \\
\hline compa3, 1.64 & 8.47 & - & $8.25(2.55)$ & $7.75(8.51)$ & $7.91(6.63)$ & $7.91(6.63)$ & 266. (-) & 254. (---) & 254. (-) \\
\hline compb, 1.72 & 7.92 & 295. & $8.20(3.59)$ & $7.97(0.68)$ & $7.98(0.73)$ & $7.98(0.73)$ & 276. (6.52) & 273. (7.45) & 273. (7.46) \\
\hline compb3, 1.72 & 7.89 & 287. & $8.16(3.43)$ & $7.97(1.00)$ & $7.95(0.79)$ & $7.95(0.79)$ & 273. (4.71) & 271. (5.42) & 271. (5.42) \\
\hline compc3, 1.60 & 7.63 & $\ldots$ & $7.74(1.38)$ & $7.53(1.31)$ & $7.53(1.29)$ & $7.53(1.29)$ & $230 .(-)$ & 225. (- & 225. (--) \\
\hline compc4, 1.66 & 8.37 & $\ldots$ & $8.32(0.59)$ & $7.89(5.78)$ & $7.99(4.57)$ & $7.99(4.57)$ & 273. (-) & 263. (--) & 263. (--) \\
\hline $7822,1.76$ & 8.31 . & 317. & $8.53(2.62)$ & $8.39(0.95)$ & $8.29(0.24)$ & $8.29(0.23)$ & $302 .(4.65)$ & $300 .(5.23)$ & $300 .(5.24)$ \\
\hline $7723,1.74$ & 8.25 & 313. & $8.44(2.25)$ & $8.30(0.65)$ & $8.20(0.56)$ & $8.20(0.56)$ & 294. (6.15) & 291. (7.08) & 291. (7.09) \\
\hline $7525,1.76$ & 8.30 & 316. & $8.49(2.31)$ & $8.34(0.48)$ & $8.25(0.58)$ & $8.25(0.58)$ & $300 .(5.07)$ & 299. (5.29) & 299. (5.30) \\
\hline $7525,1.62$ & 7.95 & 265. & $7.95(0.04)$ & $7.86(1.13)$ & 7.75 (2.49) & $7.75(2.49)$ & 249. (5.96) & 244. (7.87) & 244. (7.88) \\
\hline $7030,1.73$ & 8.06 & - & $8.32(3.16)$ & $8.16(1.21)$ & $8.09(0.38)$ & $8.09(0.38)$ & 285. (--) & 283. (--) & 283. (-) \\
\hline $6535,1.72$ & 8.04 & 292. & $8.22(2.22)$ & $8.05(0.07)$ & $8.00(0.46)$ & $8.00(0.46)$ & 277. (5.07) & $275 .(5.73)$ & 275. (5.74) \\
\hline $6040,1.74$ & 8.09 & $\ldots$ & $8.24(1.84)$ & $8.03(0.69)$ & $8.03(0.79)$ & $8.03(0.79)$ & 281. (-) & $280 .(-)$ & $279 .(--)$ \\
\hline $6040,1.72$ & 7.90 & $\ldots$ & $8.16(3.30)$ & $7.97(0.87)$ & $7.95(0.67)$ & $7.95(0.67)$ & 273. (-) & 271. (- & 271. (--) \\
\hline $5050,1.63$ & 7.66 & 231. & $7.71(0.60)$ & $7.53(1.76)$ & $7.53(1.76)$ & $7.53(1.76)$ & 235. (1.78) & 231. (0.04) & 231. (0.05) \\
\hline datb, 1.80 & 7.60 & 251. & $7.86(3.46)$ & $7.65(0.65)$ & $7.82(2.89)$ & $7.82(2.89)$ & 258. (2.61) & 265. (5.42) & 265. (5.41) \\
\hline datb, 1.78 & 7.60 & 251. & $7.79(2.46)$ & $7.58(0.21)$ & $7.74(1.86)$ & $7.74(1.86)$ & $250 .(0.26)$ & 256. (1.97) & 256. (1.97) \\
\hline degn, 1.38 & 6.76 & $\ldots$ & $7.19(6.42)$ & $6.66(1.47)$ & $6.75(0.16)$ & $6.75(0.16)$ & 183. (-) & $160 .(--)$ & 160. (--) \\
\hline $\operatorname{dipm}, 1.76$ & 7.40 & - & $7.56(2.16)$ & $7.54(1.93)$ & $7.57(2.25)$ & $7.57(2.25)$ & 239. (--) & 245. (--) & 245. (--) \\
\hline expd. 1.55 & 6.85 & $\ldots$ & $6.91(0.87)$ & $6.65(2.98)$ & $6.76(1.29)$ & $6.76(1.29)$ & 176. (-) & 166. (-) & 166. (-) \\
\hline expd, 1.48 & 6.70 & $\ldots$ & $6.66(0.67)$ & $6.41(4.28)$ & $6.50(3.05)$ & $6.50(3.05)$ & 158. (-) & 148. (--) & 148. (--) \\
\hline $\mathrm{hmx}, 1.89$ & 9.11 & 390. & $9.35(2.62)$ & $9.24(1.47)$ & $9.11(0.04)$ & $9.11(0.05)$ & 374. (4.09) & 399. (2.27) & 399. (2.24) \\
\hline$h \mathrm{mx}, 1.60$ & 7.91 & 280. & $8.14(2.94)$ & $8.16(3.19)$ & $8.04(1.60)$ & $8.04(1.61)$ & 259. (7.44) & 260. (7.02) & 260. (7.03) \\
\hline $\mathrm{hmx}, 1.40$ & 7.30 & 210. & 7.41 (1.57) & $7.46(2.17)$ & $7.35(0.64)$ & $7.35(0.65)$ & 199. (5.27) & 196. $(6.90)$ & 195. (6.91) \\
\hline hmx, 1.20 & 6.85 & 160. & $6.78(1.04)$ & $6.80(0.77)$ & $6.68(2.48)$ & $6.68(2.47)$ & 151. (5.52) & 143. (10.9) & 143. (10.9) \\
\hline hmx, 1.00 & 5.80 & 110. & $6.20(6.89)$ & $6.11(5.42)$ & $6.01(3.64)$ & $6.01(3.65)$ & $110 .(0.19)$ & 99. (9.65) & 99. (9.65) \\
\hline hmx, 0.75 & 4.88 & 60. & $5.42(11.1)$ & $5.19(6.31)$ & $5.06(3.60)$ & $5.06(3.62)$ & 64. (7.08) & 52. (12.8) & 52. (12.7) \\
\hline hnab, 1.60 & 7.31 & 205. & $7.09(3.02$ & $7.29(0.27)$ & $7.19(1.62)$ & $7.19(1.62)$ & 204. (0.63) & 207. (1.12) & 207. (1.11) \\
\hline hns, 1.60 & 6.80 & $\ldots$ & $6.88(1.15)$ & $6.83(0.49)$ & $6.88(1.15)$ & $6.88(1.15)$ & 187. (---) & 187. (- ) & 187. (--) \\
\hline hns, 1.70 & 7.00 & $\ldots$ & $7.22(3.09)$ & $7.12(1.64)$ & $7.21(2.96)$ & $7.21(2.96)$ & 214. (--) & 217. (--) & 216. (--) \\
\hline $1 \times 01,1.24$ & 6.84 & ... & $7.05(3.03)$ & $6.79(0.77)$ & $6.79(0.74)$ & $6.79(0.74)$ & 165. (--) & $152 .(-)$ & 152. (--) \\
\hline
\end{tabular}


Table 8. Measured ${ }^{10}$ and predicted detonation velocities and pressures with \%RMS errors.

\begin{tabular}{|c|c|c|c|c|c|c|c|c|c|}
\hline $\begin{array}{l}\text { Explosive and } \\
\text { density, } \mathrm{g} / \mathrm{cm}^{3}\end{array}$ & $\begin{array}{l}\mathrm{D}_{\mathrm{m}} \\
\mathrm{km} / \mathrm{s}\end{array}$ & $\begin{array}{l}\mathbf{P}_{\mathrm{m}} \\
\mathrm{kbar}\end{array}$ & $\begin{array}{c}D_{\text {BKWS }} \\
\mathrm{km} / \mathrm{s}\end{array}$ & $\begin{array}{c}D_{\text {BKwC }} \\
\mathrm{km} / \mathrm{s}\end{array}$ & $\begin{array}{c}D_{\text {JCZS-small }} \\
\mathrm{km} / \mathrm{s}\end{array}$ & $\begin{array}{c}D_{\text {JCZS-lasge }} \\
\mathrm{km} / \mathrm{s}\end{array}$ & $\begin{array}{c}\text { P }_{\text {BkwS }} \\
\text { kbar }\end{array}$ & 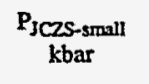 & $\underset{\mathrm{kbar}}{\text { PJcz-large }}$ \\
\hline $\mathbf{I x 1 4 , 1 . 8 4}$ & 8.83 & 370. & $9.04(2.36)$ & $8.82(0.14)$ & $8.79(0.45)$ & $8.79(0.44)$ & 345. (6.79) & 353. (4.65) & 353. (4.66) \\
\hline men, 1.02 & 5.49 & $\ldots$ & $6.00(9.34)$ & $5.19(5.42)$ & $5.22(4.90)$ & $5.22(4.91)$ & $94 .(--)$ & 75. (--) & 75. (-) \\
\hline $\mathrm{ng}, \mathbf{1 . 6 0}$ & 7.70 & 253. & $8.02(4.18)$ & $7.70(0.04)$ & $7.64(0.81)$ & $7.64(0.76)$ & 251. (0.66) & 221. (12.7) & 221. (12.7) \\
\hline $\mathrm{nm}, 1.13$ & 6.35 & 125. & $6.59(3.73)$ & $6.03(5.08)$ & $6.17(2.79)$ & $6.17(2.79)$ & 130. (4.28) & 115. (7.62) & 115. (7.62) \\
\hline nona, 1.70 & 7.40 & $\cdots$ & $7.26(1.94)$ & $7.38(0.27)$ & $\cdot 7.36(0.60)$ & $7.36(0.59)$ & 221. (-) & 226. (-) & 226. (-) \\
\hline $\mathrm{nq}, 1.78$ & 8.59 & - & $8.56(0.40)$ & $8.37(2.52)$ & $8.85(3.02)$ & $8.85(3.02)$ & 274. (-) & 293. (-) & 293. (-) \\
\hline nq, 1.72 & $\cdots$ & 245. & $8.29(-)$ & $8.12(--)$ & $8.51(-)$ & $8.51(--)$ & 252. (3.01) & 264. (7.66) & 264. (7.66) \\
\hline $\mathrm{nq}, 1.62$ & 7.93 & $\cdots$ & $7.85(1.04)$ & $7.70(2.93)$ & $7.97(0.51)$ & $7.97(0.51)$ & 219. (-) & 221. (-) & 221. (-) \\
\hline$n q, 1.55$ & 7.65 & -- & $7.55(1.31)$ & $7.40(3.21)$ & $7.61(0.51)$ & $7.61(0.51)$ & 199. (-) & 195. (-) & 195. (-) \\
\hline $7822,1.82$ & - & 342. & $8.76(-)$ & $8.58(-)$ & $8.50(-)$ & $8.50(-)$ & $326 .(4.76)$ & 326. (4.77) & 326. (4.78) \\
\hline $7623,1.81$ & 8.45 & 338. & $8.70(3.00)$ & $8.53(0.92)$ & $8.45(0.01)$ & $8.45(0.00)$ & 321. (5.16) & $322 .(4.70)$ & $322 .(4.71)$ \\
\hline $7525,1.81$ & 8.48 & $m$ & $8.69(2.45)$ & $8.51(0.31)$ & $8.44(0.51)$ & $8.44(0.51)$ & $320 .(--)$ & 321. $(--)$ & $321 .(--)$ \\
\hline $6040,1.80$ & 8.16 & 320. & $8.47(3.80)$ & $8.23(0.83)$ & $8.25(1.07)$ & $8.25(1.07)$ & 304. (5.08) & $305 .(4.70)$ & 305. (4.70) \\
\hline $9007,1.64$ & 8.09 & $\cdots$ & $8.08(0.16)$ & $7.72(4.59)$ & $7.79(3.67)$ & $7.79(3.67)$ & 256. (-) & 248. (-) & 248. (-) \\
\hline $9011,1.77$ & 8.50 & 324. & $8.65(1.72)$ & $8.30(2.36)$ & $8.37(1.55)$ & $8.37(1.55)$ & 307. (5.22) & 308. (5.05) & 308. (5.05) \\
\hline $9205,1.67$ & 8.17 & $\cdots$ & $8.25(0.94)$ & $7.94(2.78)$ & $7.96(2.52)$ & $7.96(2.52)$ & 271. (-) & 265. (-) & 265. (-) \\
\hline $9501,1.84$ & 8.83 &.-- & $9.07(2.69)$ & $8.89(0.67)$ & $8.83(0.04)$ & $8.83(0.05)$ & 348. (-) & 358. (-) & 358. (-) \\
\hline pentolit, 1.71 & 7.75 & $\cdots$ & $7.91(2.05)$ & $7.66(1.16)$ & $7.70(0.62)$ & $7.70(0.62)$ & 258. (-) & 251. (- & 251. $(-\infty)$ \\
\hline pentolit, 1.70 & $\mathbf{7 . 5 3}$ & $\cdots$ & $7.87(4.53)$ & $7.63(1.31)$ & $7.67(1.80$ & $7.67(1.80)$ & 255. (-) & 247. (-) & 247. (-) \\
\hline pentolit, 1.68 & 7.65 & 251. & $7.80(1.92)$ & $7.57(1.08)$ & $7.59(0.73)$ & $7.59(0.73)$ & 248. (1.18) & $240 .(4.25)$ & $240 .(4.25)$ \\
\hline pentolit, 1.64 & 7.63 & $\ldots$ & $7.65(1.60)$ & $7.44(1.14)$ & $7.45(1.03)$ & $7.45(1.03)$ & 235. (-) & 227. (-) & $227 .(-)$ \\
\hline petn, 1.76 & 8.27 & 337. & $8.68(4.91)$ & $8.50(2.79)$ & $8.40(1.57)$ & $8.40(1.57)$ & 312. (7.36) & 296. (12.2) & 296. (12.2) \\
\hline petn, 1.70 & 8.07 & 307. & $8.43(4.46)$ & $8.29(2.76)$ & $8.15(1.04)$ & $8.15(1.04)$ & 289. (5.91) & 271. (11.6) & 271. (11.6) \\
\hline petn, 1.60 & 7.75 & 266. & $8.03(3.68)$ & $7.96(2.71)$ & $7.75(0.02)$ & $7.75(0.02)$ & 254. (4.63) & 234. (12.0) & $234 .(12.0)$ \\
\hline petn, 1.45 & 7.18 & 208. & $7.48(4.23)$ & $7.42(3.30)$ & $7.17(0.12)$ & $7.17(0.12)$ & 208. (0.23) & 187. (10.1) & 187. (10.1) \\
\hline petn, 1.23 & 6.37 & 139. & $6.76(6.09)$ & $6.51(2.21)$ & $6.38(0.21)$ & $6.38(0.23)$ & 153. (10.2) & 133. (4.41) & 133. (4.38) \\
\hline petn, 0.99 & 5.48 & 87. & $5.99(9.35)$ & $5.59(2.00)$ & $5.58(1.74)$ & $5.58(1.77)$ & 100. (14.6) & $85 .(2.03)$ & $85 .(2.00)$ \\
\hline petn, 0.88 & 5.06 & 68. & $5.61(10.9)$ & $5.19(2.55)$ & $5.18(2.37)$ & $5.18(2.40)$ & 78. (15.2) & 65. (4.11) & 65. (4.08) \\
\hline petn, 0.48 & 3.60 & 24. & $4.12(14.3)$ & $3.83(6.36)$ & $3.50(2.89)$ & $3.50(2.81)$ & 26. (7.48) & 18. (23.6) & 18. (23.5) \\
\hline petn, 0.30 & 2.99 & 13. & $3.44(15.0)$ & $3.25(8.85)$ & $2.96(0.85)$ & $2.97(0.71)$ & 12. (5.13) & 10. (23.3) & 10. (23.1) \\
\hline
\end{tabular}


Table 8. Measured ${ }^{10}$ and predicted detonation velocities and pressures with \%RMS errors.

\begin{tabular}{|c|c|c|c|c|c|c|c|c|c|}
\hline $\begin{array}{l}\text { Explosive and } \\
\text { density, } \mathrm{g}^{\prime} \mathrm{cm}^{3}\end{array}$ & $\begin{array}{l}D_{\mathrm{m}} \\
\mathrm{km} / \mathrm{s}\end{array}$ & $\begin{array}{l}P_{m} \\
k b a r\end{array}$ & $\begin{array}{c}D_{\text {BKWS, }} \\
\mathrm{km} / \mathrm{s}\end{array}$ & $\begin{array}{c}\mathrm{D}_{\mathrm{BKwC}} \\
\mathrm{km} / \mathrm{s}\end{array}$ & $\begin{array}{c}D_{\mathrm{JCZS} \text {-small }} \\
\mathrm{km} / \mathrm{s}\end{array}$ & $\begin{array}{c}\text { D JCZS-large }_{\mathrm{km} / \mathrm{s}} \\
\mathrm{km}\end{array}$ & $\begin{array}{c}\text { PBkws; } \\
\text { kbar }\end{array}$ & $\mathrm{P}_{\mathrm{k} \text { Kbar }}$ & $\underset{\text { kbar }}{\text { PJCzS-large }}$ \\
\hline petn, 0.25 & 2.83 & 8. & $3.25(14.8)$ & $3.10(9.44)$ & $2.85(0.85)$ & $2.86(1.00)$ & 9. (18.4) & 8. $(0.12)$ & $8 .(0.36)$ \\
\hline picratol, 1.63 & 6.97 & - & $7.19(3.10)$ & $6.87(1.41)$ & $7.04(0.97)$ & $7.04(0.97)$ & $200 .(-)$ & 191. (-) & 191. (-) \\
\hline picric, 1.76 & 7.57 & $-\infty$ & $7.52(0.64)$ & $7.48(1.17)$ & $7.51(0.82)$ & $7.51(0.82)$ & 237. (-) & 239. (--) & 239. (-) \\
\hline picric, 1.71 & 7.26 & -- & 7.35 (1.19) & $7.33(1.00)$ & $7.33(1.00)$ & $7.33(1.00)$ & 222. (-) & 223. (-) & 223. (-) \\
\hline picric, 1.60 & 7.10 & - & $6.97(1.77)$ & $7.01(1.31)$ & $6.96(1.98)$ & $6.96(1.98)$ & 192. (-) & 190. (-- & 190. (-) \\
\hline $\mathrm{rdx}, 1.80$ & 8.75 & 341. & $8.96(2.45)$ & $8.91(1.83)$ & $8.78(0.34)$ & $8.78(0.34)$ & $334 .(2.00)$ & 347. (1.88) & 347. (1.86) \\
\hline $\mathrm{rdx}, 1.77$ & 8.70 & 338. & $8.84(1.58)$ & $8.80(1.12)$ & $8.67(0.38)$ & $8.67(0.38)$ & $322 .(4.86)$ & 332. (1.66) & $332 .(1.68)$ \\
\hline $\mathrm{rdx}, 1.72$ & 8.46 & 313. & $8.63(1.99)$ & $8.61(1.78)$ & $8.48(0.24)$ & $8.48(0.24)$ & $302 .(3.65)$ & $309 .(1.20)$ & 309. (1.22) \\
\hline $\mathrm{rdx}, 1.66$ & 8.24 & - & $8.38(1.75)$ & $8.39(1.81)$ & $8.26(0.24)$ & $8.26(0.24)$ & 279. (-) & 284. (--) & 284. (--) \\
\hline$r d x, 1.60$ & 8.13 & 263. & $8.15(0.24)$ & $8.17(0.50)$ & $8.04(1.07)$ & $8.04(1.06)$ & 260. (1.24) & 261. (0.76) & 261. (0.77) \\
\hline $\mathrm{rdx}, 1.46$ & 7.60 & 211. & $7.63(0.41)$ & $7.67(0.97)$ & $7.56(0.57)$ & $7.56(0.57)$ & 216. (2.37) & 214. (1.44) & 214. (1.43) \\
\hline $\mathrm{rdx}, 1.40$ & 7.46 & 213. & $7.42(0.51)$ & $7.47(0.09)$ & $7.35(1.42)$ & $7.35(1.41)$ & 199. (6.36) & 196. (7.95) & 196. (7.96) \\
\hline $\mathrm{rdx}, 1.29$ & 7.00 & 166. & $7.06(0.88)$ & $7.10(1.39)$ & $6.99(0.18)$ & $6.99(0.17)$ & 172. (3.65) & 166. $(0.27)$ & 166. (0.27) \\
\hline $\mathrm{rdx}, 1.20$ & 6.77 & 152. & $6.79(0.24)$ & $6.81(0.53)$ & $6.69(1.22)$ & $6.69(1.21)$ & 152. $(0.26)$ & 143. (5.93) & 143. (5.93) \\
\hline $\mathrm{rdx}, 1.10$ & 6.18 & 122. & $6.49(5.09)$ & $6.50(5.13)$ & $6.35(2.82)$ & $6.36(2.83)$ & $130 .(6.81)$ & 120. (1.28) & 120. (1.27) \\
\hline $\mathrm{rdx}, 1.00$ & 6.10 & 89. & $6.21(1.76)$ & $6.12(0.36)$ & $6.02(1.34)$ & $6.02(1.33)$ & 110. (23.7) & 100. (12.0) & $100 .(12.0)$ \\
\hline $\mathrm{rdx}, 0.95$ & 5.80 & 96. & $6.06(4.52)$ & $5.93(2.30)$ & $5.85(0.78)$ & $5.85(0.80)$ & 100. (4.58) & $90 .(6.59)$ & $90 .(6.58)$ \\
\hline $\mathrm{rdx}, 0.70$ & 4.65 & 48. & 5.25 (12.9) & $5.01(7.74)$ & $4.83(3.97)$ & $4.84(3.99)$ & 57. (17.9) & 45. (7.05) & 45. (7.02) \\
\hline $\mathrm{rdx}, 0.56$ & 4.05 & 32. & $4.72(16.5)$ & $4.49(10.9)$ & $4.17(2.95)$ & $4.17(2.99)$ & 38. (18.1) & 28. (13.4) & 28. (13.3) \\
\hline tacot, 1.85 & 7.25 & $\cdots$ & $7.62(5.13)$ & $7.56(4.29)$ & $7.71(6.32)$ & $7.71(6.32)$ & 253. (--) & 267. (--) & 267. (--) \\
\hline tatb, 1.88 & 7.76 & - & $8.19(5.53)$ & $7.91(1.96)$ & $8.23(6.00)$ & $8.23(6.00)$ & 285. (-) & 308. (-- & 308. (--) \\
\hline tatb, 1.85 & 7.66 & 259. & $8.07(5.39)$ & $7.81(1.99)$ & $8.10(5.74)$ & $8.10(5.74)$ & 273. (5.51) & 291. (12.4) & 291. (12.4) \\
\hline tetryl, 1.73 & 7.72 & $\cdots$ & $7.81(1.14)$ & $7.74(0.22)$ & $7.72(0.02)$ & $7.72(0.02)$ & 255. (-) & 257. (--) & 257. (-) \\
\hline tetryl, 1.71 & 7.85 & -- & $7.74(1.45)$ & $7.68(2.21)$ & $7.65(2.55)$ & $7.65(2.55)$ & 248. (-) & 250. (-) & 250. (--) \\
\hline tetryl, 1.68 & 7.50 & 239. & $7.63(1.71)$ & $7.59(1.15)$ & $7.55(0.65)$ & $7.55(0.65)$ & 239. (0.13) & $239 .(0.14)$ & $239 .(0.13)$ \\
\hline tetryl, 1.61 & 7.58 & 226. & $7.38(2.59)$ & $7.38(2.69)$ & $7.32(3.47)$ & $7.32(3.47)$ & 218. (3.73) & 217. (3.96) & 217. (3.97) \\
\hline tetryl, 1.40 & - & - & $6.70(--)$ & $6.75(--)$ & $6.66(-)$ & $6.66(-)$ & $165 .(-)$ & 161. (-) & $161 .(-)$ \\
\hline tetryl, 1.36 & 6.68 & 142. & $6.59(1.41)$ & $6.63(0.72)$ & $6.54(2.03)$ & $6.54(2.03)$ & 157. (10.4) & 152. (7.32) & 152. (7.31) \\
\hline tetryl, 1.20 & 6.34 & $\rightarrow$ & $6.15(3.00)$ & $6.16(2.77)$ & $6.09(3.89)$ & $6.09(3.89)$ & 127. (--) & 120. (--) & $120 .(-)$ \\
\hline tetryl, 1.00 & $\infty$ & $\cdots$ & $5.68(--)$ & $5.59(-)$ & $5.55(--)$ & $5.55(--)$ & 95. (--) & 85. (--) & 85. $(\ldots)$ \\
\hline
\end{tabular}


Table 8. Measured ${ }^{10}$ and predicted detonation velocities and pressures with \%RMS errors.

\begin{tabular}{|c|c|c|c|c|c|c|c|c|c|}
\hline $\begin{array}{l}\text { Explosive and } \\
\text { density, } \mathrm{g} / \mathrm{cm}^{3}\end{array}$ & $\begin{array}{l}D_{m} \\
\mathrm{~km} / \mathrm{s}\end{array}$ & $\begin{array}{l}P_{m} \\
\text { kbar }\end{array}$ & $\begin{array}{c}\mathrm{D}_{\mathrm{BKWS}} \\
\mathrm{km} / \mathrm{s}\end{array}$ & $\begin{array}{c}\mathrm{D}_{\mathrm{BKWC}} \\
\mathrm{km} / \mathrm{s}\end{array}$ & $\begin{array}{c}\text { DJCZS-small } \\
\mathrm{km} / \mathrm{s}\end{array}$ & $\begin{array}{c}\mathrm{D}_{\mathrm{JCZ} \text {-Jarge }} \\
\mathrm{km} / \mathrm{s}\end{array}$ & $\begin{array}{c}\mathrm{P}_{\mathrm{BKWS}} \\
\mathrm{kbar}\end{array}$ & $\begin{array}{c}\text { PJCZs-small }_{\mathrm{kbar}} \\
\end{array}$ & $\begin{array}{c}\text { PJCZS-large } \\
\text { kbar }\end{array}$ \\
\hline tnt, 1.64 & 6.93 & 210. & $7.19(3.69)$ & $6.84(1.25)$ & $7.03(1.42)$ & $7.03(1.42)$ & 203. (3.20) & 195. (6.93) & 195. (6.93) \\
\hline tnt, 1.45 & 6.50 & 144. & $6.51(0.21)$ & $6.27(3.60)$ & $6.37(1.97)$ & $6.37(1.97)$ & 153. (6.54) & 147. (1.85) & $147 .(1.84)$ \\
\hline tnt, 1.36 & 6.20 & 124. & $6.22(0.29)$ & $6.00(3.30)$ & $6.09(1.84)$ & $6.09(1.85)$ & 134. (8.39) & 128. (3.27) & 128. (3.26) \\
\hline tnt, 1.00 & 5.00 & 67. & $5.21(4.26)$ & $4.98(0.34)$ & $5.06(1.14)$ & $5.06(1.14)$ & 77. (15.5) & 70. (3.78) & 70. (3.78) \\
\hline tnt, 0.80 & 4.34 & 37. & $4.74(9.21)$ & $4.48(3.13)$ & $4.45(2.53)$ & $4.45(2.52)$ & 53. (43.6) & 43. (15.8) & 43. (15.7) \\
\hline btf, 1.86 & 8.49 & 360. & $8.16(3.95)$ & $8.60(1.24)$ & $8.60(1.32)$ & $8.60(1.34)$ & $310 .(13.8)$ & $331 .(8.16)$ & 331. (8.15) \\
\hline btf, 1.76 & 8.26 & $\cdots$ & $7.84(5.04)$ & $8.34(0.96)$ & $8.26(0.01)$ & $8.26(0.04)$ & 278. (-) & 292. (-) & 292. (-) \\
\hline hnb, 1.97 & 9.30 & -- & $8.86(4.78)$ & $9.25(0.50)$ & $8.76(5.78)$ & $8.77(5.69)$ & 373. $(--)$ & 348. (-) & 347. (--) \\
\hline $\operatorname{tnm}, 1.64$ & 6.36 & 159. & $5.50(13.5)$ & $6.32(0.60)$ & $6.24(1.89)$ & $6.28(1.30)$ & 114. (28.1) & 145. (8.56) & 141. (11.1) \\
\hline tntab, 1.74 & 8.58 & $\cdots$ & $8.02(6.52)$ & $8.79(2.41)$ & $8.48(1.13)$ & $8.49(1.09)$ & 286. (-) & $303 .(-)$ & 303. (-) \\
\hline fefo, 1.59 & 7.50 & 250. & $7.30(2.66)$ & $7.30(2.69)$ & $7.35(1.97)$ & $7.45(0.66)$ & 222. (11.1) & 243. (2.65) & 235. (5.95) \\
\hline $1 \times 04,1.86$ & 8.46 & 350. & $8.34(1.38)$ & $8.28(2.11)$ & $8.35(1.26)$ & $8.36(1.20)$ & 310. (11.4) & 310. (11.5) & $310 .(11.5)$ \\
\hline $1 \times 07,1.87$ & 8.64 & -- & $8.68(0.45)$ & $8.60(0.47)$ & $8.61(0.40)$ & $8.61(0.35)$ & $332 .(--)$ & 338. (-) & 338. $(--)$ \\
\hline $1 \times 09,1.84$ & 8.81 & 377. & $9.05(2.76)$ & $8.93(1.39)$ & $8.84(0.32)$ & $8.84(0.33)$ & 348. (7.67) & $360 .(4.58)$ & $360 .(4.60)$ \\
\hline $1 \times 10,1.86$ & 8.82 & 375. & $8.94(1.31)$ & $8.85(0.29)$ & $8.78(0.45)$ & $8.78(0.42)$ & 345. (7.93) & 356. (5.05) & 356. (5.05) \\
\hline $1 \times 11,1.86$ & 8.32 & - & $8.04(3.32)$ & $8.00(3.85)$ & $8.15(2.09)$ & $8.15(2.01)$ & 293. (-) & 297. (- & 297. (-) \\
\hline ap, 1.00 & 3.70 & $\cdots$ & $4.02(8.57)$ & $3.66(1.18)$ & $3.73(0.88)$ & $3.71(0.15)$ & 40. (-) & 36. (-) & 35. (-) \\
\hline $1 \times 15,1.58$ & 6.84 & $\cdots$ & $6.70(2.04)$ & $6.61(3.41)$ & 6.642 .87() & $6.64(2.85)$ & 179. $(-)$ & 177. (-) & 177. (-) \\
\hline $1 \times 17,1.91$ & 7.63 & $\cdots$ & $7.96(4.34)$ & $7: 73$ (1.35) & $7.92(3.80)$ & $7.92(3.81)$ & 282. (-) & 283. (-) & 284. (-) \\
\hline $9010,1.78$ & 8.37 & 328. & $8.33(0.46)$ & $8.34(0.33)$ & $8.06(3.66)$ & $8.06(3.65)$ & $300 .(8.44)$ & 289. (11.8) & 289. (11.8) \\
\hline $9404,1.84$ & 8.80 & 375. & $9.01(2.37)$ & $8.90(1.12)$ & $8.81(0.13)$ & $8.81(0.13)$ & 344. (8.15) & 353. (5.74) & 353. (5.76) \\
\hline 94071.60 & 7.91 & 287. & $7.94(0.43)$ & $7.90(0.16)$ & $7.76(1.87)$ & $7.76(1.86)$ & 251. (12.4) & 245. (14.8) & 245. (14.8) \\
\hline $9502,1.91$ & 7.71 & $\cdots$ & $8.08(4.82)$ & $7.83(1.52)$ & $8.07(4.62)$ & $8.07(4.63)$ & 287. (-) & 298. (- & 298. (-) \\
\hline $9503,1.90$ & 7.71 & $\ldots$ & $8.21(6.49)$ & $7.98(3.50)$ & $8.13(5.51)$ & $8.14(5.51)$ & 296. (-) & 306. (-) & 306. (-) \\
\hline
\end{tabular}

*The acronyms and heats of formations for these explosives can be found in Ref. 10. 
cal temperature measurements which may be as high as $20 \%$. Table 8 shows the specific measured and predicted detonation temperatures used to calculate the overall percent RMS error for the temperatures. The JCZS predicted detonation temperatures are similar to measured detonation temperatures for homogeneous explosive. For example, the RMS error for the NM case is $1.05 \%$ for the JCZS-EOS compared to $5.45 \%$ for the BKWC-EOS.

\subsection{Expansion States}

As an additional evaluation of the JCZS-EOS at expanded states, the total energy of detonation and expansion energies at relative volumes of $2.2,4.1$, and 6.5 were compared to the tabulated values ${ }^{12}$ for the explosives in the LLNL performance database. Table 9 gives the percent RMS error for the total energy of detonation which is labeled as E, and the expansion energies as relative volumes of $2.2,4.1$, and 6.5 labeled as $\mathrm{E}_{2.2}, \mathrm{E}_{4.1}$, and $\mathrm{E}_{6.5}$.

Table 9. Percent RMS errors for $\mathbf{E}, \mathbf{E}_{2.2}, \mathbf{E}_{4.1}, \mathbf{E}_{6.5}{ }^{*}$

\begin{tabular}{|c|c|c|c|c|c|c|c|c|}
\hline \multirow{2}{*}{ EOS } & \multicolumn{2}{|c|}{ E } & \multicolumn{2}{c|}{$\mathbf{E}_{2.2}$} & \multicolumn{2}{c|}{$\mathbf{E}_{4.1}$} & \multicolumn{2}{c|}{$\mathbf{E}_{6.5}$} \\
\cline { 2 - 9 } & $1.4^{\dagger}$ & $2.0^{\ddagger}$ & $1.4^{\dagger}$ & $2.0^{\ddagger}$ & $1.4^{\dagger}$ & $2.0^{\ddagger}$ & $1.4^{\dagger}$ & $2.0^{\ddagger}$ \\
\hline BKWS & 11.7 & 8.0 & 12.2 & 10.8 & 10.4 & 9.1 & 8.7 & 7.4 \\
\hline BKWC & 9.3 & 6.5 & 5.8 & 5.8 & 5.4 & 5.2 & 5.3 & 4.9 \\
\hline JCZS & 8.5 & 6.5 & 11.9 & 8.0 & 8.9 & 6.9 & 7.9 & 7.0 \\
\hline
\end{tabular}

* JCZS-small and JCZS-large give essentially the same results $\uparrow$ CHEETAH $1.4 \div$ CHEETAH 2.0

The JCZS prediction of the total energy of detonation was better than the BKW predictions. The expansion energies for the BKWC-EOS was better than the BKWS and JCZS predictions. However, the BKWC used the expansion states to calibrate 31 constants and is expected to match the experimental measurements closest. A better comparisons of the expansion energy would be to compare cylinder wall velocities as predicted with a shock physics code.

\subsection{Detonation in Condensed Explosives with Low Initial Densities}

Figure 18 shows the measured and predicted detonation velocity and pressure for PETN for a wide range of initial densities. The agreement is good over the entire density range for both detonation velocity and pressure. The predictions made using the BKWS-EOS do not agree with the data as well as the predictions made using the JCZSEOS especially at low initial densities.
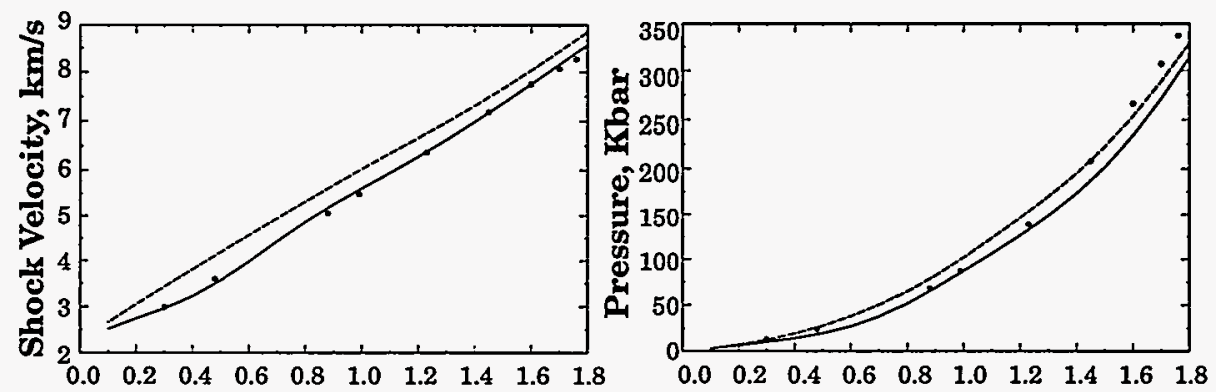

Fig. 18. Comparison of measured (symbols) detonation velocity and pressure for PETN to predictions using the BKWSEOS (dashed lines) and the JCZS-EOS (solid lines). 


\subsection{High Pressure Gas Detonations}

Another method of evaluating the JCZS-EOS database is to compare measured detonation velocity of gases at high initial pressures to predictions. The detonation velocity of various gases at high initial pressures were measured by Bauer ${ }^{35}$ and evaluated by Schmitt. ${ }^{36}$.

Figure 6 shows predicted (lines) and measured (symbols) detonation velocities of various gases at different elevated initial pressures The compositions of the gas mixtures are also shown in Figure 6. The BKWC database does not consider $\mathrm{H}$ and $\mathrm{OH}$ as reaction products and cannot adequately predict the detonation velocities for the hydrogen oxygen system as shown in Figure 6.A. The JCZS-EOS database adequately predicts the detonation velocity for all the gas mixtures in Figure 6.

\section{Summary and Conclusions}

The JCZ3 product species library has been expanded to include approximately 750 gas-phase products. The force constants for this library, $r^{*}$ and $\varepsilon / k$, have been obtained by using pure liquid shock Hugoniot data, by correcting the LJ characteristic approach radii $(\sigma)$ to conform to the mathematical form of the EXP 6 potential function and using literature values for the potential well depth, using corresponding states theory to calculate the EXP 6 force constants, using a semiempirical formula based on the species volume to determine the approach radii and obtaining the potential well depth by matching isentropes with the BKWS-EOS. Some of the EXP 6 parameters were slightly adjusted to predict optimal detonation velocities using the optimization toolkit, DAKOTA.

Detonation simulations have been performed with the JCZS-EOS database and have displayed adequate agreement with experimental results for detonation velocity, detonation pressure, and detonation temperature. Predicted detonation velocities with the JCZS-EOS are shown to be within $2 \%$ of measured values for many explosives. The predicted velocities with the BKWC-EOS for the same set of explosives was shown to be within $3 \%$. The detonation pressure, temperature, and expansion states were all shown to be within $10 \%$ of reported values. The JCZS-EOS is shown to predict low density explosives and high pressure gaseous detonations with the same accuracy as high density explosives. The better agreement at these intermediate states is attributed to modeling molecular interactions which is not done in the semiempirical BKW-EOS.

The JCZ-EOS with the improved product species library has been shown to adequately predict detonation states as well as expansion states for various explosives. Better agreement between measured detonation performance and predicted detonation performance for low density explosives such as PETN is attributed to a better description of molecular interaction at intermediate pressure regimes. Such predictions supports the hypothesis that improved predictions of explosive performance can be realized by using a more fundamental EOS with an adequate number of product species, rather than merely increasing the number of fitting parameters used by empirical based equations-ofstates. 


\section{References}

1. Cowperthwaite, M. and Zwisler, W. K., "The JCZ Equations of State for Detonation Products and Their Incorporation into the TIGER Code," Sixth Symposium (International) on Detonation, ACR-221, Office of Naval Research, Naval Surface Weapons Center, 162 (1976).

2. Chase, M. W. Jr., Davies, C. A., Downey, J.R. Jr., Frurip, D. J., McDonald, R. A., Syverud, A. N., JANAF Thermochemical Tables, Third Edition, Journal of Physical and Chemical Reference Data, 14, Supplement No. 1 (1985).

3. Ross, M. and Ree, F. H., "Repulsive forces of simple molecules and mixtures at high density and temperature," $J$. Chem. Phys. 73(12), 6146 (1980).

4. Jacobs, S. J., "On the Equation of State of Compressed Liquids and Solids," NOLTR 68-214, United States Naval Ordnance Laboratory, White Oak, Maryland (1968).

5. Hobbs, M. L., and Baer, M. R., "Four Parameter Corresponding States Method Applied to the JCZ3 Force Constants," Internal Memorandum to A. C. Ratzel, Sandia National Laboratories, Albuquerque, New Mexico (December 12, 1994). See also Hobbs, M. L. and Baer, M. R., "Using Corresponding State Theory to Obtain Intermolecular Potentials to Calculate Pure Liquid Shock Hugoniots," Twenty-Seventh International Symposium on Combustion, Submitted, Boulder, CO (August 2-7, 1998).

6. Hirschfelder, J. O., Curtiss, C. F., and Bird, R. B., Molecular Theory of Gases and Liquids, Wiley, New York, 34 (1954).

7. Hirschfelder, J. O., Curtiss, C. F., and Bird, R. B., Molecular Theory of Gases and Liquids, Wiley, New York, 234 (1954).

8. Wilding, W. V., and Rowley, R. L., "Four-Parameter corresponding states Method for the Prediction of Thermodynamic Properties of Polar and Nonpolar Fluids," International Journal of Thermophysics, 7 (3), 525 (1986).

9. Rowley, R. L., "ELK, Extended Lee-Kesler--A Four-Parameter Corresponding States Method for Prediction of Thermophysical Properties of Pure Fluids and Mixtures," IBM PC compatible software and manual, Dept. of Chem. Eng., Brigham Young University, Provo, Utah (1993).

10. Hobbs, M. L., and Baer, M. R., "Calibrating the BKW-EOS with a Large Product Species database and Measured C-J Properties," Tenth Symposium (International) on Detonation, Boston, MA, (1993).

11. Mader, C. L., Numerical Modeling of Detonations, Univ. of California Press, Los Angeles, CA 1979.

12. Fried, L. E., "CHEETAH 1.22 User's Manual", UCRL-MA-117541 Rev.2, Lawrence Livermore National Laboratory (August, 3, 1995). See also Fried, L. E. and Souers, P. C., "BKWC: An Empirical BKW parameterization based on cylinder test data," Propellants, Explosives, and Pyrotechnics, 21, 215 (1996).

13. Finger, M., Lee, E., Helm, F. H., Hayes, B., Hornig, H., McGuire, R., Kahara, M., and Guidry, M., "The Effect of Elemental Composition on the Detonation Behavior of Explosives," Sixth Symposium (International) on Detonation, ACR-221, 1976, p. 710.

14. Souers, P. C. and Kury, J. W., "Comparison of Cylinder Data and Code Calculations for Homogeneous Explosives," UCRL-JC-110661, Lawrence Livermore National Laboratory, Livermore, California (May 1992).

15. Cowperthwaite, M. and Zwisler, W. H., TIGER Computer Program Documentation, Stanford Research Institute, Menlo Park, California, 1973.

16. Ree, F. H., "A statistical theory of chemically reacting multiphase mixture: application to the detonation properties of PETN," J. Chem. Phys., 81, 1251 (1984).

17. Sheffield, S. A., private communication at Sandia National Laboratories (1996).

18. Woolfolk, R. W., Cowperthwaite, M., and Shaw, R., "A 'Universal' Hugoniot for Liquids," Thermochimica Acta, 5, 409 (1973).

19. Marsh, S. P., editor, LASL Shock Hugoniot Data, University of California Press, Berkeley, California (1980).

20. Lyzenga, G. A., Ahrens, T. J., Nellis, W. J., and Mitchell, A. C., "The temperature of shock-compressed water," J. Chem. Phys., 76 (12), 6282 (1982).

21. Nellis, W. J., Mitchell, A. C., van Thiel, M., Devine, G. J., and Trainor, R. J., "Equation-of-state data for molecular hydrogen and deuterium at shock pressures in the range 2-76 GPa (20-760 kbar)," J. Chem. Phys., 79 (3), 1480 (1983).

22. Nellis, W. J., Ree, F. H., van Thiel, M., Mitchell, A. C., "Shock Compression of Liquid Carbon Monoxide and 
Methane to $90 \mathrm{GPa}$ (900 kbar)," J. Chem. Phys., 75 (6), 3055 (1981).

23. Schott, G. L., "Shocked Liquid Carbon Dioxide," Bull. Am. Phys. Soc., 31, 824 (1986).

24. Zubarev, V. N., Telegin, G. S., "The Impact Compressibility of Liquid Nitrogen and Solid Carbon Dioxide," Soviet Physics - Doklady, 7 (1), 34 (1962).

25. Kovel, M. I., "The Shock Wave Hugoniot and Electrical Conductivity of Liquid Ammonia in the Pressure Range $45 \mathrm{~kb}$ to $282 \mathrm{~kb}$," Ph.D. Theses, Lawrence Livermore Laboratory, UCRL-51367, University of California, Livermore, California (1973).

26. Radousky, H. B., Mitchell, A. C., Nellis, W. J., and Ross, M., "Shock Temperature Measurements in Ammonia," in Shock Waves in Condensed Matter, edited by Gupta, Y. M., Plenum Press, New York (1986).

27. Nellis, W. J. and Mitchell, A. C., "Shock Compression of Liquid Argon, Nitrogen, and Oxygen to $90 \mathrm{GPa}(900$ kbar)," J. Chem. Phys., 73 (12), 6137 (1980).

28. van Thiel, M. and Alder, B. J., "Shock Compression of Argon," J. Chem. Phys., 44(3), 1056 (1966).

29. Cowan, R. D., and Fickett, W., "Calculation of the detonation properties of solid explisives with the Kistiakowsky-Wilson equation of state," J. Chem. Phy., 24, 932 (1956).

30. Hobbs, M. L., and Baer, M. R., Nonideal Thermoequilbrium Calculations Using a Large Product Species Data Base, SAND92-0482, UC-741, Sandia National Laboratories, Albuquerque, NM, 13 (1992).

31. Eldred, M. S., Hart, W. E., Bohnhoff, W. J., Romero, V. J., Hutchinson, S. A., and Salinger, A. G., "Utilizing Object-Oriented Design to Build Advanced Optimization Strategies with Generic Implementation," AAIAA4164 in Proceedings of the $6^{\text {th }}$ AIAA/USAF/NASA/ISSMO Symposium on Multidisciplinary Analysis and Optimization, Bellevue, WA, 1568 (Sept. 4-6, 1996). See also Eldred, M. S., Outka, D. E., Bohnhoff, W. J., Witkowski, W. R., Romero, V. J., Ponslet, E. R., and Chen, K. S., "Optimization of Complex Mechanics Simulations with Object-Oriented Software Design," Computer Modeling and Simulation in Engineering, 1,3 (August 1996).

32. Sjaardema, G. D., "APREPRO: An Algebraic Preprocessor for Parameterizing Finite Element Analyses," SAND92-2291, UC-705, Sandia National Laboratories, Albuquerque, NM (1994).

33. Davis, W. C., and Venable, D., "Pressure Measurements for Composition B-3," Fifth Symposium (International) on Detonation, ACR-184, 13 (1970).

34. Fickett, W., "Intermolecular Potential Functions for Some Simple Molecules from Available Experimental Data," Los Alamos National Laboratory Report No. LA-2665, TID-4500 (1962).

35. Bauer, P. A., "Contribution of L'Etude De La Detonation De Melanges Explosifs Gazeux A Pression Initiale Elevvee," Ph. D. Thesis L'Universite De Pointiers (1985).

36. Schmitt, R. G., "Analysis of Gas-phase Detonation Wave Structure at Elevated Initial Pressures," Ph. D Thesis, The University of Iowa (1994). See also, Schmitt, R. G., and Butler, P. B., "Detonation Properties of Gases at Elevated Initial Pressures," Combust. Sci. and Tech., 106167 (1995).

37. Daubert, T. E., Danner, R. P., Sibul, H. M., and Stebbins, C. C., Physical and Thermodynamic Properties of Pure Compounds: Data Compilation, extant 1994 (core with 4 supplements), Taylor \& Francis, Bristol, PA (1994).

38. Stephenson, R. M., Malanowski, S., Ambrose, D., "Vapor-Liquid Critical Constants of Fluids," in the Handbook of Thermodynamics of Organic Compounds, Elsevier, New York (1987).

39. McCormick, S., TAPP (version 2.20) - A Database of Thermochemical and Physical Properties, E. S. Microware, Hamilton, $\mathrm{OH}$ (1996).

40. Reid, R. C., Prausnitz, J. M., and Poling, B. E., The Properties of Gases and Liquids, 4th ed., McGraw-Hill, New York (1987).

41. TRCTHERMO data search, Sandia Laboratories Technical Library, Albuquerque, NM (1997).

42. Svehla, R. A., "Estimated Viscosities and Thermal Conductivities of Gases at High Temperatures," NASA Technical Report R-132 (1962).

43. Warnatz, J., "Calculation of the Structure of Laminar Flat Flames I: Flame Velocity of Freely Propagating Ozone Decomposition Flames," Ber. Beunsenges. Phys. Chem., 82, 193 (1978). See also Warnatz, J., "Influence of Transport Models and Boundary Conditions on Flame Structure," in Numerical Methods in Flame Propagation, Editors N. Petersand J. Warnatz, Friedr. Vieweg and Sohn, Wiesbaden (1982). 


\section{Appendix A}

Appendix A documents the resources of all the critical properties and Lennard-Jones parameters used to establish the JCZS database.

This table indicates the source of each critical volume obtained in the literature search.

Table A.1 Species with known critical volumes

\begin{tabular}{|c|c|c|c|c|c|c|c|c|c|}
\hline $\mathrm{Al}^{\mathrm{a}}$ & $\mathrm{Br}_{3} \mathrm{HSi}^{\mathrm{b}}$ & $\mathrm{CF}_{2} \mathrm{O}^{\mathrm{a}}$ & $\mathrm{CH}_{3} \mathrm{OH}^{\mathrm{a}}$ & $\mathrm{C}_{2} \mathrm{~N}_{2}{ }^{\mathrm{a}}$ & $\mathrm{Cl}_{3} \mathrm{HSi}^{\mathbf{a}}$ & $D_{2} S^{b}$ & $\mathrm{~F}_{4} \mathrm{Si}^{\mathrm{a}}$ & $\mathrm{H}_{4} \mathrm{~N}_{2}{ }^{\mathrm{a}}$ & $\mathrm{N}_{2} \mathrm{O}^{2}$ \\
\hline $\mathrm{AlBr}_{3}{ }^{\mathrm{a}}$ & $\mathrm{Br}_{2} \mathrm{Hg}^{\mathrm{b}}$ & $\mathrm{CF}_{4}^{\mathrm{a}}$ & $\mathrm{CH}_{4}^{\mathrm{a}}$ & $\mathrm{C}_{3} \mathrm{H}_{6}{ }^{\mathrm{a}}$ & $\mathrm{Cl}_{3} \mathrm{P}^{\mathrm{a}}$ & $\mathrm{D}_{3} \mathrm{~N}^{\mathrm{e}}$ & $\mathrm{F}_{6} \mathrm{Mo}^{\mathrm{b}}$ & $\mathrm{H}_{4} \mathrm{Si}^{\mathrm{a}}$ & $\mathrm{N}_{2} \mathrm{O}_{3}{ }^{\mathrm{a}}$ \\
\hline $\mathrm{AlCl}_{3}{ }^{\mathrm{a}}$ & $\mathrm{Br}_{3} \mathrm{P}^{\mathrm{b}}$ & $\mathrm{CHBr}_{3}{ }^{\mathrm{c}}$ & $\mathrm{CO}^{\mathrm{a}}$ & $\mathrm{C}_{3} \mathrm{H}_{8}{ }^{2}$ & $\mathrm{Cl}_{4} \mathrm{OW}^{\mathrm{b}}$ & $\mathrm{FH}^{\mathrm{a}}$ & $\mathrm{F}_{6} \mathrm{~S}^{\mathrm{a}}$ & $\mathrm{He}^{\mathrm{c}}$ & $\mathrm{N}_{2} \mathrm{O}_{4}{ }^{\mathrm{a}}$ \\
\hline $\mathrm{All}_{3}^{\mathrm{c}}$ & $\mathrm{Br}_{4} \mathrm{Si}^{\mathrm{b}}$ & $\mathrm{CHClF}_{2}{ }^{\mathrm{a}}$ & $\cos ^{a}$ & $\mathrm{C}_{3} \mathrm{H}_{9} \mathrm{Cl}_{3} \mathrm{Si}^{\mathrm{a}}$ & $\mathrm{Cl}_{4} \mathrm{Si}^{\mathrm{a}}$ & $\mathrm{FNa}^{\mathrm{a}}$ & $\mathrm{F}_{6} \mathrm{~W}^{\mathrm{b}}$ & $\mathrm{Hg}^{\mathrm{a}}$ & $\mathrm{Na}^{\mathrm{a}}$ \\
\hline$A r^{d}$ & $\mathrm{Br}_{4} \mathrm{Ti}^{\mathrm{b}}$ & $\mathrm{CHCl}_{2} \mathrm{~F}^{\mathrm{a}}$ & $\mathrm{CO}_{2}^{\mathrm{a}}$ & $\mathrm{C}_{3} \mathrm{O}_{2}{ }^{\mathrm{e}}$ & $\mathrm{Cl}_{4} \mathrm{Ti}^{\mathrm{a}}$ & $\mathrm{FNO}_{2}{ }^{\mathrm{e}}$ & $\mathrm{Fe}^{\mathrm{a}}$ & $\mathrm{Hgl}_{2}{ }^{\mathrm{e}}$ & $\mathrm{Ne}^{\mathrm{c}}$ \\
\hline $\mathrm{BBr}_{3}{ }^{\mathrm{b}}$ & $\mathrm{Br}_{4} \mathrm{Zr}^{\mathrm{b}}$ & $\mathrm{CHCl}_{3}^{\mathrm{a}}$ & $\mathrm{CS}_{2}^{\mathrm{a}}$ & $\mathrm{CID}^{\mathrm{e}}$ & $\mathrm{Cl}_{4} \mathrm{Zr}^{\mathrm{b}}$ & $\mathrm{F}_{2}^{\mathrm{a}}$ & $\mathrm{HI}^{\mathrm{a}}$ & $\mathrm{I}_{4} \mathrm{Si}^{\mathrm{b}}$ & $\mathrm{O}_{2}^{\mathrm{a}}$ \\
\hline $\mathrm{BCl}_{3}{ }^{\mathrm{a}}$ & $\mathrm{Br}_{5} \mathrm{Nb}^{\mathrm{b}}$ & $\mathrm{CHF}_{3}{ }^{\mathrm{a}}$ & $\mathrm{C}_{2} \mathrm{Cl}_{4}^{\mathrm{a}}$ & $\mathrm{ClF}_{5}^{\mathrm{b}}$ & $\mathrm{Cl}_{5} \mathrm{Mo}^{\mathrm{b}}$ & $c-\mathrm{F}_{2} \mathrm{~N}_{2}{ }^{\mathrm{e}}$ & $\mathrm{HNO}_{3}{ }^{\mathrm{a}}$ & $\mathrm{I}_{4} \mathrm{Ti}^{\mathrm{d}}$ & $\mathrm{O}_{2} \mathrm{~S}^{\mathrm{a}}$ \\
\hline $\mathrm{BF}_{3}{ }^{\mathrm{a}}$ & $C^{c}$ & $\mathrm{CHN}^{\mathrm{a}}$ & $\mathrm{C}_{2} \mathrm{Cl}_{6}{ }^{\mathrm{a}}$ & $\mathrm{ClF}_{5} \mathrm{~S}^{\mathrm{e}}$ & $\mathrm{Cl}_{5} \mathrm{Nb}^{\mathrm{c}}$ & $\mathrm{t}-\mathrm{F}_{2} \mathrm{~N}_{2}{ }^{\mathrm{e}}$ & $\mathrm{HNaO}^{\mathrm{a}}$ & $\mathrm{I}_{4} \mathrm{Zr}^{\mathrm{b}}$ & $\mathrm{O}_{3}^{\mathrm{a}}$ \\
\hline $\mathrm{BI}_{3}^{\mathrm{b}}$ & $\mathrm{CBrF}_{3}{ }^{\mathrm{a}}$ & $\mathrm{CH}_{2} \mathrm{ClF}^{\mathrm{a}}$ & $\mathrm{C}_{2} \mathrm{~F}_{3} \mathrm{~N}^{\mathrm{d}}$ & $\mathrm{ClH}^{\mathrm{a}}$ & $\mathrm{Cl}_{5} \mathrm{P}^{\mathrm{e}}$ & $\mathrm{F}_{2} \mathrm{O}^{\mathrm{e}}$ & $\mathrm{H}_{2}{ }^{\mathrm{a}}$ & $\mathrm{K}^{\mathrm{a}}$ & $\mathrm{O}_{3} \mathrm{~S}^{\mathrm{a}}$ \\
\hline $\mathrm{B}_{2} \mathrm{H}_{6}{ }^{\mathrm{a}}$ & $\mathrm{CClF}_{3}{ }^{\mathrm{a}}$ & $\mathrm{CH}_{2} \mathrm{Cl}_{2}{ }^{\mathrm{a}}$ & $\mathrm{C}_{2} \mathrm{~F}_{4}^{\mathrm{a}}$ & $\mathrm{ClNO}^{\mathrm{a}}$ & $\mathrm{Cl}_{5} \mathrm{Ta}^{\mathrm{b}}$ & $\mathrm{F}_{3} \mathrm{~N}^{\mathrm{a}}$ & $\mathrm{H}_{2} \mathrm{O}^{\mathrm{a}}$ & $\mathrm{Kr}^{\mathrm{c}}$ & $p^{e}$ \\
\hline $\mathrm{BrH}^{\mathrm{c}}$ & $\mathrm{CClN}^{\mathrm{a}}$ & $\mathrm{CH}_{2} \mathrm{~F}_{2}^{\mathrm{a}}$ & $\mathrm{C}_{2} \mathrm{~F}_{6}^{\mathrm{a}}$ & $\mathrm{ClNa}^{\mathrm{a}}$ & $\mathrm{Cl}_{6} \mathrm{~W}^{\mathrm{b}}$ & $\mathrm{F}_{3} \mathrm{NO}^{\mathrm{b}}$ & $\mathrm{H}_{2} \mathrm{O}_{2}{ }^{\mathrm{a}}$ & $\mathrm{Li}^{\mathrm{a}}$ & $S^{c}$ \\
\hline $\mathrm{BrI}^{\mathrm{e}}$ & $\mathrm{CCl}_{2} \mathrm{~F}_{2}^{\mathrm{a}}$ & $\mathrm{CH}_{2} \mathrm{O}^{\mathrm{a}}$ & $\mathrm{C}_{2} \mathrm{H}_{2}^{\mathrm{a}}$ & $\mathrm{Cl}_{2}^{\mathrm{a}}$ & $\mathrm{Cs}^{\mathrm{e}}$ & $\mathrm{F}_{3} \mathrm{P}^{\mathrm{e}}$ & $\mathrm{H}_{2} \mathrm{~S}^{\mathrm{a}}$ & $\mathrm{MgO}^{\mathrm{a}}$ & $\mathrm{Si}^{\mathrm{a}}$ \\
\hline $\mathrm{BrK}^{\mathrm{a}}$ & $\mathrm{CCl}_{2} \mathrm{O}^{\mathrm{a}}$ & $\mathrm{CH}_{2} \mathrm{O}_{2}{ }^{\mathrm{a}}$ & $\mathrm{C}_{2} \mathrm{H}_{4}^{\mathrm{a}}$ & $\mathrm{Cl}_{2} \mathrm{H}_{2} \mathrm{Si}^{\mathrm{a}}$ & $\mathrm{DH}^{\mathrm{e}}$ & $\mathrm{F}_{3} \mathrm{PS}^{\mathrm{e}}$ & $\mathrm{H}_{2} \mathrm{SO}_{4}{ }^{\mathrm{a}}$ & $\mathrm{NO}^{\mathrm{a}}$ & $\mathrm{UF}_{6}^{\mathrm{b}}$ \\
\hline $\mathrm{BrNa}^{\mathrm{a}}$ & $\mathrm{CCl}_{3} \mathrm{~F}^{\mathrm{a}}$ & $\mathrm{CH}_{3} \mathrm{Cl}^{\mathrm{a}}$ & $\mathrm{C}_{2} \mathrm{H}_{4} \mathrm{O}^{\mathrm{a}}$ & $\mathrm{Cl}_{2} \mathrm{Hg}^{\mathrm{e}}$ & $D_{2}^{c}$ & $\mathrm{~F}_{4} \mathrm{~N}_{2}^{\mathrm{a}}$ & $\mathrm{H}_{3} \mathrm{~N}^{\mathrm{a}}$ & $\mathrm{NO}_{2}{ }^{\mathrm{a}}$ & $X e^{c}$ \\
\hline $\mathrm{Br}_{2}{ }^{\mathrm{a}}$ & $\mathrm{CCl}_{4}{ }^{\mathrm{a}}$ & $\mathrm{CH}_{3} \mathrm{~F}^{\mathrm{a}}$ & $\mathrm{C}_{2} \mathrm{H}_{6}{ }^{\mathrm{a}}$ & $\mathrm{Cl}_{2} \mathrm{O}_{2} \mathrm{~S}^{\mathrm{c}}$ & $\mathrm{D}_{2} \mathrm{O}^{\mathrm{c}}$ & $\mathrm{F}_{4} \mathrm{~S}^{\mathrm{e}}$ & $\mathrm{H}_{3} \mathrm{P}^{\mathrm{a}}$ & $\mathrm{N}_{2}{ }^{\mathrm{a}}$ & $\mathrm{Zn}^{\mathrm{c}}$ \\
\hline
\end{tabular}

a. Ref. [35], Daubert, T. E., Danner, R. P., Sibul, H. M. and Stebbins, C. C., Physical and Thermodynamic Properties of Pure Compounds: Data Compilation, Taylor \& Francis, Bristol, PA (1994).

b. Ref. [36], Stephenson, R. M., Malanowski, S., Ambrose, D., "Vapor-Liquid Critical Constants of Fluids" in Handbook of Thermodynamics of Organic Compound, Elsevier, New York (1987).

c. Ref. [37], McCormick, S., TAPP (version 2.20) - A Database of Thermochemical And Physical Properties, E. S. Microware, Hamilton, OH (1996).

d. Ref. [38], Reid, R. C., Prausnitz, J. M., and Poling, B. E., The Properties of Gases and Liquids, 4th ed., McGraw-Hill, New York (1987).

e. Ref. [39], TRCTHERMO data search (1997). 
This table indicates the source of each critical temperature obtained in the literature search.

Table A.2 Species with known critical temperatures

\begin{tabular}{|c|c|c|c|c|c|c|c|c|c|}
\hline $\mathrm{Al}^{\mathfrak{a}}$ & $\mathrm{Br}_{3} \mathrm{HSi}^{\mathrm{b}}$ & $\mathrm{CHF}_{3}{ }^{\mathrm{a}}$ & $\mathrm{C}_{2} \mathrm{~F}_{4}{ }^{\mathrm{a}}$ & $\mathrm{ClH}^{\mathrm{a}}$ & $\mathrm{Cl}_{5} \mathrm{Ta}^{\mathrm{b}}$ & $\mathrm{t}-\mathrm{F}_{2} \mathrm{~N}_{2}^{\mathrm{b}}$ & $\mathrm{H}_{2} \mathrm{O}_{2}{ }^{\mathrm{a}}$ & $\mathrm{Mg}^{\mathrm{c}}$ & $\mathrm{P}^{\mathrm{a}}$ \\
\hline $\mathrm{AlBr}_{3}{ }^{\mathrm{b}}$ & $\mathrm{Br}_{3} \mathrm{P}^{\mathrm{b}}$ & $\mathrm{CHN}^{\mathrm{a}}$ & $\mathrm{C}_{2} \mathrm{~F}_{6}^{\mathrm{a}}$ & $\mathrm{ClNO}^{\mathrm{a}}$ & $\mathrm{Cl}_{6} \mathrm{~W}^{\mathrm{b}}$ & $\mathrm{F}_{2} \mathrm{O}^{\mathrm{d}}$ & $\mathrm{H}_{2} \mathrm{~S}^{\mathrm{a}}$ & $\mathrm{MgO}^{\mathrm{a}}$ & $\mathrm{P}_{2}^{\mathrm{c}}$ \\
\hline $\mathrm{AlCl}_{3}{ }^{\mathrm{a}}$ & $\mathrm{Br}_{4} \mathrm{Si}^{\mathrm{b}}$ & $\mathrm{CH}_{2} \mathrm{ClF}^{\mathrm{a}}$ & $\mathrm{C}_{2} \mathrm{H}_{2}{ }^{\mathrm{a}}$ & $\mathrm{ClNa}^{\mathrm{a}}$ & $\mathrm{Cs}^{\mathrm{c}}$ & $\mathrm{F}_{3} \mathrm{~N}^{\mathrm{a}}$ & $\mathrm{H}_{2} \mathrm{SO}_{4}{ }^{\mathrm{a}}$ & $\mathrm{Mn}^{\mathrm{c}}$ & $\mathrm{P}_{4}{ }^{\mathrm{c}}$ \\
\hline $\mathrm{AlI}_{3}^{\mathrm{b}}$ & $\mathrm{Br}_{4} \mathrm{Ti}^{\mathrm{b}}$ & $\mathrm{CH}_{2} \mathrm{Cl}_{2}^{\mathrm{a}}$ & $\mathrm{C}_{2} \mathrm{H}_{4}{ }^{\mathrm{a}}$ & $\mathrm{ClO}_{2}^{\mathrm{a}}$ & $\mathrm{Cs}_{2}{ }^{\mathrm{c}}$ & $\mathrm{F}_{3} \mathrm{NO}^{\mathrm{b}}$ & $\mathrm{H}_{3} \mathrm{~N}^{\mathrm{a}}$ & $\mathrm{Mo}^{\mathrm{c}}$ & $\mathrm{Pb}^{\mathrm{c}}$ \\
\hline$A r^{\mathfrak{c}}$ & $\mathrm{Br}_{4} \mathrm{Zr}^{\mathrm{b}}$ & $\mathrm{CH}_{2} \mathrm{~F}_{2}{ }^{\mathrm{a}}$ & $\mathrm{C}_{2} \mathrm{H}_{4} \mathrm{O}^{\mathrm{a}}$ & $\mathrm{Cl}_{2}^{\mathrm{a}}$ & $\mathrm{Cu}^{\mathrm{c}}$ & $\mathrm{F}_{3} \mathrm{P}^{\mathrm{d}}$ & $\mathrm{H}_{3} \mathrm{P}^{\mathrm{a}}$ & $\mathrm{NO}^{\mathrm{a}}$ & $\mathrm{Pb}_{2}{ }^{\mathrm{c}}$ \\
\hline $\mathrm{BBr}_{3}{ }^{\mathrm{b}}$ & $\mathrm{Br}_{5} \mathrm{Nb}^{\mathrm{b}}$ & $\mathrm{CH}_{2} \mathrm{O}^{\mathrm{a}}$ & $\mathrm{C}_{2} \mathrm{H}_{6}{ }^{\mathrm{a}}$ & $\mathrm{Cl}_{2} \mathrm{H}_{2} \mathrm{Si}^{\mathrm{a}}$ & $\mathrm{Cu}_{2}^{\mathrm{c}}$ & $\mathrm{F}_{3} \mathrm{PS}^{\mathrm{b}}$ & $\mathrm{H}_{4} \mathrm{~N}_{2}{ }^{\mathrm{a}}$ & $\mathrm{NO}_{2}{ }^{\mathrm{a}}$ & $S^{c}$ \\
\hline $\mathrm{BCl}_{3}{ }^{\mathrm{a}}$ & $C^{c}$ & $\mathrm{CH}_{2} \mathrm{O}_{2}{ }^{\mathrm{a}}$ & $\mathrm{C}_{2} \mathrm{~N}_{2}{ }^{\mathrm{a}}$ & $\mathrm{Cl}_{2} \mathrm{Hg}^{\mathrm{b}}$ & $D^{c}$ & $\mathrm{~F}_{4} \mathrm{~N}_{2}{ }^{\mathrm{a}}$ & $\mathrm{H}_{4} \mathrm{Si}^{\mathrm{a}}$ & $\mathrm{N}_{2}{ }^{\mathrm{a}}$ & $\mathrm{S}_{2}{ }^{\mathrm{C}}$ \\
\hline $\mathrm{BF}_{3}^{\mathrm{a}}$ & $\mathrm{CBrF}_{3}{ }^{\mathrm{a}}$ & $\mathrm{CH}_{3} \mathrm{Cl}^{\mathrm{a}}$ & $\mathrm{C}_{3} \mathrm{H}_{6}{ }^{\mathrm{a}}$ & $\mathrm{Cl}_{2} \mathrm{O}_{2} \hat{\mathrm{S}}^{\mathbf{c}}$ & $\mathrm{DH}^{\mathrm{e}}$ & $\mathrm{F}_{4} \mathrm{~S}^{\mathrm{b}}$ & $\mathrm{He}^{c}$ & $\mathrm{~N}_{2} \mathrm{O}^{\mathrm{a}}$ & $\mathrm{S}_{8}{ }^{\mathrm{c}}$ \\
\hline $\mathrm{BI}_{3}{ }^{\mathrm{b}}$ & $\mathrm{CClF}_{3}{ }^{\mathrm{a}}$ & $\mathrm{C}_{3} \mathrm{H}_{9} \mathrm{Cl}_{3} \mathrm{Si}^{\mathrm{a}}$ & $\mathrm{C}_{3} \mathrm{H}_{8}{ }^{\mathrm{a}}$ & $\mathrm{Cl}_{3} \mathrm{FSi}^{\mathrm{b}}$ & $\mathrm{D}_{2}^{\mathrm{c}}$ & $\mathrm{F}_{4} \mathrm{Si}^{\mathrm{a}}$ & $\mathrm{Hg}^{\mathrm{a}}$ & $\mathrm{N}_{2} \mathrm{O}_{3}{ }^{\mathrm{a}}$ & $\mathrm{Si}^{\mathrm{a}}$ \\
\hline $\mathrm{B}_{2} \mathrm{H}_{6}^{\mathrm{a}}$ & $\mathrm{CClN}^{\mathrm{a}}$ & $\mathrm{CH}_{3} \mathrm{~F}^{\mathrm{a}}$ & $\mathrm{C}_{3} \mathrm{O}_{2}{ }^{\mathrm{d}}$ & $\mathrm{Cl}_{3} \mathrm{HSi}^{\mathrm{a}}$ & $\mathrm{D}_{2} \mathrm{O}^{\mathrm{c}}$ & $\mathrm{F}_{6} \mathrm{Mo}^{\mathrm{b}}$ & $\mathrm{HgI}_{2}{ }^{\mathrm{b}}$ & $\mathrm{N}_{2} \mathrm{O}_{4}^{\mathrm{a}}$ & $\mathrm{Sn}^{\mathrm{c}}$ \\
\hline $\mathrm{Ba}^{\mathrm{c}}$ & $\mathrm{CCl}_{2} \mathrm{~F}_{2}^{\mathrm{a}}$ & $\mathrm{CH}_{3} \mathrm{OH}^{\mathrm{a}}$ & $\mathrm{Ca}^{\mathrm{c}}$ & $\mathrm{Cl}_{3} \mathrm{OP}^{\mathrm{a}}$ & $D_{2} S^{b}$ & $\mathrm{~F}_{6} \mathrm{~S}^{\mathrm{a}}$ & $\mathrm{I}^{\mathrm{c}}$ & $\mathrm{Na}^{\mathrm{a}}$ & $\mathrm{Sr}^{\mathrm{c}}$ \\
\hline $\mathrm{Be}^{\mathrm{c}}$ & $\mathrm{CCl}_{2} \mathrm{O}^{\mathrm{a}}$ & $\mathrm{CH}_{4}{ }^{\mathrm{a}}$ & $\mathrm{CaCl}_{2}^{\mathrm{a}}$ & $\mathrm{Cl}_{3} \mathrm{P}^{\mathrm{a}}$ & $\mathrm{D}_{3} \mathrm{~N}^{\mathrm{b}}$ & $\mathrm{F}_{6} \mathrm{~W}^{\mathrm{b}}$ & $\mathrm{I}_{2} \mathrm{Mg}^{\mathrm{c}}$ & $\mathrm{Na}_{2}{ }^{\mathrm{c}}$ & $\mathrm{Ta}^{c}$ \\
\hline $\mathrm{Bi}^{\mathfrak{c}}$ & $\mathrm{CCl}_{3} \mathrm{~F}^{\mathrm{a}}$ & $\mathrm{CNNa}^{\mathrm{a}}$ & $\mathrm{Ca}_{2}{ }^{\mathrm{c}}$ & $\mathrm{Cl}_{4} \mathrm{OW}^{\mathrm{b}}$ & $\mathrm{F}^{\mathrm{c}}$ & $\mathrm{Fe}^{\mathrm{a}}$ & $\mathrm{I}_{4} \mathrm{Si}^{\mathrm{b}}$ & $\mathrm{Nb}^{\mathrm{c}}$ & $U^{c}$ \\
\hline $\mathrm{Bi}_{2}{ }^{\mathrm{c}}$ & $\mathrm{CCl}_{4}{ }^{\mathrm{a}}$ & $\mathrm{CO}^{\mathrm{a}}$ & $\mathrm{Cl}^{\mathrm{c}}$ & $\mathrm{Cl}_{4} \mathrm{Si}^{\mathrm{a}}$ & $\mathrm{FH}^{\mathrm{a}}$ & $\mathrm{H}^{\mathrm{c}}$ & $\mathrm{I}_{4} \mathrm{Ti}^{\mathrm{d}}$ & $\mathrm{Ne}^{\mathrm{c}}$ & $\mathrm{UF}_{6}^{\mathrm{b}}$ \\
\hline $\mathrm{BrH}^{\mathrm{c}}$ & $\mathrm{CF}_{2} \mathrm{O}^{\mathrm{a}}$ & $\cos ^{a}$ & $\mathrm{ClCu}^{\mathrm{a}}$ & $\mathrm{Cl}_{4} \mathrm{Ti}^{\mathrm{a}}$ & $\mathrm{FNO}^{\mathrm{b}}$ & $\mathrm{HI}^{\mathrm{a}}$ & $\mathrm{I}_{4} \mathrm{Zr}^{\mathrm{b}}$ & $\mathrm{Ni}^{\mathrm{c}}$ & $v^{c}$ \\
\hline $\mathrm{Brl}^{\mathrm{e}}$ & $\mathrm{CF}_{4}^{\mathrm{a}}$ & $\mathrm{CO}_{2}^{\mathrm{a}}$ & $\mathrm{ClD}^{\mathrm{b}}$ & $\mathrm{Cl}_{4} \mathrm{Zr}^{\mathrm{b}}$ & $\mathrm{FNO}_{2}{ }^{\mathrm{b}}$ & $\mathrm{HNO}_{3}{ }^{\mathrm{a}}$ & $K^{a}$ & $\mathrm{O}_{2}^{\mathrm{a}}$ & $W^{c}$ \\
\hline $\mathrm{BrK}^{\mathrm{a}}$ & $\mathrm{CHBr}_{3}{ }^{\mathrm{c}}$ & $\mathrm{CS}_{2}{ }^{\mathrm{a}}$ & $\mathrm{ClF}_{3}{ }^{\mathrm{c}}$ & $\mathrm{Cl}_{5} \mathrm{Mo}^{\mathrm{b}}$ & $\mathrm{FNa}^{\mathrm{a}}$ & $\mathrm{HNaO}^{\mathrm{a}}$ & $\mathrm{Kr}^{\mathrm{c}}$ & $\mathrm{O}_{2} \mathrm{~S}^{\mathrm{a}}$ & $\mathrm{Xe}^{\mathrm{c}}$ \\
\hline $\mathrm{BrNa}^{\mathrm{a}}$ & $\mathrm{CHClF}_{2}{ }^{\mathrm{a}}$ & $\mathrm{C}_{2} \mathrm{Cl}_{4}{ }^{\mathrm{a}}$ & $\mathrm{ClF}_{3} \mathrm{Si}^{\mathrm{b}}$ & $\mathrm{Cl}_{5} \mathrm{Nb}^{\mathrm{c}}$ & $\mathrm{F}_{2}^{\mathrm{a}}$ & $\mathrm{H}_{2}{ }^{\mathrm{a}}$ & $\mathrm{Li}^{\mathrm{a}}$ & $\mathrm{O}_{3}{ }^{\mathrm{a}}$ & $\mathrm{Zn}^{\mathrm{c}}$ \\
\hline $\mathrm{Br}_{2}{ }^{\mathrm{a}}$ & $\mathrm{CHCl}_{2} \mathrm{~F}^{\mathrm{a}}$ & $\mathrm{C}_{2} \mathrm{Cl}_{6}^{\mathrm{a}}$ & $\mathrm{ClF}_{5}{ }^{\mathrm{b}}$ & $\mathrm{Cl}_{5} \mathrm{P}^{\mathrm{c}}$ & $c-F_{2} N_{2}^{d}$ & $\mathrm{H}_{2} \mathrm{O}^{\mathrm{a}}$ & $\mathrm{Li}_{2}{ }^{\mathrm{c}}$ & $\mathrm{O}_{3} \mathrm{~S}^{\mathrm{a}}$ & $\mathrm{Zr}^{\mathrm{c}}$ \\
\hline $\mathrm{Br}_{2} \mathrm{Hg}^{\mathrm{b}}$ & $\mathrm{CHCl}_{3}{ }^{\mathrm{a}}$ & $\mathrm{C}_{2} \mathrm{~F}_{3} \mathrm{~N}^{\mathrm{d}}$ & $\mathrm{CIF}_{5} S^{\mathrm{b}}$ & & & & & & \\
\hline
\end{tabular}

a. Ref. [36], Stephenson, R. M., Malanowski, S., Ambrose, D., "Vapor-Liquid Critical Constants of Fluids" in the Handbook of Thermodynamics of Organic Compound, Elsevier, New York (1987).

b. Ref. [35], Daubert, T. E., Danner, R. P., Sibul, H. M. and Stebbins, C. C., Physical and Thermodynamic Properties of Pure Compounds: Data Compilation, Taylor \& Francis, Bristol, PA (1994).

c. Ref. [37], McCormick, S., TAPP (version 2.20) - A Database of Thermochemical And Physical Properties, E. S. Microware, Hamilton, OH (1996).

d. Ref. [38], Reid, R. C., Prausnitz, J. M., and Poling, B. E., The Properties of Gases and Liquids, 4th ed., McGraw-Hill, New York (1987).

e. Ref. [39], TRCTHERMO data search (1997). 
This table indicates the source of each Lennard-Jones parameters obtained in the literature search.

Table A.3 Species with known Lennard-Jones parameters

\begin{tabular}{|c|c|c|c|c|c|c|c|c|c|}
\hline $\mathrm{Al}^{\mathrm{a}}$ & $\mathrm{B}_{2}{ }^{\mathrm{a}}$ & $\mathrm{CCl}^{\mathrm{a}}$ & $\mathrm{CHO}^{\mathrm{b}}$ & $C S^{a}$ & $\mathrm{ClLi}^{\mathrm{a}}$ & $\mathrm{FMg}^{\mathrm{a}}$ & $\mathrm{HNaO}^{\mathrm{a}}$ & $\mathrm{KO}^{\mathrm{b}}$ & $O P^{a}$ \\
\hline $\mathrm{AlCl}^{\mathrm{a}}$ & $\mathrm{B}_{2} \mathrm{H}_{6}{ }^{\mathrm{a}}$ & $\mathrm{CClF}_{3}{ }^{\mathrm{a}}$ & $\mathrm{CH}_{2}{ }^{\mathrm{b}}$ & $\mathrm{CS}_{2}^{\mathrm{a}}$ & $\mathrm{ClMg}^{\mathrm{a}}$ & $\mathrm{FNa}^{\mathrm{a}}$ & $\mathrm{HO}^{\mathrm{a}}$ & $\mathrm{Kr}^{\mathrm{a}}$ & $O S^{b}$ \\
\hline $\mathrm{AlCl}_{3}{ }^{\mathrm{a}}$ & $\mathrm{B}_{2} \mathrm{O}_{3}{ }^{\mathrm{a}}$ & $\mathrm{CClN}^{\mathrm{a}}$ & $\mathrm{CH}_{2} \mathrm{ClF}^{\mathrm{a}}$ & $\mathrm{C}_{2}^{\mathrm{b}}$ & $\mathrm{CINO}^{\mathrm{a}}$ & $\mathrm{FO}^{\mathrm{a}}$ & $\mathrm{HO}_{2}{ }^{b}$ & $\mathbf{K}^{\mathrm{b}}$ & $\mathrm{OSi}^{\mathrm{a}}$ \\
\hline $\mathrm{AlF}^{\mathrm{a}}$ & $B e^{a}$ & $\mathrm{CCl}_{2}{ }^{\mathrm{a}}$ & $\mathrm{CH}_{2} \mathrm{Cl}_{2}{ }^{\mathrm{a}}$ & $\mathrm{C}_{2} \mathrm{Cl}_{4}^{\mathrm{a}}$ & $\mathrm{ClNa}^{\mathrm{a}}$ & $\mathrm{FP}^{\mathrm{a}}$ & $\mathrm{HS}^{\mathrm{a}}$ & $\mathbf{L i}^{\mathrm{a}}$ & $\mathrm{O}_{2}^{\mathrm{b}}$ \\
\hline $\mathrm{AlF}_{3}{ }^{\mathrm{a}}$ & $\mathrm{BeBr}_{2}{ }^{\mathrm{a}}$ & $\mathrm{CCl}_{2} \mathrm{~F}_{2}^{\mathrm{a}}$ & $\mathrm{CH}_{2} \mathrm{~F}_{2}{ }^{\mathrm{a}}$ & $\mathrm{C}_{2} \mathrm{H}^{\mathrm{b}}$ & $\mathrm{ClO}^{\mathrm{a}}$ & $\mathrm{FSi}^{\mathrm{a}}$ & $\mathrm{HSi}^{\mathrm{a}}$ & $\mathbf{L i O}^{\mathbf{a}}$ & $\mathrm{O}_{2} \mathrm{~S}^{\mathrm{b}}$ \\
\hline AlN $^{\mathrm{a}}$ & $\mathrm{BeCl}^{\mathrm{a}}$ & $\mathrm{CCl}_{3}{ }^{\mathrm{a}}$ & $\mathrm{CH}_{2} \mathrm{O}^{\mathrm{b}}$ & $\mathrm{C}_{2} \mathrm{H}_{2}{ }^{\mathrm{a}}$ & $\mathrm{ClP}^{\mathrm{a}}$ & $\mathrm{F}_{2}^{\mathrm{b}}$ & $\mathrm{H}_{2}^{\mathrm{b}}$ & $\mathbf{L i}_{2}{ }^{\mathbf{a}}$ & $\mathrm{O}_{2} \mathrm{Si}^{\mathrm{a}}$ \\
\hline $\mathrm{AlO}^{\mathrm{a}}$ & $\mathrm{BeCl}_{2}^{\mathrm{a}}$ & $\mathrm{CCl}_{3} \mathrm{~F}^{\mathrm{a}}$ & $\mathrm{CH}_{3}{ }^{\mathrm{b}}$ & $\mathrm{C}_{2} \mathrm{H}_{4}^{\mathrm{b}}$ & $\mathrm{ClSi}^{\mathrm{a}}$ & $\mathrm{F}_{2} \mathrm{Mg}^{\mathrm{a}}$ & $\mathrm{H}_{2} \mathrm{~N}^{\mathrm{b}}$ & $\mathrm{Li}_{2} \mathrm{O}^{\mathrm{a}}$ & $\mathrm{O}_{3}^{\mathrm{b}}$ \\
\hline $\mathrm{AlS}^{\mathrm{a}}$ & $\mathrm{BeF}^{\mathrm{a}}$ & $\mathrm{CCl}_{4}^{\mathrm{a}}$ & $\mathrm{CH}_{3} \mathrm{Cl}^{\mathrm{a}}$ & $\mathrm{C}_{2} \mathrm{H}_{6}{ }^{\mathrm{b}}$ & $\mathrm{Cl}_{2}^{\mathrm{a}}$ & $\mathrm{F}_{2} \mathrm{O}^{\mathrm{a}}$ & $\mathrm{H}_{2} \mathrm{~N}_{2}{ }^{\mathrm{a}}$ & $\mathrm{Mg}^{\mathrm{a}}$ & $\mathrm{O}_{3} \mathrm{~S}^{\mathrm{b}}$ \\
\hline $\mathrm{Al}_{2}^{\mathrm{a}}$ & $\mathrm{BeF}_{2}{ }^{\mathrm{a}}$ & $\mathrm{CF}^{\mathrm{a}}$ & $\mathrm{CH}_{3} \mathrm{~F}^{\mathrm{a}}$ & $\mathrm{C}_{2} \mathrm{~N}^{\mathrm{b}}$ & $\mathrm{Cl}_{2} \mathrm{H}_{2} \mathrm{Si}^{\mathrm{b}}$ & $\mathrm{F}_{2} \mathrm{~S}_{2}^{\mathrm{a}}$ & $\mathrm{H}_{2} \mathrm{O}^{\mathrm{b}}$ & $\mathrm{Mg}_{2}{ }^{\mathrm{a}}$ & $\mathrm{P}^{\mathrm{a}}$ \\
\hline $\mathrm{Ar}^{\mathrm{a}}$ & $\mathrm{BeI}_{2}{ }^{\mathrm{a}}$ & $\mathrm{CFN}^{\mathrm{a}}$ & $\mathrm{CH}_{4}{ }^{\mathrm{b}}$ & $\mathrm{C}_{2} \mathrm{~N}_{2}{ }^{\mathrm{a}}$ & $\mathrm{Cl}_{2} \mathrm{Hg}^{\mathrm{a}}$ & $\mathrm{F}_{3} \mathrm{HSi}^{\mathrm{b}}$ & $\mathrm{H}_{2} \mathrm{O}_{2}{ }^{\mathrm{b}}$ & $N^{b}$ & $\mathrm{PS}^{\mathrm{a}}$ \\
\hline $\mathrm{B}^{\mathrm{a}}$ & $\mathrm{Br}^{\mathrm{a}}$ & $\mathrm{CF}_{2}^{\mathrm{a}}$ & $\mathrm{CH}_{3} \mathrm{OH}^{\mathrm{a}}$ & $\mathrm{C}_{2} \mathrm{O}^{\mathrm{b}}$ & $\mathrm{Cl}_{2} \mathrm{Mg}^{\mathrm{a}}$ & $\mathrm{F}_{3} \mathrm{~N}^{\mathrm{a}}$ & $\mathrm{H}_{2} \mathrm{~S}^{\mathrm{a}}$ & $\mathrm{NO}^{b}$ & $P 2^{\mathrm{a}}$ \\
\hline $\mathrm{BBr}_{3}{ }^{\mathrm{a}}$ & $\mathrm{BrF}^{\mathrm{a}}$ & $\mathrm{CF}_{3}^{\mathrm{a}}$ & $\mathrm{CN}^{\mathrm{a}}$ & $\mathrm{C}_{3} \mathrm{H}_{6}{ }^{\mathrm{b}}$ & $\mathrm{Cl}_{2} \mathrm{Si}^{\mathrm{b}}$ & $\mathrm{F}_{3} \mathrm{P}^{\mathrm{a}}$ & $\mathrm{H}_{3} \mathrm{~N}^{\mathrm{b}}$ & $\mathrm{NO}_{2}{ }^{\mathrm{b}}$ & $\mathrm{P} 4^{\mathrm{a}}$ \\
\hline $\mathrm{BCl}^{\mathrm{a}}$ & $\mathrm{BrF}_{3}{ }^{\mathrm{a}}$ & $\mathrm{CF}_{4}{ }^{\mathrm{a}}$ & $\mathrm{CNNa}^{\mathrm{a}}$ & $\mathrm{C}_{3} \mathrm{H}_{8}{ }^{b}$ & $\mathrm{Cl}_{3} \mathrm{FSi}^{\mathrm{a}}$ & $\mathrm{F}_{3} \mathrm{Si}^{\mathrm{b}}$ & $\mathrm{H}_{3} \mathrm{P}^{\mathrm{a}}$ & $N P^{a}$ & $S^{b}$ \\
\hline $\mathrm{BCl}_{2}^{\mathrm{a}}$ & $\mathrm{BrH}^{\mathrm{a}}$ & $\mathrm{CH}^{\mathrm{a}}$ & $\mathrm{CO}^{\mathrm{b}}$ & $\mathrm{Cl}^{\mathrm{a}}$ & $\mathrm{Cl}_{3} \mathrm{P}^{\mathrm{a}}$ & $F_{4} \mathrm{Si}^{\mathrm{a}}$ & $\mathrm{H}_{4} \mathrm{~N}_{2}{ }^{\mathrm{b}}$ & $\mathrm{N}_{2}{ }^{\mathrm{b}}$ & $\mathrm{S}_{2}{ }^{\mathrm{a}}$ \\
\hline $\mathrm{BCl}_{3}{ }^{\mathrm{a}}$ & $\mathrm{BrLi}^{\mathrm{a}}$ & $\mathrm{CHBr}_{3}{ }^{\mathrm{a}}$ & $\cos ^{a}$ & $\mathrm{ClF}^{\mathrm{a}}$ & $\mathrm{Cl}_{4} \mathrm{Si}^{\mathrm{a}}$ & $\mathrm{F}_{6} \mathrm{~S}^{\mathrm{a}}$ & $\mathrm{H}_{4} \mathrm{Si}^{\mathrm{a}}$ & $\mathrm{N}_{2} \mathrm{O}^{\mathrm{b}}$ & $\mathrm{Si}^{\mathrm{a}}$ \\
\hline $\mathrm{BF}^{\mathrm{a}}$ & $\mathrm{BrNa}^{\mathrm{a}}$ & $\mathrm{CHClF}_{2}{ }^{\mathrm{a}}$ & $\mathrm{CO}_{2}^{\mathrm{b}}$ & $\mathrm{ClF}_{3}{ }^{\mathrm{a}}$ & $D_{2}^{b}$ & $\mathrm{H}^{\mathrm{b}}$ & $\mathrm{He}^{\mathrm{b}}$ & $\mathrm{Na}^{\mathrm{a}}$ & $\mathrm{Si}_{2}{ }^{\mathrm{a}}$ \\
\hline $\mathrm{BF}_{2}{ }^{\mathrm{a}}$ & $\mathrm{Br}_{2}^{\mathrm{a}}$ & $\mathrm{CHCl}_{3}{ }^{\mathrm{a}}$ & $\mathrm{CNN}^{\mathrm{b}}$ & $\mathrm{ClF}_{3} \mathrm{Si}^{\mathrm{a}}$ & $F^{\mathfrak{a}}$ & $\mathrm{HI}^{\mathrm{a}}$ & $\mathrm{Hg}^{\mathrm{a}}$ & $\mathrm{NaO}^{\mathrm{a}}$ & $\mathrm{Si}_{3}{ }^{\mathrm{b}}$ \\
\hline $\mathrm{BF}_{3}{ }^{\mathrm{a}}$ & $\mathrm{Br}_{2} \mathrm{Hg}^{\mathrm{a}}$ & $\mathrm{CHF}_{3}{ }^{\mathrm{a}}$ & $\mathrm{CN}_{2}{ }^{\mathrm{b}}$ & $\mathrm{ClH}^{\mathrm{a}}$ & $\mathrm{FH}^{\mathrm{b}}$ & $\mathrm{HK}^{\mathrm{b}}$ & $\mathrm{HgI}_{2}{ }^{\mathrm{a}}$ & $\mathrm{Na}_{2}{ }^{\mathrm{a}}$ & $\mathrm{UF}_{6}{ }^{\mathrm{a}}$ \\
\hline $\mathrm{BI}_{3}{ }^{\mathrm{a}}$ & $c^{b}$ & $\mathrm{CHN}^{\mathrm{b}}$ & $\mathrm{CNO}^{\mathrm{b}}$ & $\mathrm{ClI}^{\mathrm{a}}$ & $\mathrm{FHO}^{\mathrm{a}}$ & $\mathrm{HKO}^{\mathrm{b}}$ & $I^{a}$ & $\mathrm{Ne}^{\mathrm{a}}$ & $\mathrm{Xe}^{\mathrm{a}}$ \\
\hline $\mathrm{BO}^{\mathrm{a}}$ & $\mathrm{CBrF}_{3}{ }^{\mathrm{a}}$ & $\mathrm{CHNO}^{\mathrm{b}}$ & $\mathrm{CP}^{\mathrm{a}}$ & $\mathrm{ClK}^{\mathrm{b}}$ & $\mathrm{FLi}^{\mathrm{a}}$ & $\mathrm{HN}^{\mathrm{a}}$ & $\mathrm{ILi}^{\mathrm{a}}$ & $\mathrm{O}^{\mathrm{a}}$ & $\mathrm{Zn}^{\mathrm{a}}$ \\
\hline
\end{tabular}

a. Ref. [40], Svehla, R. A., Estimated Viscosities and Thermal Conductivities of Gases at High Temperatures, NASA Technical Report R-132, (1962).

b. Ref. [41], Warnatz, J., "Calculation of the Structure of Laminar Flat Flames I: Flame Velocity of Freely Propagating Ozone Decomposition Flames," Ber. Beunsenges. Phys. Chem., 82, 193 (1978). See also

Warnatz, J., "Influence of Transport Models and Boundary Conditions on Flame Structure," in Numerical Methods in Flame Propagation, Eds. N. Peters and J. Warnatz, Friedr. Vieweg and Sohn, Wiesbaden (1982). 


\section{Appendix B}

All the constants in the JCZS database are given here. Information regarding this database should be directed to:

Michael L. Hobbs

Energetic and Multi-phase Processes, Dept. 9112

Engineering Sciences Center

Sandia National Laboratories

Albuquerque, NM 87185-0834

Voice: (505)844-5988

Fax: (505) 844-8251

Email: mlhobbs@sandia.gov

The method used to obtain the force constants are discussed in detail in the text.

Table B.1 The complete JCZS database of $\boldsymbol{r}^{*}$ and $\varepsilon / k$ values

\begin{tabular}{|l|l|l|l|l|l|l|l|}
\hline Species & $r^{*}$ & $\varepsilon / k$ & Method & Species & $r^{*}$ & $\varepsilon / \boldsymbol{k}$ & Method \\
\hline \hline AL & 2.98 & 2750 & LJ & BCLF & 5.14 & 150 & FIT \\
\hline AL* & 2.98 & 2750 & LJ & BCLF2 & 5.16 & 150 & FIT \\
\hline CAL & 5.10 & 300 & FIT & BCLO & 5.15 & 350 & FIT \\
\hline ALCL & 5.16 & 500 & FIT & BCL2 & 4.74 & 682 & LJ \\
\hline ALCLF & 5.27 & 300 & FIT & BCL2F & 5.44 & 250 & FIT \\
\hline ALCLF2 & 5.39 & 300 & FIT & BCL3 & 5.75 & 338 & LJ \\
\hline ALCLO & 5.29 & 500 & FIT & BF & 4.74 & 300 & FIT \\
\hline ALCL2 & 5.58 & 400 & FIT & BFO & 4.74 & 300 & FIT \\
\hline ALCL2F & 5.70 & 300 & FIT & BF2 & 3.98 & 399 & LJ \\
\hline ALCL3 & 5.76 & 472 & LJ & BF3 & 4.71 & 186 & LJ \\
\hline ALF & 4.76 & 200 & FIT & BH & 4.30 & 100 & FIT \\
\hline ALFO & 4.91 & 300 & FIT & BHO & 4.76 & 450 & FIT \\
\hline ALF2 & 4.90 & 150 & FIT & BHO2 & 4.83 & 400 & FIT \\
\hline ALF3 & 5.02 & 150 & FIT & BH2 & 4.30 & 100 & FIT \\
\hline
\end{tabular}


Table B.I The complete JCZS database of $r^{*}$ and $\varepsilon / k$ values

\begin{tabular}{|c|c|c|c|c|c|c|c|}
\hline Species & $r^{*}$ & $\varepsilon / k$ & Method & Species & $r^{*}$ & $\varepsilon / k$ & Method \\
\hline ALH & 4.71 & 300 & FIT & $\mathrm{BH} 2 \mathrm{O} 2$ & 4.76 & 200 & $\mathrm{FTT}$ \\
\hline ALHO & 4.83 & 150 & FIT & $\mathrm{BH} 3$ & 4.30 & 100 & FIT \\
\hline ALHO2 & 5.01 & 500 & FIT & $\mathrm{BH} 3 \mathrm{O} 3$ & 4.76 & 400 & FIT \\
\hline ALN & 4.85 & 100 & FIT & $\mathrm{BN}$ & 4.81 & 200 & FIT \\
\hline ALO & 4.78 & 100 & FIT & $\mathrm{BO}$ & 4.74 & 250 & FIT \\
\hline ALS & 5.17 & 700 & FIT & $\mathrm{BS}$ & 5.09 & 500 & FIT \\
\hline A2CL6 & 6.98 & 500 & FIT & B2CL4 & 6.12 & 325 & $\mathrm{FIT}$ \\
\hline $\mathrm{AL} 2 \mathrm{O}$ & 5.59 & 500 & FIT & $\mathrm{B} 2 \mathrm{H} 6$ & 5.09 & 100 & FIT \\
\hline $\mathrm{AL} 2 \mathrm{O} 2$ & 5.48 & 150 & FIT & $\mathrm{B} 2 \mathrm{O} 2$ & 5.38 & 350 & FIT \\
\hline $\mathrm{B}$ & 2.27 & 3300 & $\mathrm{LJ}$ & $\mathrm{B} 2 \mathrm{O} 3$ & 4.67 & 2092 & $\mathrm{LJ}$ \\
\hline $\mathrm{B} 2$ & 5.29 & 100 & FIT & B3CL3O3 & 7.50 & 200 & FIT \\
\hline $\mathrm{BCL}$ & 5.09 & 700 & FIT & B3F3O3 & 5.93 & 300 & FIT \\
\hline В3Н3O6 & 6.42 & 300 & FIT & CCL2O & 5.25 & 368 & SCS \\
\hline B3H6N3 & 5.77 & 300 & FTT & CCL3F & 5.74 & 381 & SCS \\
\hline B5H9 & 5.57 & 200 & FIT & CCL4 & 5.98 & 631 & HUG \\
\hline B10H14 & 6.51 & 300 & FIT & CF & 4.37 & 300 & FIT \\
\hline $\mathrm{BE}$ & 2.94 & 3603 & $\mathrm{LJ}$ & CFN & 4.56 & 300 & FIT \\
\hline C2BE & 5.32 & 700 & FIT & $\mathrm{CF} 2$ & 4.87 & 94.2 & OPT, LJ \\
\hline BECL & 5.20 & 900 & FIT & CF2O & 5.59 & 240 & OPT, SCS \\
\hline BECLF & 5.27 & 325 & FIT & CF3 & 5.65 & 121 & OPT, LJ \\
\hline BECL2 & 5.53 & 400 & FIT & CF4 & 6.40 & 134 & OPT, LJ \\
\hline BEF & 4.89 & 400 & FIT & $\mathrm{CH}$ & 4.29 & 100 & FIT \\
\hline $\mathrm{BEF} 2$ & 3.87 & 1266 & $\mathrm{LJ}$ & $\mathrm{CHCF} 2$ & 5.14 & 261 & $\mathrm{LJ}$ \\
\hline $\mathrm{BEH}$ & 4.40 & 100 & FIT & $\mathrm{CHC} 2 \mathrm{~F}$ & 5.80 & 400 & FIT \\
\hline BEHO & 4.90 & 350 & FIT & CHCL3 & 6.05 & 340 & HUG \\
\hline
\end{tabular}


Table B.1 The complete JCZS database of $r^{*}$ and $\varepsilon / k$ values

\begin{tabular}{|l|l|l|l|l|l|l|l|}
\hline \multicolumn{1}{|c|}{ Species } & $\boldsymbol{r}^{*}$ & $\boldsymbol{\varepsilon} / \boldsymbol{k}$ & Method & \multicolumn{1}{c|}{ Species } & $\boldsymbol{r}^{*}$ & $\varepsilon / \boldsymbol{k}$ & Method \\
\hline \hline BEH2 & 4.40 & 100 & FIT & CHFO & 4.50 & 150 & OPT, FIT \\
\hline BEH2O2 & 4.97 & 100 & FIT & CHF3 & 5.71 & 242 & OPT, SCS \\
\hline BEO & 4.89 & 300 & FIT & CHN & 4.74 & 400 & FIT \\
\hline BE2CL4 & 7.40 & 300 & FIT & CHNO & 4.80 & 232 & OPT, LJ \\
\hline BE2O2 & 5.47 & 200 & FIT & CHO & 4.41 & 400 & FIT \\
\hline BE3O3 & 6.11 & 175 & FIT & CH2 & 4.29 & 50.0 & FIT \\
\hline BE4O4 & 6.62 & 150 & FIT & CH2CLF & 4.86 & 318 & OPT, LJ \\
\hline BE5O5 & 7.05 & 200 & FIT & CH2CL & 5.26 & 200 & FIT \\
\hline BE6O6 & 7.13 & 200 & FIT & CH2F2 & 4.36 & 318 & OPT, FIT \\
\hline C & 3.70 & 71.4 & LJ & CH2O & 4.40 & 330 & OPT, SCS \\
\hline CCL & 4.81 & 500 & FIT & CH3 & 4.15 & 144 & OPT, LJ \\
\hline CCLFO & 5.06 & 300 & OPT, FIT & CH3CL & 4.73 & 337 & SCS \\
\hline CCLF3 & 4.71 & 244 & OPT, SCS & CH3CL3SI & 6.15 & 275 & FIT \\
\hline CCLN & 4.99 & 363 & SCS & CH3F & 4.95 & 256 & OPT, SCS \\
\hline CH3F3SI & 5.34 & 550 & FIT & CLF & 4.12 & 203 & LJ \\
\hline CH4 & 4.23 & 154 & SCS & CLFLI2 & 9.50 & 300 & FIT \\
\hline CH3OH & 4.23 & 482 & OPT, LJ & CLFMG & 5.43 & 550 & FIT \\
\hline CN & 4.33 & 75.0 & LJ & CLF3 & 4.81 & 336 & LJ \\
\hline CNNA & 5.58 & 500 & FIT & CLF3SI & 5.58 & 231 & LJ \\
\hline CO & 3.88 & 98.0 & OPT, LJ & CLH & 3.35 & 345 & OPT, SCS \\
\hline COS & 5.02 & 200 & FIT & CLHO & 4.50 & 350 & FIT \\
\hline CO2 & 4.22 & 244 & LJ & CLH3SI & 5.25 & 250 & LJ \\
\hline CP & 4.94 & 227 & LJ & CLLI & 6.00 & 600 & FIT \\
\hline CS & 4.73 & 199 & LJ & CLLIO & 7.00 & 500 & FIT \\
\hline CS2 & 5.03 & 467 & LJ & CLMG & 5.33 & 700 & FIT \\
\hline
\end{tabular}


Table B.1 The complete JCZS database of $\boldsymbol{r}^{*}$ and $\varepsilon / k$ values

\begin{tabular}{|l|l|l|l|l|l|l|l|}
\hline \multicolumn{1}{|c|}{ Species } & $r^{*}$ & $\varepsilon / k$ & Method & Species & $r^{*}$ & $\varepsilon / k$ & Method \\
\hline \hline C2 & 4.06 & 98.0 & LJ & CLNO & 4.74 & 356 & LJ \\
\hline C2F2 & 4.87 & 400 & FIT & CLNA & 5.54 & 800 & FIT \\
\hline C2F4 & 6.03 & 248 & OPT, SCS & CLO & 4.31 & 184 & LJ \\
\hline C2H2 & 4.42 & 249 & LJ & CLO2 & 4.64 & 400 & FIT \\
\hline C2H4 & 4.50 & 281 & OPT, LJ & CLSI & 5.08 & 300 & FIT \\
\hline C2H4O & 4.75 & 380 & SCS & CLTI & 5.43 & 200 & FIT \\
\hline C2H6 & 4.01 & 252 & OPT, LJ & CL2H2SI & 5.71 & 324 & LJ \\
\hline C3H6 & 5.59 & 267 & LJ & CL2LI2 & 6.27 & 300 & FIT \\
\hline C3H8 & 5.59 & 267 & LJ & CL2MG & 6.00 & 500 & FIT \\
\hline C2N2 & 5.30 & 324 & SCS & CL2O & 5.07 & 300 & FIT \\
\hline C3 & 5.05 & 300 & FIT & CL2SI & 5.51 & 300 & FIT \\
\hline C3O2 & 5.22 & 361 & OPT, LJ & CL2TI & 6.30 & 500 & FIT \\
\hline C4 & 5.32 & 700 & FIT & CL2ZR & 6.25 & 500 & FIT \\
\hline C4N2 & 7.00 & 350 & FIT & CL3FSI & 6.22 & 329 & LJ \\
\hline C5 & 7.00 & 300 & FIT & CL3HSI & 5.89 & 388 & SCS \\
\hline CL & 4.06 & 131 & LJ & CL3LI3 & 7.10 & 250 & FIT \\
\hline CL3OP & 5.79 & 350 & FIT & F2O & 4.35 & 161 & LJ \\
\hline CL3P & 5.88 & 419 & LJ & F2OS & 4.78 & 150 & FIT \\
\hline CL3PS & 6.12 & 200 & FIT & F2O2S & 4.89 & 100 & FIT \\
\hline CL3TI & 6.15 & 300 & FIT & F2P & 4.69 & 100 & FIT \\
\hline F2FE & 5.09 & 300 & FIT & F2SI & 4.81 & 100 & FIT \\
\hline CL3ZR & 6.25 & 300 & FIT & F3FE & 5.26 & 250 & FIT \\
\hline CL4SI & 6.71 & 390 & LJ & F4S & 4.81 & 294 & SCS \\
\hline CL4TI & 6.38 & 516 & SCS & F2TI & 5.25 & 300 & FIT \\
\hline CL4ZR & 6.24 & 629 & SCS & F2ZR & 5.46 & 150 & FIT \\
\hline
\end{tabular}


Table B.1 The complete JCZS database of $r^{*}$ and $\varepsilon / k$ values

\begin{tabular}{|c|c|c|c|c|c|c|c|}
\hline Species & $\boldsymbol{r}^{*}$ & $\varepsilon / k$ & Method & Species & $r^{*}$ & $\varepsilon / k$ & Method \\
\hline CL5P & 5.94 & 523 & SCS & F3HSI & 5.25 & 181 & $\mathrm{LJ}$ \\
\hline$F$ & 3.33 & 113 & $\mathrm{LJ}$ & F3LI3 & 6.31 & 200 & FIT \\
\hline $\mathrm{FH}$ & 3.70 & 330 & OPT, LJ & F3N & 4.49 & 189 & SCS \\
\hline $\mathrm{FHO}$ & 3.95 & 400 & FIT & F3P & 4.89 & 203 & $\mathrm{LJ}$ \\
\hline FH3SI & 4.88 & 200 & FIT & F3TI & 5.35 & 100 & $\mathrm{FIT}$ \\
\hline FLI & 5.05 & 1000 & FIT & OS2 & 5.06 & 300 & $\mathrm{FIT}$ \\
\hline FLIO & 6.00 & 500 & FIT & F3ZR & 5.54 & 100 & FIT \\
\hline FMG & 4.98 & 200 & FIT & F4SI & 5.05 & 172 & LJ \\
\hline FN & 4.01 & 300 & FIT & F4TI & 5.48 & 100 & FIT \\
\hline FNO & 4.25 & 200 & FIT & F4ZR. & 5.63 & 100 & $\mathrm{FTT}$ \\
\hline FNA & 5.24 & 300 & FIT & F6S & 5.09 & 100 & FIT \\
\hline FO & 3.83 & 110 & $\mathrm{LJ}$ & $\mathrm{H}$ & 2.00 & 145 & OPT, LJ \\
\hline FP & 4.63 & 271 & $\mathrm{LJ}$ & HLI. & 5.02 & 75.0 & FIT \\
\hline FPS & 5.12 & 500 & FIT & HILIO. & 5.11 & 500 & $\mathrm{FIT}$ \\
\hline FSI & 4.67 & 150 & FIT & HMG & 4.94 & 200 & FIT \\
\hline F2H2SI & 4.94 & 200 & FIT & HMGO & 5.07 & 300 & FIT \\
\hline F2LI2 & 5.57 & 150 & FIT & $\mathrm{HN}$ & 3.72 & 65.0 & $\mathrm{LJ}$ \\
\hline F2MG & 5.11 & 200 & FIT & HNA & 5.13 & 50.0 & FIT \\
\hline HNAO & 4.27 & 1962 & LJ & NP & 4.61 & 125 & FIT \\
\hline $\mathrm{HO}$ & 3.29 & 80.0 & OPT, LJ & NS & 4.54 & 150 & FIT \\
\hline $\mathrm{HP}$ & 4.42 & 200 & FIT & NSI & 4.76 & 100 & FIT \\
\hline HS & 4.38 & 847 & LJ & $\mathrm{N} 2 \mathrm{O}$ & 4.30 & 232 & OPT, LJ \\
\hline HSI & 4.60 & 200 & FIT & $\mathrm{N} 2 \mathrm{O} 3$ & 5.30 & 344 & SCS \\
\hline $\mathrm{H} 2 \mathrm{LI} 2 \mathrm{O} 2$ & 5.60 . & 200 & $\mathrm{FIT}$ & $\mathrm{N} 2 \mathrm{O} 4$ & 7.00 & 100 & $\mathrm{FIT}$ \\
\hline $\mathrm{H} 2 \mathrm{~N}$ & 3.87 & 150 & FIT & N2O5 & 7.00 & 100 & FIT \\
\hline
\end{tabular}


Table B.1 The complete JCZS database of $r^{*}$ and $\varepsilon / k$ values

\begin{tabular}{|c|c|c|c|c|c|c|c|}
\hline Species & $r^{*}$ & $\varepsilon / k$ & Method & Species & $r^{*}$ & $\varepsilon / k$ & Method \\
\hline $\mathrm{H} 2 \mathrm{O}$ & 3.06 & 356 & REE & $\mathrm{NA}$ & 4.00 & 1375 & $\mathrm{LJ}$ \\
\hline $\mathrm{H} 2 \mathrm{O} 2$ & 3.90 & 591 & SCS & NAO & 5.26 & 300 & $\mathrm{FIT}$ \\
\hline $\mathrm{H} 2 \mathrm{P}$ & 4.51 & 150 & FIT & NA2 & 6.12 & 400 & FIT \\
\hline $\mathrm{H} 2 \mathrm{~S}$ & 4.07 & 301 & $\mathrm{LJ}$ & 0 & 3.42 & 107 & LJ \\
\hline $\mathrm{H} 3 \mathrm{~N}$ & 3.33 & 481 & $\mathrm{LJ}$ & $\mathrm{OP}$ & 4.69 & 264 & $\mathrm{LJ}$ \\
\hline H3P & 4.58 & 100 & FIT & OS & 4.48 & 301 & $\mathrm{LJ}$ \\
\hline $\mathrm{H} 4 \mathrm{~N} 2$ & 4.75 & 205 & $\mathrm{LJ}$ & OSI & 3.79 & 569 & $\mathrm{LJ}$ \\
\hline H4SI & 4.66 & 218 & LJ & OTI & 5.08 & 75.0 & FIT \\
\hline $\mathrm{LI}$ & 3.30 & 3305 & $\mathrm{LJ}$ & OZR & 5.34 & 100 & FIT \\
\hline LIN & 5.15 & 500 & FIT & $\mathrm{O} 2 \mathrm{P}$ & 4.70 & 200 & $\mathrm{FIT}$ \\
\hline LIO & 5.08 & 500 & FIT & $\mathrm{O} 2 \mathrm{~S}$ & 4.53 & 348 & SCS \\
\hline $\mathrm{LIO} 2$ & 5.17 & 150 & FIT & $\mathrm{O} 2 \mathrm{SI}$ & 4.84 & 200 & $\mathrm{FIT}$ \\
\hline LI2 & 5.90 & 250 & FIT & $\mathrm{O} 2 \mathrm{TI}$ & 5.17 & 100 & FIT \\
\hline LI2O & 5.89 & 500 & FIT & O2ZR & 5.42 & 100 & FIT \\
\hline MG & 3.28 & 1614 & $\mathrm{LJ}$ & $\mathrm{O} 3$ & 4.60 & 180 & $\mathrm{LJ}$ \\
\hline MGO & 5.00 & 150 & FIT & O3S & 4.59 & 397 & $\mathrm{LJ}$ \\
\hline MGS & 5.35 & 400 & FIT & O6P4 & 6.08 & 100 & FIT \\
\hline$N$ & 3.70 & 71.0 & $\mathrm{LJ}$ & O10P4 & 7.50 & 100 & FIT \\
\hline NO & 4.15 & 117 & OPT, LJ & $\mathbf{P}$ & 4.62 & 50.0 & FIT \\
\hline NO2 & 4.77 & 349 & OPT, SCS & PS & 4.97 & 200 & FIT \\
\hline $\mathrm{P} 2$ & 5.02 & 200 & FIT & $\mathrm{HI}$ & 4.53 & 343 & $\mathrm{LJ}$ \\
\hline P4 & 6.11 & 300 & FIT & I & 4.85 & 211 & LJ \\
\hline P4S3 & 6.92 & 500 & FIT & ILI & 7.00 & 500 & FIT \\
\hline$S$ & 4.31 & 50.0 & FIT & I2LI2 & 6.64 & 300 & FIT \\
\hline SSI & 5.09 & 300 & FIT & ALBR & 5.32 & 1000 & FIT \\
\hline
\end{tabular}


Table B.1 The complete JCZS database of $\boldsymbol{r}^{*}$ and $\varepsilon / k$ values

\begin{tabular}{|c|c|c|c|c|c|c|c|}
\hline Species & $r^{*}$ & $\varepsilon / k$ & Method & Species & $\dot{r}^{*}$ & $\varepsilon / k$ & Method \\
\hline S2 & 4.92 & 200 & $\mathrm{FIT}$ & ALBR3 & 6.18 & 617 & SCS \\
\hline S8 & 7.07 & 100 & FIT & AII & 6.5 & 500 & $\mathrm{FIT}$ \\
\hline SI & 5.62 & 4174 & $\mathrm{LJ}$ & ALI3 & 6.77 & 795 & SCS \\
\hline SIOH & 5.01 & 250 & FIT & AL2BR6 & 7.33 & 200 & FIT \\
\hline OHSI & 5.58 & 400 & FIT & AL2I6 & 9.00 & 200 & FIT \\
\hline SI2 & 5.31 & 200 & FIT & BBR & 5.26 & 1000 & FIT \\
\hline $\mathrm{SI3}$ & 6.50 & 500 & FIT & BBR3 & 5.91 & 470 & SCS \\
\hline $\mathrm{TI}$ & 4.00 & 100 & FIT & $\mathrm{BI3}$ & 6.63 & 570 &. $\mathrm{LJ}$ \\
\hline $\mathrm{ZR}$ & 4.50 & 100 & FIT & BEBR & 5.33 & 1000 & FIT \\
\hline CCL2F2 & 5.49 & 311 & SCS & BEBR2 & 5.78 & 700 & FIT \\
\hline FTI & 5.12 & 100 & FIT & BEI & 6.00 & 1000 & FIT \\
\hline LINAO & 5.88 & 700 & FIT & BEI2 & 6.18 & 1000 & FIT \\
\hline CLZR & 5.64 & 300 & FIT & BRHG & 5.75 & 300 & FIT \\
\hline FZR & 5.36 & 100 & FIT & BRK & 6.21 & 2850 & SCS \\
\hline BF2H & 4.79 & 150 & FIT & BRTI & 5.59 & 1000 & FIT \\
\hline $\mathrm{BR}$ & 4.12 & 237 & $\mathrm{LJ}$ & $\mathrm{BR} 2 \mathrm{~K} 2$ & 6.95 & 300 & FIT \\
\hline BRH & 4.24 & 294 & SCS & BR4TI & 6.86 & 644 & SCS \\
\hline BRLI & 6.50 & 500 & FIT & CLHG & 5.64 & 500 & FIT \\
\hline BR2 & 4.69 & 473 & $\mathrm{LJ}$ & CLK & 7.81 & 2810 & $\mathrm{LJ}$ \\
\hline BR2LI2 & 6.36 & 200 & FIT & CL2K2 & 6.77 & 200 & FIT \\
\hline BF2O & 4.74 & 150 & FIT & $\mathrm{FHG}$ & 5.37 & 150 & FIT \\
\hline CCLO & 4.92 & 250 & FIT & FK & 5.26 & 200 & FIT \\
\hline $\mathrm{F} 2 \mathrm{HG}$ & 5.48 & 200 & FIT & $\mathrm{FI}$ & 4.97 & 300 & FIT \\
\hline $\mathrm{F} 2 \mathrm{~K} 2$ & 6.17 & 200 & FIT & FNO2 & 4.46 & 283 & SCS \\
\hline $\mathrm{HG}$ & 3.50 & 1400 & SCS & FPB & 5.38 & 300 & $\mathrm{FIT}$ \\
\hline
\end{tabular}


Table B.1 The complete JCZS database of $\boldsymbol{r}^{*}$ and $\boldsymbol{\varepsilon} / \boldsymbol{k}$ values

\begin{tabular}{|c|c|c|c|c|c|c|c|}
\hline Species & $r^{*}$ & $\dot{\varepsilon} / k$ & Method & Species & $r^{*}$ & $\varepsilon / k$ & Method \\
\hline HGI & 5.95 & 300 & FIT & F2PB & 5.51 & 300 & FIT \\
\hline IK & 7.00 & 500 & FIT & F5I & 5.41 & 100 & FIT \\
\hline $\mathrm{I} 2 \mathrm{~K} 2$ & 7.24 & 350 & FIT & F7I & 5.61 & 100 & FIT \\
\hline CFO & 4.71 & 200 & OPT, FIT & HKO & 5.07 & 1213 & $\mathrm{LJ}$ \\
\hline I2TI & 7.50 & 400 & FIT & HPB & 5.31 & 150 & FIT \\
\hline I4TI & 7.27 & 841 & SCS & HGI2 & 5.85 & 867 & $\mathrm{LJ}$ \\
\hline $\mathrm{K}$ & 4.77 & 850 & $\mathrm{LJ}$ & INO & 6.00 & 500 & FIT \\
\hline $\mathrm{K} 2$ & 7.00 & 500 & FIT & IPB & 5.99 & 500 & FIT \\
\hline W & 5.40 & 1000 & FIT & $\mathrm{I} 2 \mathrm{~PB}$ & 6.57 & 500 & FIT \\
\hline BBR2 & 5.69 & 300 & FIT & I4ZR & 7.39 & 777 & SCS \\
\hline $\mathrm{BI} 2$ & 6.08 & 400 & FIT & OPB & 5.37 & 300 & FIT \\
\hline C2F6 & 7.36 & 237 & OPT, SCS & $\mathrm{PB}$ & 5.26 & 50.0 & FIT \\
\hline FFE & 4.96 & 100 & FIT & PB2 & 6.29 & 300 & FIT \\
\hline BRNO & 5.50 & 500 & FIT & BLIO2 & 6.50 & 300 & FIT \\
\hline BRPB & 5.79 & 500 & FIT & BRF & 4.29 & 239 & $\mathrm{LJ}$ \\
\hline BR2HG & 5.70 & 686 & $\mathrm{LJ}$ & BRF3 & 4.90 & 482 & $\mathrm{LJ}$ \\
\hline BR2PB & 6.24 & 500 & FIT & BR4PB & 6.94 & 300 & FIT \\
\hline BR2ZR & 6.90 & 400 & FIT & $\mathrm{CKN}$ & 5.67 & 500 & FIT \\
\hline BR4ZR & 6.86 & 651 & SCS & C2K2N2 & 7.20 & 300 & FIT \\
\hline CLI & 5.26 & 437 & $\mathrm{LJ}$ & F4OW & 5.71 & 50.0 & FIT \\
\hline CLPB & 5.61 & 500 & FIT & F4PB & 5.70 & 100 & FIT \\
\hline CL2HG & 6.20 & 500 & FIT & $\mathrm{H} 2 \mathrm{~K} 2 \mathrm{O} 2$ & 6.39 & 200 & FIT \\
\hline CL2PB & 6.02 & 500 & FIT & I2ZR & 6.50 & 400 & FIT \\
\hline CLAPB & 6.59 & 300 & FIT & $\mathbf{C U}$ & 4.69 & 50.0 & FIT \\
\hline $\mathrm{I} 4 \mathrm{~PB}$ & 7.46 & 300 & $\mathrm{FIT}$ & B2BEO4 & 6.70 & 300 & FIT \\
\hline
\end{tabular}


Table B.1 The complete JCZS database of $r^{*}$ and $\varepsilon / k$ values

\begin{tabular}{|l|l|l|l|l|l|l|l|}
\hline Species & $r^{*}$ & $\varepsilon / \boldsymbol{k}$ & Method & Species & $\boldsymbol{r}^{*}$ & $\varepsilon / \boldsymbol{k}$ & Method \\
\hline \hline OW & 5.47 & 100 & FIT & BEF3LI & 5.11 & 400 & FIT \\
\hline O2W & 5.73 & 100 & FIT & BRN & 4.75 & 500 & FIT \\
\hline O3W & 5.62 & 100 & FIT & BR5W & 7.08 & 200 & FIT \\
\hline O9W3 & 7.18 & 200 & FIT & BR6W & 7.52 & 100 & FIT \\
\hline ALF4LI & 6.00 & 300 & FIT & CLS & 4.91 & 300 & FIT \\
\hline BBRCL2 & 5.81 & 400 & FIT & CLNO2 & 4.90 & 300 & FIT \\
\hline BBRF2 & 5.31 & 300 & FIT & CL5W & 6.70 & 100 & FIT \\
\hline BBR2CL & 5.93 & 450 & FIT & CL6W & 6.87 & 100 & FIT \\
\hline BBR2F & 5.70 & 300 & FIT & F2N & 4.24 & 150 & FIT \\
\hline BF4K & 6.70 & 300 & FIT & H2O4W & 5.68 & 200 & FIT \\
\hline CBRN & 6.00 & 500 & FIT & KO & 5.29 & 150 & FIT \\
\hline BRCL & 5.04 & 500 & FIT & B3FH2O3 & 5.75 & 300 & FIT \\
\hline BRF5 & 5.26 & 100 & FIT & B3F2HO3 & 6.00 & 300 & FIT \\
\hline BRI & 4.73 & 582 & SCS & B3HO & 5.13 & 350 & FIT \\
\hline CIN & 6.50 & 500 & FIT & BR3OP & 6.14 & 300 & FIT \\
\hline CL2O2W & 6.14 & 300 & FIT & BR3PS & 6.43 & 300 & FIT \\
\hline CL2W & 6.02 & 500 & FIT & CLF2OP & 5.33 & 300 & FIT \\
\hline CL4OW & 6.36 & 633 & FIT & CL2FOP & 5.53 & 300 & FIT \\
\hline CL4W & 6.52 & 200 & FIT & FNO3 & 4.73 & 200 & FIT \\
\hline FW & 5.47 & 100 & FIT & F3OP & 4.94 & 150 & FIT \\
\hline F6W & 5.77 & 50.0 & FIT & F3PS & 5.52 & 280 & SCS \\
\hline BBRCL & 6.00 & 500 & FIT & HK & 5.16 & 100 & FIT \\
\hline BBRF & 5.29 & 500 & FIT & HNO & 4.06 & 500 & FIT \\
\hline BBRO & 5.70 & 500 & FIT & O12W4 & 8.20 & 200 & FIT \\
\hline CB & 5.00 & 100 & FIT & BI & 6.30 & 500 & FIT \\
\hline
\end{tabular}


Table B.1 The complete JCZS database of $\boldsymbol{r}^{*}$ and $\varepsilon / k$ values

\begin{tabular}{|l|l|l|l|l|l|l|l|}
\hline \multicolumn{1}{|c|}{ Species } & $r^{*}$ & $\varepsilon / \boldsymbol{k}$ & Method & \multicolumn{1}{|c|}{ Species } & $r^{*}$ & $\varepsilon / k$ & Method \\
\hline \hline BF2HO & 4.83 & 300 & FIT & BO2 & 4.82 & 100 & FIT \\
\hline BEN & 4.96 & 300 & FIT & F2NA2 & 6.02 & 200 & FIT \\
\hline BRP & 5.15 & 800 & FIT & F4MG2 & 6.70 & 300 & FIT \\
\hline CLP & 5.11 & 454 & SCS & ITI & 6.50 & 500 & FIT \\
\hline F5P & 5.04 & 100 & FIT & I3TI & 6.95 & 300 & FIT \\
\hline HHG & 5.32 & 100 & FIT & I3ZR & 6.95 & 300 & FIT \\
\hline HNO2 & 4.89 & 200 & FIT & BRNA & 6.72 & 400 & FIT \\
\hline NO2H & 4.91 & 300 & FIT & BRZR & 5.77 & 300 & FIT \\
\hline HNO3 & 4.80 & 421 & SCS & BR2NA2 & 6.74 & 300 & FIT \\
\hline HZR & 5.31 & 150 & FIT & IZR & 6.02 & 700 & FIT \\
\hline NZR & 5.41 & 200 & FIT & B2F4 & 5.30 & 100 & FIT \\
\hline BE2O & 5.61 & 300 & FIT & CL2NA2 & 6.55 & 150 & FIT \\
\hline CLOTI & 5.49 & 300 & FIT & NO3 & 4.60 & 150 & FIT \\
\hline CL2OTI & 5.85 & 350 & FIT & NO3* & 4.37 & 150 & FIT \\
\hline FOTI & 5.18 & 200 & FIT & BNAO2 & 6.20 & 300 & FIT \\
\hline F2OSI & 4.95 & 200 & FIT & FE & 2.77 & 7556 & SCS \\
\hline F2OTI & 5.27 & 100 & FIT & FE* & 2.77 & 7556 & SCS \\
\hline F3SI & 4.89 & 310 & LJ & CF4O & 6.40 & 200 & OPT, FIT \\
\hline BR3P & 6.11 & 575 & SCS & CCL2 & 5.27 & 213 & LJ \\
\hline CBR4 & 6.34 & 200 & FIT & CCL3 & 5.97 & 268 & LJ \\
\hline ALOH & 4.91 & 600 & FIT & CLFE & 5.28 & 200 & FIT \\
\hline F4N2 & 5.46 & 250 & SCS & CL2FE & 5.90 & 500 & FIT \\
\hline HO2 & 3.97 & 300 & FIT & CL3FE & 6.04 & 300 & FIT \\
\hline LI2O2 & 5.68 & 100 & FIT & CL6FE2 & 9.00 & 100 & FIT \\
\hline MGN & 5.09 & 150 & FIT & FEO & 4.98 & 150 & FIT \\
\hline
\end{tabular}


Table B.1 The complete JCZS database of $r^{*}$ and $\varepsilon / k$ values

\begin{tabular}{|l|l|l|l|l|l|l|l|}
\hline Species & $r^{*}$ & $\varepsilon / k$ & Method & Species & $r^{*}$ & $\varepsilon / k$ & Method \\
\hline \hline BR2TI & 6.50 & 400 & FIT & F2N2 & 4.62 & 220 & SCS \\
\hline BR3TI & 6.43 & 300 & FIT & F2N2T & 4.61 & 210 & SCS \\
\hline BR3ZR & 6.50 & 300 & FIT & H2N2 & 4.26 & 71.0 & LJ \\
\hline BBR2H & 5.68 & 300 & FIT & LINO & 5.7 & 500 & FIT \\
\hline BCL2H & 5.42 & 200 & FIT & O6W2 & 6.5 & 200 & FIT \\
\hline B2H4O4 & 5.80 & 300 & FIT & O8W3 & 9.5 & 200 & FIT \\
\hline C2N2NA & 6.80 & 300 & FIT & C2H & 4.60 & 209 & LJ \\
\hline CLCU & 5.19 & 250 & FIT & CL10W2 & 7.85 & 200 & FIT \\
\hline CL3CU3 & 6.75 & 250 & FIT & ACIDG & 4.99 & 200 & FIT \\
\hline H2NA2O2 & 6.14 & 200 & FIT & MO & 5.21 & 100 & FIT \\
\hline ALBO2 & 5.52 & 500 & FIT & CSI & 5.03 & 250 & FIT \\
\hline BBEO2 & 6.00 & 500 & FIT & CSI2 & 6.0 & 500 & FIT \\
\hline B2O & 5.34 & 300 & FIT & C2N & 4.30 & 232 & LJ \\
\hline BE2F2O & 6.00 & 300 & FIT & C2SI & 5.7 & 500 & FIT \\
\hline BRMG & 6.50 & 300 & FIT & NSI2 & 5.50 & 600 & FIT \\
\hline BR2MG & 6.50 & 500 & FIT & BRW & 5.85 & 300 & FIT \\
\hline CNN & 4.30 & 232 & LJ & CBR & 5.00 & 1000 & FIT \\
\hline CN2 & 4.30 & 232 & LJ & CLW & 5.73 & 500 & FIT \\
\hline C2O & 4.30 & 232 & LJ & H2MGO2 & 6.0 & 300 & FIT \\
\hline CLF5 & 5.16 & 100 & FIT & HGO & 5.38 & 200 & FIT \\
\hline CUF & 4.84 & 100 & FIT & MOO & 5.30 & 100 & FIT \\
\hline CUF2 & 4.97 & 300 & FIT & C2CL4 & 5.74 & 502 & SCS \\
\hline FEH2O2 & 5.42 & 300 & FIT & C2CL6 & 6.20 & 300 & FIT \\
\hline BR2FE & 6.50 & 400 & FIT & COBALT & 4.79 & 50.0 & FIT \\
\hline BR4FE2 & 9.00 & 200 & FIT & C2HF & 5.50 & 500 & FIT \\
\hline
\end{tabular}


Table B.1 The complete JCZS database of $r^{*}$ and $\varepsilon / k$ values

\begin{tabular}{|l|l|l|l|l|l|l|l|}
\hline \multicolumn{1}{|c|}{ Species } & $r^{*}$ & $\varepsilon / \boldsymbol{k}$ & Method & Species & $\boldsymbol{r}^{*}$ & $\varepsilon / \boldsymbol{k}$ & Method \\
\hline \hline CUO & 4.86 & 150 & FIT & ALO2 & 4.95 & 300 & FIT \\
\hline CU2 & 5.49 & 200 & FIT & CLCS & 6.08 & 700 & FIT \\
\hline FO2 & 4.20 & 300 & FIT & CL2CS2 & 7.38 & 300 & FIT \\
\hline FEI2 & 7.00 & 500 & FIT & CESIUM & 5.71 & 50.0 & FIT \\
\hline FE2I4 & 6.58 & 100 & FIT & CSF & 5.81 & 200 & FIT \\
\hline CESIU2 & 6.99 & 1000 & FIT & CAHO & 5.29 & 500 & FIT \\
\hline CS2F2 & 6.82 & 300 & FIT & CL2MOO2 & 5.94 & 200 & FIT \\
\hline MGOH & 5.07 & 300 & FIT & COF2 & 5.04 & 200 & FIT \\
\hline MOO2 & 5.38 & 100 & FIT & F3NO & 4.82 & 245 & SCS \\
\hline MOO3 & 5.46 & 100 & FIT & F4MOO & 5.58 & 100 & FIT \\
\hline C2CL2 & 6.50 & 300 & FIT & F6MO & 5.68 & 50.0 & FIT \\
\hline C2HCL & 6.20 & 500 & FIT & H2MOO4 & 5.61 & 200 & FIT \\
\hline CA & 5.07 & 50.0 & FIT & B2F4O & 5.62 & 300 & FIT \\
\hline CAF & 5.21 & 150 & FIT & BA & 5.69 & 50.0 & FIT \\
\hline CAF2 & 5.36 & 300 & FIT & CNO & 4.89 & 232 & OPT, LJ \\
\hline CL4MO & 6.48 & 200 & FIT & CL4FE2 & 9.00 & 200 & FIT \\
\hline CL5MO & 6.68 & 100 & FIT & N3 & 4.41 & 300 & FIT \\
\hline CL6MO & 6.86 & 100 & FIT & SR & 5.32 & 50.0 & FIT \\
\hline CSO & 5.83 & 300 & FIT & BKO2 & 5.85 & 300 & FIT \\
\hline CS2O & 6.90 & 500 & FIT & CLFO2S & 5.27 & 300 & FIT \\
\hline CBRF3 & 5.62 & 235 & LJ & CL2O2S & 5.55 & 441 & SCS \\
\hline CF3I & 5.46 & 300 & FIT & CSHO & 6.50 & 500 & FIT \\
\hline CHCL & 4.82 & 400 & FIT & CS2H2O2 & 7.02 & 300 & FIT \\
\hline CHF & 4.41 & 300 & FIT & FHO3S & 4.87 & 500 & FIT \\
\hline CHP & 4.89 & 700 & FIT & BACL & 6.02 & 500 & FIT \\
\hline
\end{tabular}


Table B.1 The complete JCZS database of $\boldsymbol{r}^{*}$ and $\varepsilon / k$ values

\begin{tabular}{|c|c|c|c|c|c|c|c|}
\hline Species & $r^{*}$ & $\varepsilon / k$ & Method & Species & $r^{*}$ & $\varepsilon / k$ & Method \\
\hline $\mathrm{C} 2 \mathrm{~F} 3 \mathrm{~N}$ & 5.86 & 252 & OPT, SCS & BACL2 & 6.37 & 500 & FIT \\
\hline CL3SI & 5.87 & 300 & FIT & $\mathrm{BAF}$ & 5.77 & 100 & FIT \\
\hline CL4MG2 & 9.00 & 100 & FIT & BAF2 & 5.88 & 150 & FIT \\
\hline ALF4NA & 6.50 & 300 & FIT & CLSR & 5.73 & 350 & FIT \\
\hline AL2F6 & 5.77 & 300 & FIT & CL2SR & 6.09 & 500 & FIT \\
\hline CACL & 5.53 & 300 & FIT & FSR & 5.43 & 100 & FIT \\
\hline CACL2 & 6.50 & 500 & FIT & F2SR & 5.57 & 200 & FIT \\
\hline NB & 5.23 & 50.0 & $\mathrm{FIT}$ & CAI & 7.00 & 500 & FIT \\
\hline $\mathrm{TA}$ & 5.40 & 50.0 & FIT & CAI2 & 8.00 & 300 & FIT \\
\hline CR & 4.90 & 50.0 & FIT & ISR & 6.08 & 1000 & $\mathrm{FTT}$ \\
\hline PBS & 5.70 & 1000 & FIT & I2SR & 8.20 & 300 & FIT \\
\hline V & 4.94 & 50.0 & FIT & BABR & 6.15 & 300 & FIT \\
\hline OSR & 5.45 & 200 & FIT & BABR2 & 7.70 & 300 & FIT \\
\hline CLCO & 5.26 & 200 & FIT & BRCA & 5.66 & 1000 & FIT \\
\hline CL2CO & 6.00 & 500 & $\mathrm{FIT}$ & BRSR & 5.86 & 400 & FIT \\
\hline CL3CO & 5.96 & 200 & FIT & BR5NB & 7.11 & 100 & FIT \\
\hline $\mathrm{CL} A \mathrm{CO} 2$ & 9.00 & 100 & FIT & CAO & 5.22 & 100 & FIT \\
\hline CRN & 5.07 & 100 & FIT & $\mathrm{CA} 2$ & 6.19 & 1000 & FIT \\
\hline CRO & 5.01 & 100 & FIT & CL5NB & 6.71 & 650 & SCS \\
\hline $\mathrm{CRO} 2$ & 5.12 & 100 & FIT & CL5TA & 6.74 & 621 & SCS \\
\hline CRO3 & 5.22 & 100 & FIT & IMG & 6.20 & 1000 & FIT \\
\hline NV & 5.10 & 100 & FIT & $\mathrm{I} 2 \mathrm{MG}$ & 7.00 & 500 & FIT \\
\hline NBO & 5.30 & 100 & FIT & MG2 & 5.83 & 500 & FIT \\
\hline $\mathrm{NBO} 2$ & 5.47 & 100 & FIT & BAHO & 6.30 & 500 & FIT \\
\hline OTA & 5.46 & 100 & FIT & HOSR & 6.00 & 500 & FIT \\
\hline
\end{tabular}


Table B.1 The complete JCZS database of $\boldsymbol{r}^{*}$ and $\varepsilon / k$ values

\begin{tabular}{|c|c|c|c|c|c|c|c|}
\hline Species & $r^{*}$ & $\varepsilon / k$ & Method & Species & $r^{*}$ & $\varepsilon / k$ & Method \\
\hline OV & 5.04 & 50.0 & FIT & BHS & 5.10 & 700 & FIT \\
\hline O2TA & 5.52 & 100 & FIT & $\mathrm{BAH} 2 \mathrm{O} 2$ & 6.00 & 300 & FIT \\
\hline $\mathrm{O} 2 \mathrm{~V}$ & 5.13 & 100 & FIT & $\mathrm{CAH} 2 \mathrm{O} 2$ & 6.50 & 300 & $\mathrm{FIT}$ \\
\hline BAI & 6.35 & 500 & FIT & $\mathrm{H} 2 \mathrm{O} 2 \mathrm{SR}$ & 6.70 & 300 & $\mathrm{FIT}$ \\
\hline $\mathrm{BAI} 2$ & 8.50 & 300 & $\mathrm{FIT}$ & ALF2O & 5.05 & 200 & FIT \\
\hline $\mathrm{BAO}$ & 5.80 & 200 & FIT & FS & 4.45 & 100 & $\mathrm{FIT}$ \\
\hline $\mathrm{BR} 2 \mathrm{CA}$ & 7.20 & 300 & FIT & F2S & 4.64 & 100 & FIT \\
\hline BR2SR & 7.60 & 300 & FIT & FSSF & 5.19 & 300 & FIT \\
\hline BR4MG2 & 9.50 & 200 & FIT & F2S2 & 5.28 & 206 & $\mathrm{LJ}$ \\
\hline F3S & 4.81 & 207 & $\mathrm{FIT}$ & D2S & 4.40 & 100 & DEUT \\
\hline F5S & 5.03 & 100 & FIT & $\mathrm{D} 3 \mathrm{~N}$ & 3.80 & 328 & SCS \\
\hline I4SI & 7.52 & 764 & SCS & BAS & 6.05 & 500 & FIT \\
\hline BRH3SI & 5.60 & 500 & FIT & BES & 5.50 & 550 & FIT \\
\hline BRSI & 6.20 & 500 & $\mathrm{FIT}$ & CAS & 5.56 & 300 & $\mathrm{FIT}$ \\
\hline BR2H2SI & 5.70 & 200 & FTT & CLNI & 5.23 & 250 & FIT \\
\hline BR2SI & 5.78 & 500 & FIT & CL2NI & 5.63 & 550 & FIT \\
\hline BR3HSI & 6.78 & 644 & SCS & FES & 5.31 & 250 & FIT \\
\hline BR4SI & 6.15 & 494 & SCS & SSR & 5.77 & 400 & FIT \\
\hline HI3SI & 6.73 & 300 & FIT & BRF5S & 5.61 & 200 & FIT \\
\hline H2I2SI & 6.18 & 500 & FIT & BR3SI & 6.22 & 300 & $\mathrm{FIT}$ \\
\hline H3ISI & 6.50 & 500 & $\mathrm{FIT}$ & CF8S & 5.55 & 150 & FIT \\
\hline ISI & 6.20 & 500 & FIT & CLF5S & 5.37 & 316 & SCS \\
\hline I2SI & 6.21 & 500 & FIT & F10S2 & 5.88 & 250 & FIT \\
\hline $\mathrm{NI}$ & 4.73 & 50.0 & FIT & I3SI & 6.76 & 350 & FIT \\
\hline NIS & 5.25 & 300 & FIT & C4NIO4 & 6.40 & 300 & FIT \\
\hline
\end{tabular}


Table B.1 The complete JCZS database of $r^{*}$ and $\varepsilon / k$ values

\begin{tabular}{|l|l|l|l|l|l|l|l|}
\hline Species & $r^{*}$ & $\varepsilon / k$ & Method & Species & $r^{*}$ & $\varepsilon / k$ & Method \\
\hline \hline D & 2.30 & 145 & DEUT & C5FEO5 & 6.29 & 300 & FIT \\
\hline CLD & 3.75 & 345 & DEUT & CL2S2 & 6.50 & 200 & FIT \\
\hline DF & 3.53 & 330 & DEUT & CLS2 & 5.40 & 400 & FIT \\
\hline DH & 3.66 & 38.0 & DEUT & CL2S & 5.40 & 350 & FIT \\
\hline DHO & 3.50 & 524 & AVE & K2O4S & 5.70 & 350 & FIT \\
\hline DN & 3.72 & 65.0 & DEUT & NA2O4S & 6.26 & 300 & FIT \\
\hline DO & 3.53 & 80.0 & DEUT & MOBR & 5.72 & 250 & FIT \\
\hline DS & 4.38 & 847 & DEUT & MOBR2 & 6.70 & 400 & FIT \\
\hline D2N & 3.86 & 100 & FIT & MOBR3 & 6.52 & 350 & FIT \\
\hline D2N2 & 4.11 & 200 & FIT & MOBR4 & 6.82 & 200 & FIT \\
\hline D2O & 3.50 & 521 & SCS & IMO & 5.94 & 500 & FIT \\
\hline I2MO & 7.40 & 400 & FIT & XE & 4.54 & 231 & LJ \\
\hline I3MO & 6.98 & 400 & FIT & SN & 4.94 & 50.0 & FIT \\
\hline I4MO & 7.40 & 250 & FIT & SNF & 5.12 & 300 & FIT \\
\hline FMO & 5.29 & -100 & FIT & SNF2 & 5.28 & 300 & FIT \\
\hline F2MO & 5.38 & 200 & FIT & SNO & 5.08 & 200 & FIT \\
\hline F3MO & 5.46 & 100 & FIT & CH2O2 & 4.44 & 200 & OPT, FIT \\
\hline F4MO & 5.54 & 100 & FIT & MN & 4.86 & 50.0 & FIT \\
\hline F5MO & 5.58 & 50.0 & FIT & MNS & 5.39 & 300 & FIT \\
\hline LI2O4S & 7.00 & 300 & FIT & BIZ & 4.94 & 50.0 & FIT \\
\hline ZN & 2.93 & 2565 & SCS & BIZ2 & 5.93 & 500 & FIT \\
\hline CLDO & 4.50 & 350 & FIT & BIF & 5.15 & 800 & FIT \\
\hline F10MO2 & 6.55 & 200 & FIT & BIF3 & 5.52 & 400 & FIT \\
\hline F15MO3 & 9.00 & 200 & FIT & UGAS & 3.61 & 50.0 & FIT \\
\hline HF & 3.64 & 2000 & FIT & UF & 5.20 & 500 & FIT \\
\hline
\end{tabular}


Appendix B

Table B.1 The complete JCZS database of $r^{*}$ and $\varepsilon / k$ values

\begin{tabular}{|l|c|c|l|l|l|l|l|}
\hline \multicolumn{1}{|c|}{ Species } & $r^{*}$ & $\varepsilon / \boldsymbol{k}$ & Method & Species & $r^{*}$ & $\varepsilon / \boldsymbol{k}$ & Method \\
\hline \hline AL2 & 5.46 & 250 & FIT & UF2 & 5.30 & 500 & FIT \\
\hline CS2O4S & 7.75 & 300 & FIT & UF3 & 5.50 & 300 & FIT \\
\hline CL2 & 4.73 & 316 & LJ & UF4 & 5.50 & 300 & FIT \\
\hline F2 & 3.71 & 126 & LJ & UF5 & 5.39 & 300 & FIT \\
\hline H2 & 2.85 & 38.0 & HUG & UF6 & 5.53 & 100 & FIT \\
\hline N2 & 4.00 & 102 & SCS & CHBR3 & 5.98 & 559 & LJ \\
\hline O2 & 3.86 & 125 & SCS & F2H2 & 2.60 & 2000 & FIT \\
\hline AR & 3.98 & 93.3 & LJ & F3H3 & 2.20 & 2000 & FIT \\
\hline D2 & 3.31 & 39.3 & LJ & F4H4 & 2.20 & 2000 & FIT \\
\hline HE & 2.89 & 10.2 & LJ & F5H5 & 2.20 & 2000 & FIT \\
\hline KR & 4.10 & 179 & LJ & F6H6 & 2.20 & 2000 & FIT \\
\hline NE & 3.17 & 33.0 & LJ & F7H7 & 2.20 & 2000 & FIT \\
\hline
\end{tabular}




\section{Appendix C}

Appendix $\mathrm{C}$ contains the CHEETAF input deck for the explosives listed in Table 2, the Formula deck with all the explosives in the CHEETAH input deck, the DAKOTA input deck, C-shell script used in the DAKOTA optimization, the FORTRAN code used to construct the APREPRO include file for the DAKOTA optimization, a FORTRAN code used to calculate the root mean square error, rms.f., and the CHEETAH input deck for the explosives listed in Table 5.

\section{CHEETAH INPUT DECK FOR THE EXPLOSIVES LISTED IN TABLE 2}

\# Template for standard CHEETAH run

library file, jcz.chl

gas eos, jcz3

set, $j c z 3, m, 6$

set, jcz3, $1, \quad 13$

\#\#dp12

composition, dp12, 100.

hug0, p, 1, rho, 1.26

$c-j$

\#\#afx902

composition, nq, 95, viton, 5

hug0, p, 1, rho, 1.742

$c-j$

\#\#fefo

composition, fefo, 100.

hug0, p, 1, rho, 1.61

$c-j$

\#\#fm1

composition, fefo, $23, \mathrm{mf}-1,52$, bdnpf, 25

hug0, p, 1, rho, 1.509

c-j

\#\#pf

composition, picfluoride, 100.

hug $0, p, 1$, rho, 1.833

c-j

\#\#rx36ah

composition, hmx, 51.32, btf, 43.68, viton, 5

hug0, $\mathrm{p}, 1$, rho, 1.830

c-j

\#\#rx41ab

composition, $\mathrm{k}-6,95$, viton, 5

hug0, p, 1, rho, 1.857

$c-j$

\#\#1x17

composition, tatb, 92.5, kel-f, 7.5

hug0, p, 1, rho, 1.905

c-j

\#\#rx27ad

composition, tacot, 92.5, kel-f, 7.5

hug0, p, 1, rho, 1.638

$c-j$

\#\#rx45aa

composition, anta, 95, kel-f, 5

hug0, p, 1, rho, 1.752

$c-j$

\#\#rx47aa

composition, cl-14, 92.51, kel-f, 7.49 


\section{Appendix C}

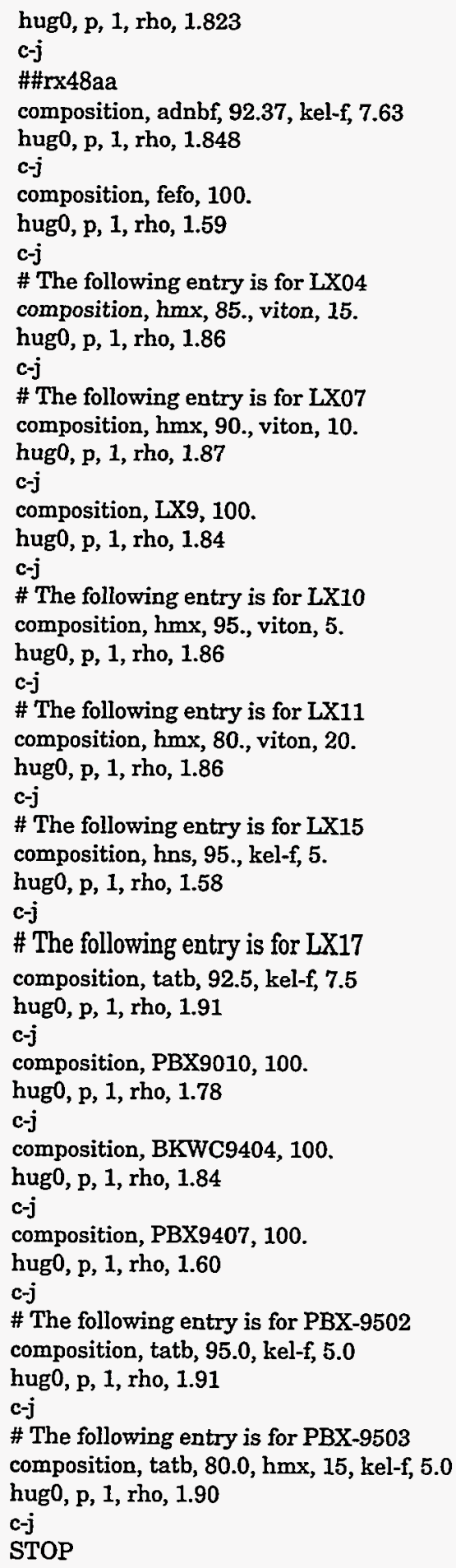

Formula deck with all the explosives in the CHEETAH input deck is also included.

\#Lawrence Livermore National Laboratory CHEETAH Reactant Library V1.0

\# Explosives

for, be, $0.0,5.0,0.0$, be, 1 


\section{Appendix C}

for, lithium din, $-63300.0,45.919,0,1 \mathrm{l}, 1, \mathrm{n}, 3,0,4$ for, al, $\quad 0$., 9.985, 0., al, 1 for, k2so4, -343640.0, 65.488, 0.0, k, 2, s, 1, o, 4 for, sio2, $\quad-215940 ., 26.12,0 ., \mathrm{si}, 1, \mathrm{o}, 2$ for, adn, $\quad-35700$., 68.92, 0., h, 4, n, 4, o, 4 for, adnbf, $\quad 36790 ., 126.8,0 ., \mathrm{c}, 6, \mathrm{~h}, 3, \mathrm{n}, 5,0,6$ for, ammazide, 20400., 44.65, 0., h, 4, n, 4 for, ammpicrate, $000 ., 143.27,0 ., \mathrm{c}, 6, \mathrm{~h}, 6, \mathrm{n}, 4,0,7$

for, anpz, $\quad-5400 ., 111.0,0 ., \mathrm{c}, 4, \mathrm{~h}, 4, \mathrm{n}, 6,0,4$ for, anta, 14400., 70.96, 0., c, 2, h, 3, n, 5, o, 2 for, bicyclohmx, 25000., 157.46, 0., c, 4, h, 6, n, 8, o, 8 for, btf, $\quad 144500 ., 132.62,0 ., \mathrm{c}, 6, \mathrm{n}, 6, \mathrm{o}, 6$ for, cl-12, $\quad 81000 ., 214.80,0 ., c, 6, h, 6, n, 12,0,12$ for, cl-14, 20630., 131.89, 0., c, 6, h, 4, n, 6, 0, 6 for, cl-20, $\quad 90000 ., 214.38,0 ., c, 6, h, 6, n, 12,0,12$ for, datb, $\quad-29230 ., 132.35,0 ., \mathrm{c}, 6, \mathrm{~h}, 5, \mathrm{n}, 5,0,6$ for, dftnb, $\quad-49690 ., 132.90,0 ., \mathrm{c}, 6, \mathrm{~h}, 1, \mathrm{n}, 3,0,6, \mathrm{f}, 2$ for, dina, $\quad-75400 ., 161.4,0 ., \mathrm{c}, 4, \mathrm{~h}, 8, \mathrm{n}, 4, \mathrm{o}, 8$ for, dipam, $\quad-20100 ., 249.03,0 ., \mathrm{c}, 12, \mathrm{~h}, 6, \mathrm{n}, 8, \mathrm{o}, 12$ for, dipehn, -233790., 321.59, 0., c, 10, h, 16, n, 6, o, 19 for, dnb, $\quad-6200 ., 106.73,0 ., \mathrm{c}, 6, \mathrm{~h}, 4, \mathrm{n}, 2, \mathrm{o}, 4$ for, dnbt, $\quad 94000 ., 125.6,0 ., c, 4, h, 2, n, 8,0,4$ for, dnbtzl, $\quad 0 ., 113.7,0 ., \mathrm{c}, 6, \mathrm{~h}, 3, \mathrm{n}, 5,0,4$ for, dni24, 4900., 108.96, 0., c, 3, h, 2, n, 4, o, 4 for, dnpa, $\quad-110000 ., 138.84,0 ., \mathrm{c}, 6, \mathrm{~h}, \mathrm{8}, \mathrm{n}, 2,0,6$ for, dnt, $\quad-16300 ., 119.72,0 ., c, 7, h, 6, n, 2,0,4$ for, dp12, $\quad-48000 ., 116.00,0 ., \mathrm{c}, 3, \mathrm{~h}, 6, \mathrm{n}, 2, \mathrm{f}, 4$ for, edd, -155766., 118.01, 0., c, 2, h, 10, $n, 4,0,6$ for, edna, $\quad-24706 ., 87.78,0 ., c, 2, h, 6, n, 4,0,4$ for, ednp, $\quad-140000 ., 172.02,0 ., \mathrm{c}, 7, \mathrm{~h}, 12, \mathrm{n}, 2,0,6$ for, ethcarb, -138900., 66.66, 0., c, 3, h, 4, o, 3 for, ethpicrate, -48020 ., 165.93, 0., c, 8, h, 7, n, 3, o, 7 for, fefo, -177530., 199.20, 0., c, 5, h, 6, n, 4, o, 10, f, 2 for, hk6, 25000., 115.1, 0., c, 3, h, 5, n, 5, o, 5 for, hmx, $\quad 17930 ., 155.46,0 ., \mathrm{c}, 4, \mathrm{~h}, 8, \mathrm{n}, 8, \mathrm{o}, 8$ for, hnb, $\quad 15700 ., 172.33,0 ., \mathrm{c}, 6, \mathrm{n}, 6, \mathrm{o}, 12$ for, hnab, $\quad 67900 ., 251.37,0 ., \mathrm{c}, 12, \mathrm{~h}, 4, \mathrm{n}, 8, \mathrm{o}, 12$ for, hndp, $\quad 9570 ., 267.81,0 ., \mathrm{c}, 12, \mathrm{~h}, 5, \mathrm{n}, 7, \mathrm{o}, 12$ for, hne, $\quad 28600 ., 162.22,0 ., \mathrm{c}, 2, \mathrm{n}, 6,0,12$ for, hns, $\quad 18700 ., 258.80,0 ., \mathrm{c}, 14, \mathrm{~h}, 6, \mathrm{n}, 6, \mathrm{o}, 12$ for, hnx, 104000., 206.1, 0., c, 8, h, 5, o, 6, n, 13 for, hydrazine, 12050 ., 19.02, 0., h, 4, n, 2

for, hydnitrate, -59000 ., $56.41,0 ., \mathrm{h}, 5, \mathrm{n}, 3, \mathrm{o}, 3$ for, $\mathrm{k}-6, \quad-10000 ., 122.2,0 ., \mathrm{c}, 3, \mathrm{~h}, 4, \mathrm{n}, 6,0,7$ for, licom, . -78400., 114.9, 0., c, 2, h, 3, n, 5, o, 6, li, 1, cl, 1 for, medina, $\quad-13840 ., 78.42,0 ., \mathrm{c}, 1, \mathrm{~h}, 4, \mathrm{n}, 4, \mathrm{o}, 4$ for, mf-1, -160115., 206.10, 0., c, 6, h, 9, n, 4, o, 10, f, 1 for, ng, $\quad-88600 ., 142.29,0 ., c, 3, h, 5, n, 3,0,9$ for, nglycol, -58250., 102.5, 0., c, 2, h, 4, n, 2, o, 6 for, nibtn, $\quad-54600 ., 170.3,0 ., \mathrm{c}, 4, \mathrm{~h}, 6, \mathrm{n}, 4, \mathrm{o}, 11$ for, $\mathrm{nm}$-27030., 54.02, 0., c, 1, h, 3, n, 1, o, 2 for, nq, $\quad-22100 ., 58.63,0 ., \mathrm{c}, 1, \mathrm{~h}, 4, \mathrm{n}, 4, \mathrm{o}, 2$ for, nto, $\quad-28000 ., 67.39,0 ., \mathrm{c}, 2, \mathrm{~h}, 2, \mathrm{n}, 4,0,3$ for, petn, $\quad-128700 ., 177.61,0 ., \mathrm{c}, 5, \mathrm{~h}, 8, \mathrm{n}, 4, \mathrm{o}, 12$ for, petrin, -134000., 176.0, 0., c, 5, h, 9, n, 3, o, 10 for, picchloride, 6410 ., $137.78,0 ., \mathrm{c}, 6, \mathrm{~h}, 2, \mathrm{n}, 3, \mathrm{o}, 6, \mathrm{cl}, 1$ for, picfluoride,-62000., 126.1, $0 ., c, 6, h, 2, n, 3,0,6, f, 1$ for, picric acid,-51300., 129.44, 0., c, 6, h, 3, n, 3, o, 7 for, pran, $\quad 50000$., 158.4, 0., c, 7, h, 4, n, 8, o, 6 for, pzo, $\quad-3100 ., 113.0,0 ., \mathrm{c}, 4, \mathrm{~h}, 4, \mathrm{n}, 6, \mathrm{o}, 5$ 


\section{Appendix C}

for, rdx, 14710., 122.99, 0., c, 3, h, 6, n, 6, o, 6 for, styph acid,-103900., 133.9, 0., c, 6, h, 3, n, 3, o, 8 for, tacot, $\quad 110500 ., 209.85,0 ., \mathrm{c}, 12, \mathrm{~h}, 4, \mathrm{n}, 8,0,8$ for, tatb, $\quad-36850$., 133.21, 0., c, 6, h, 6, 0, 6, n, 6 for, tena, $\quad-11690 ., 146.28,0 ., \mathrm{c}, 6, \mathrm{~h}, 3, \mathrm{n}, 5, \mathrm{o}, 8$ for, tetrazene, $45200 ., 110.71,0 ., \mathrm{c}, 2, \mathrm{~h}, 8, \mathrm{n}, 10, \mathrm{o}, 1$ for, tetryl, $\quad 4670 ., 165.98,0 ., \mathrm{c}, 7, \mathrm{~h}, 5, \mathrm{n}, 5,0,8$ for, tna, $\quad-17790 ., 129.46,0 ., \mathrm{c}, 6, \mathrm{~h}, 4, \mathrm{n}, 4, \mathrm{o}, 6$ for, tnan, $\quad-36610 ., 150.99,0 ., \mathrm{c}, 7, \mathrm{~h}, 5, \mathrm{n}, 3, \mathrm{o}, 7$ for, tnaz, $\quad 2800$., 104.40, 0., c, $3, \mathrm{~h}, 4, \mathrm{n}, 4,0,6$ for, tnb, $\quad-8480 ., 121.00,0 ., c, 6, h, 3, n, 3,0,6$ for, tnc, $\quad-60290 ., 144.70,0 ., \mathrm{c}, 7, \mathrm{~h}, 5, \mathrm{n}, 3,0,7$ for, tneb, $\quad-21650 ., 148.87,0 ., \mathrm{c}, 8, \mathrm{~h}, 7, \mathrm{n}, 3,0,6$ for, tneoc, $\quad-282130 ., 397.9,0 ., \mathrm{c}, 9, \mathrm{~h}, 8, \mathrm{n}, 12, \mathrm{o}, 28$

for, tngu, $\quad 12000 ., 157.9,0 ., \mathrm{c}, 4, \mathrm{~h}, 2, \mathrm{n}, 8, \mathrm{o}, 10$

for, tnm, $\quad 13000 ., 118.81,0 ., \mathrm{c}, 1, \mathrm{n}, 4,0,8$ for, tnp, 79000., 120.96, 0., c, 5, h, 2, n, 4, o, 6 for, tht, $\quad-15000 ., 137.3,0 ., \mathrm{c}, 7, \mathrm{~h}, 5, \mathrm{n}, 3,0,6$ for, urea, $\quad-79610 ., 45.39,0 ., \mathrm{c}, 1, \mathrm{~h}, 4, \mathrm{n}, 2, \mathrm{o}, 1$ for, ureanit, -130610 ., 73.21, 0., c, 1, h, 5, n, 3, 0, 4

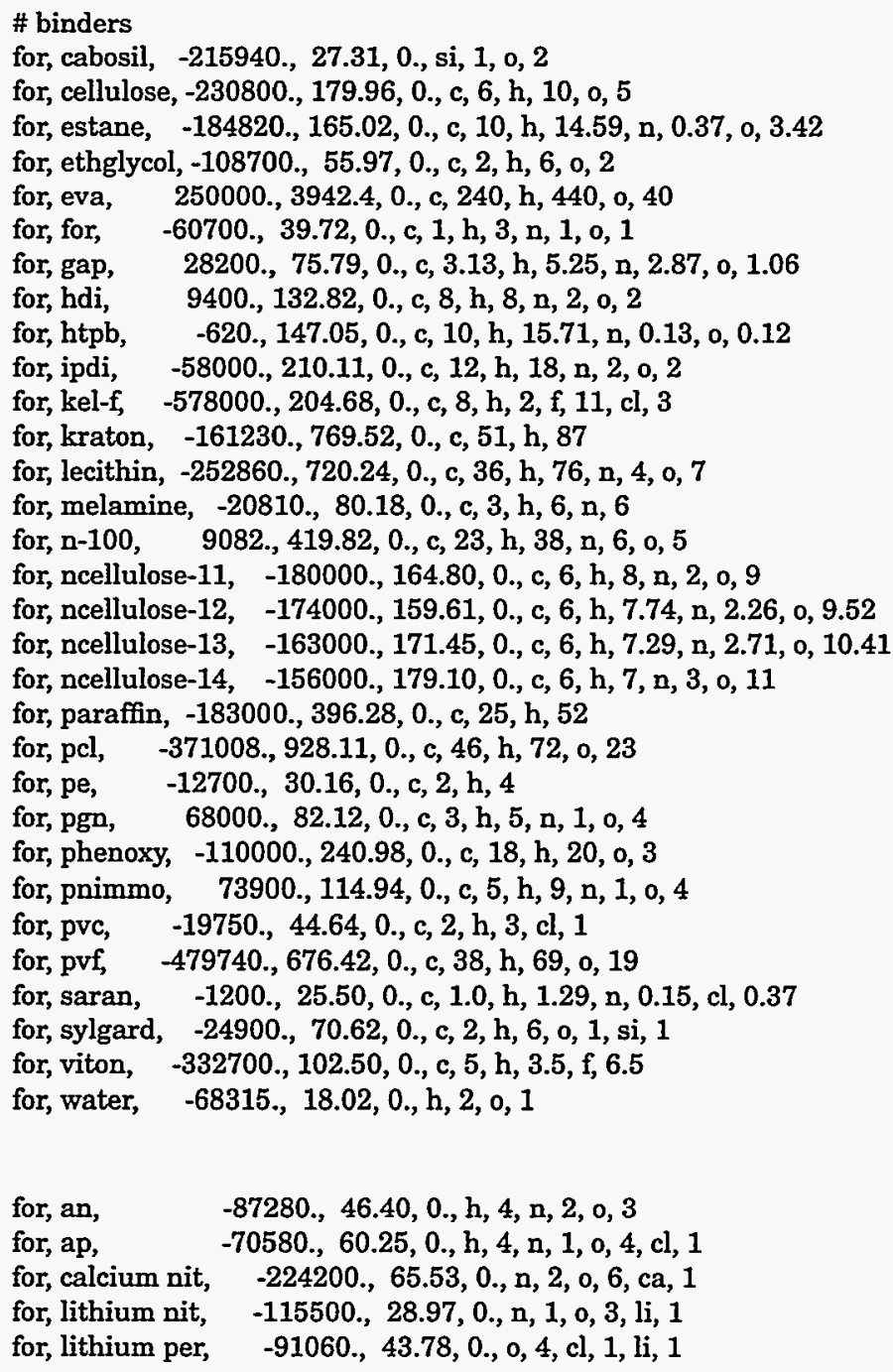


for, magnesium per, -140600., 101.0, 0., o, 8, cl, 2, mg, 1

for, nitric acid, $\quad-41610 ., 41.92,0 ., \mathrm{h}, 1, \mathrm{n}, 1,0,3$

for, potassium nit, -118200., 47.94, 0., 0, 3, n, 1, k, 1

for, potassium per, -103400., 55.00, 0., o, 4, cl, 1, k, 1

for, sodium nit, $\quad-111800 ., 37.59,0 ., \mathrm{n}, 1,0,3$, na, 1

for, sodium per, $\quad-91610 ., 48.98,0 ., 0,4, \mathrm{cl}, 1, \mathrm{na}, 1$

$\begin{array}{ll}\text { for, bdnpa, } & -151300 ., 234.69,0 ., \mathrm{c}, 8, \mathrm{~h}, 14, \mathrm{n}, 4, \mathrm{o}, 10 \\ \text { for, bdnpf, } & -142700 ., 224.60,0 ., \mathrm{c}, 7, \mathrm{~h}, 12, \mathrm{n}, 4, \mathrm{o}, 10 \\ \text { for, cef, } & -300000 ., 200.35,0 ., \mathrm{c}, 6, \mathrm{~h}, 12, \mathrm{o}, 4, \mathrm{cl}, 3, \mathrm{p}, 1 \\ \text { for, dop, } & -268200 ., 396.15,0 ., \mathrm{c}, 24, \mathrm{~h}, 38, \mathrm{o}, 4 \\ \text { for, tegdn, } & -145400 ., 180.58,0 ., \mathrm{c}, 6, \mathrm{~h}, 12, \mathrm{n}, 2, \mathrm{o}, 8 \\ \text { for, tmetn, } & -105800 ., 173.56,0 ., \mathrm{c}, 5, \mathrm{~h}, 9, \mathrm{n}, 3, \mathrm{o}, 9\end{array}$

\# reducers

for, al, $\quad 0 ., 9.985,0 .$, al, 1

for, al inert, $\quad 0 ., 9.985,0$. al inert, 1

for, $b$, $\quad 0 ., 4.62,0 ., b, 1$

for, fuel oil, 70000., 115.9, 0., c, 7, h, 12

for, graphite, $\quad 0 ., \quad 5.34,0 ., \mathrm{c}, 1$

for, $\mathrm{ABH}, \quad 116000 ., 533.0,75.0, \mathrm{C}, 24, \mathrm{H}, 6, \mathrm{~N}, 14, \mathrm{O}, 24$

for, COMPA3, 2840., 59.8, 70.0, C, 1.87, H, 3.74, N, 2.46, O, 2.46

for, COMPA3, 2840., 59.8, 70.0, C, 1.87, H, 3.74, N, 2.46, O, 2.46

for, COMPB, 1000., 139.3, 75.0, C, 2.03, H, 2.64, N, 2.18, O, 2.67

for, COMPC3, -6450., 59.9, 75.0, C, 1.90, H, 2.83, N, 2.34, O, 2.60

for, COMPC4, 3330., 59.9, 75.0, C, 1.82, H, 3.54, N, 2.46, O, 2.51

for, DATB-SNL, -23600., 132.3, 70.0, C, 6., H, 5., N, 5., O, 6 .

for, DEGN, -99400., 141.0, 70.0, C, 4, H, 8, N, 2, O, 7

for, DIPM, -6800., 253.7, 70.0, C, 12, H, 6, N, 8, O, 12

for, EXPD, -94000., 150.9, 70.0, C, 6, H, 6, N, 4, O, 7

for, LX9, 2004., 53.6, 70.0, C,1.43,H,2.74,N,2.59, O,2.72,F,0.02

for, MEN, -74300., 98.3, 70.0, C, 2.06, H, 7.06, N, 1.33, O, 3.10

for, NONA, 27400., 374.0, 75.0, C, 18, H, 5, N, 9, O, 18

for, PBX9007, 7130., 58.9, 70.0, C, 1.97, H, 3.22, N, 2.43, 0, 2.44

for, PBX9010,-7870.,55.,70.0,C,1.39, H,2.43,N,2.43,O,2.43,CL,.09, F,.26

for, PBX9011, -4050., 55.7, 70.0, C, 1.73, H, 3.18, N, 2.45, O, 2.61

for, PBX9205, 5810., 58.1, 70.0, C, 1.83, H, 3.14, N, 2.49, O, 2.51

for, PBX9404,80.,53.6,70.,C,1.40,H,2.75,N,2.57,0,2.69,CL,.03,P..01

for, BKWC9404,80.,53.6,70.,C,1.40,H,2.75,N,2.57,0,2.69,CL,.03

for, PBX9407,810.,55.2,70.,C,1.41,H,2.66,N,2.54,0,2.54,CL,.07,F..09

for, PBX9501, 2300., 54.0, 70.0, C, 1.47, H, 2.86, N, 2.60, O, 2.69

for, PBX9502,-20800.,51.5,70.,C,2.30,H,2.23,N,2.21, O,2.21,CL,.038,F, 0.13

for, PBX9503, -17700.,51.7,70.0,C,2.16, H,2.28,N,2.26, O,2.26,CL,.038

for, NPRO, -30000.,24464.0, 85.0, C, $3, \mathrm{H}, 7, \mathrm{~N}, 1, \mathrm{O}, 2$

for, tntab, 270000., 193.1, 75.0, C, 6, N, 12, O, 6

\section{DAKOTA INPUT DECK}

\# DAKOTA INPUT FILE - dakota_sample.in

\# NOTES: Sections are delimited by newline characters. Therefore, to continue a

\# section onto multiple lines, the back-slash character is needed to

\# escape the newline. Input is order-independent and white-space

\# insensitive. Keywords may be abbreviated so long as the abbreviation

$\#$ is unique. Comments are preceded by \#. Helpful NOTES precede each

\# section specification; however, the definitive resource for input

\# grammar is Dakota/src/dakota.input.spec. 


\section{Appendix C}

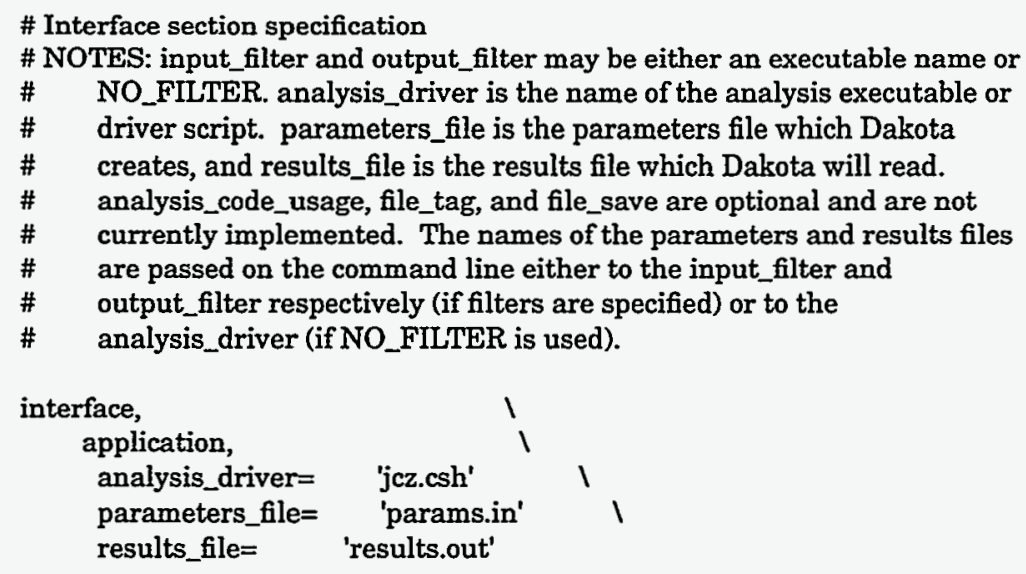

\# Variables specification

\# NOTES: Each of the $n$ design parameters can have an initial point, a lower

\# bound, an upper bound, and a descriptive tag. The uncertain variables \# specification is a placeholder for the time being.

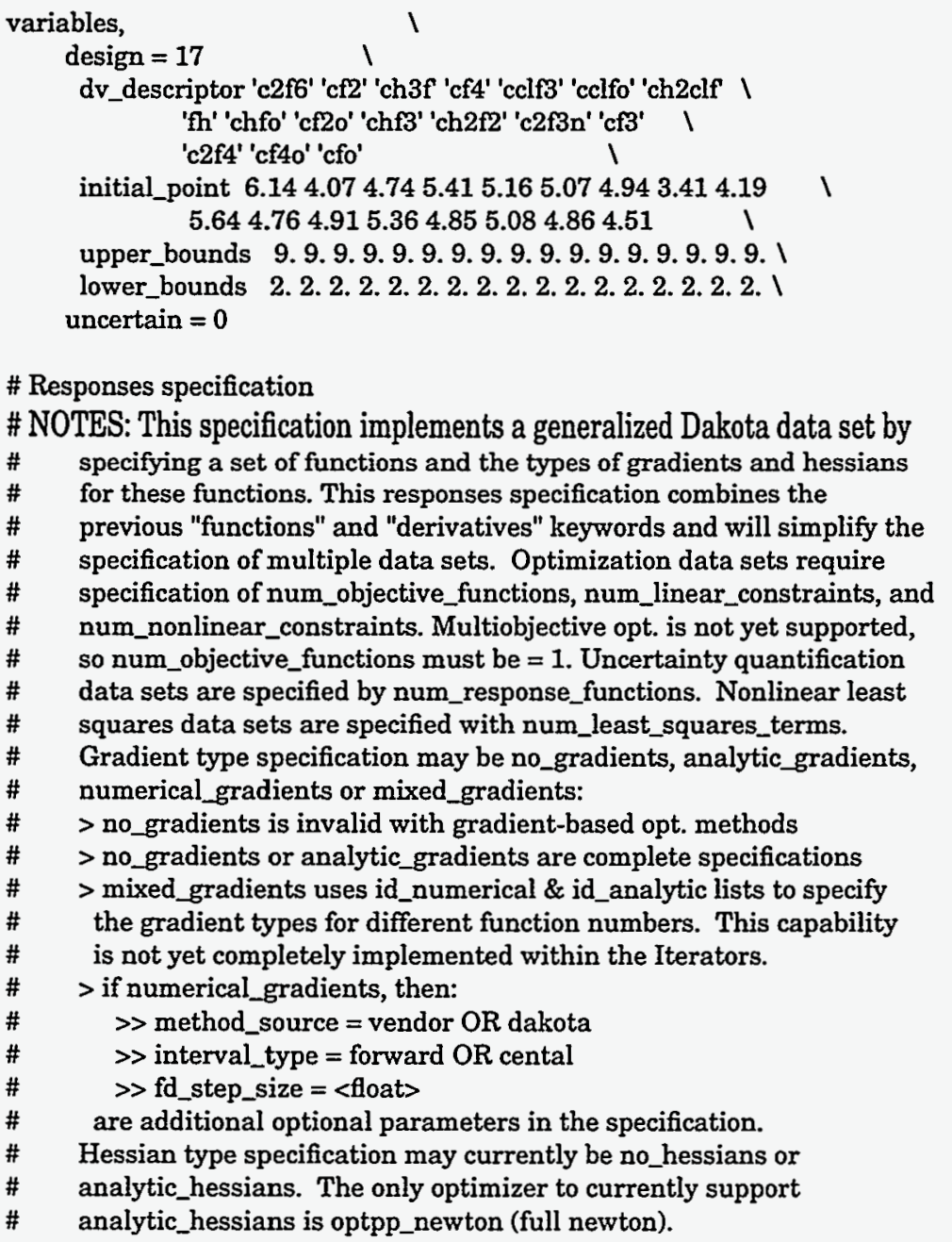




\section{Appendix C}

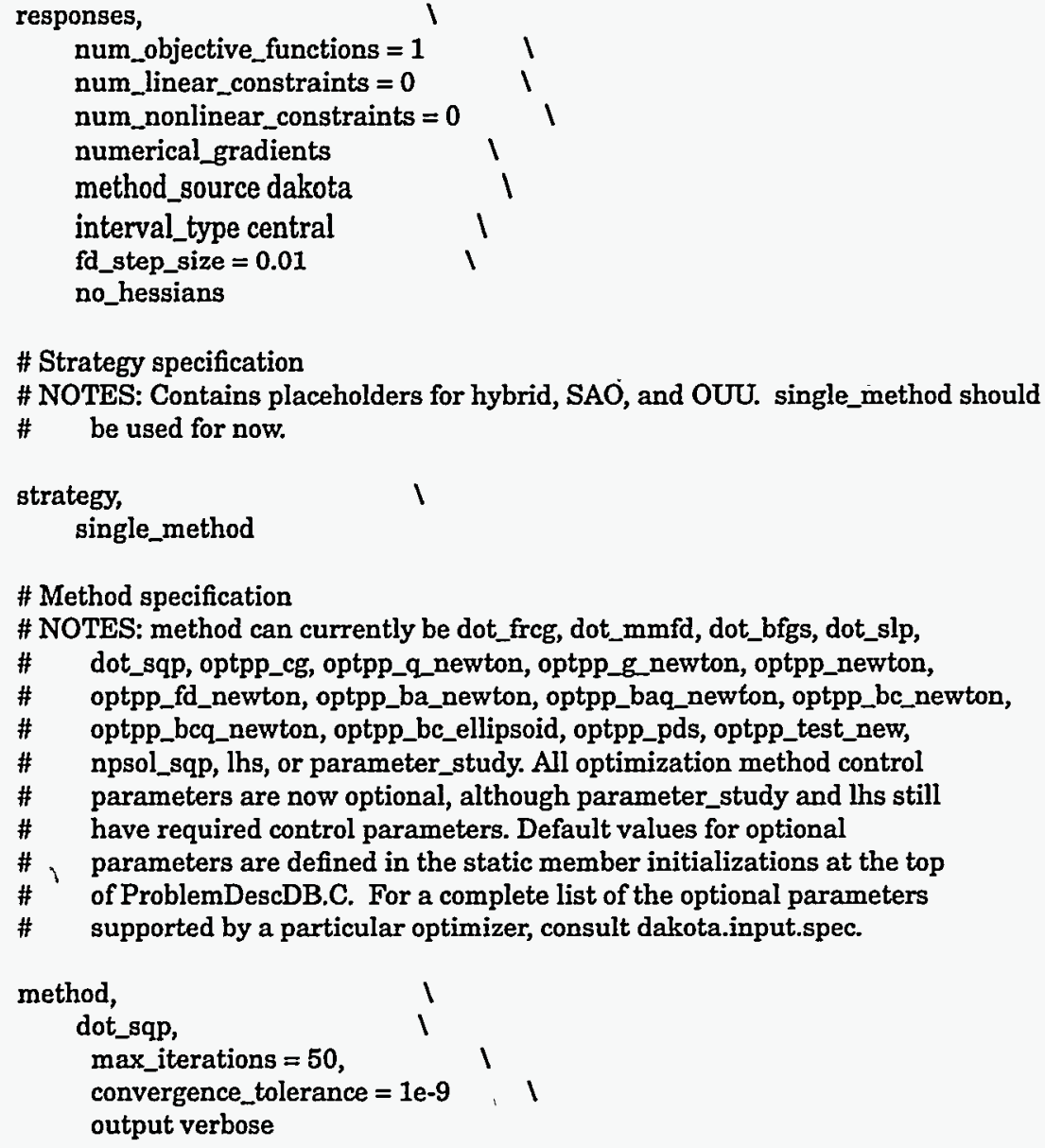

\section{C-shell scipt used to run the DAKOTA optimizer, jcz.csh}

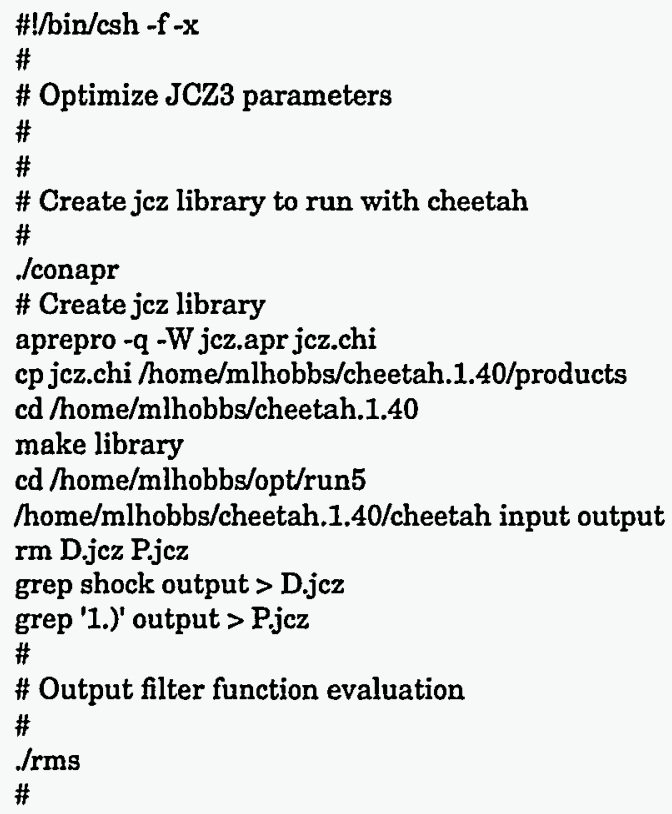




\section{Appendix C}

echo "output filter created results.out"

\#

FORTRAN code used to construct the APREPRO include file for the DAKOTA optimization

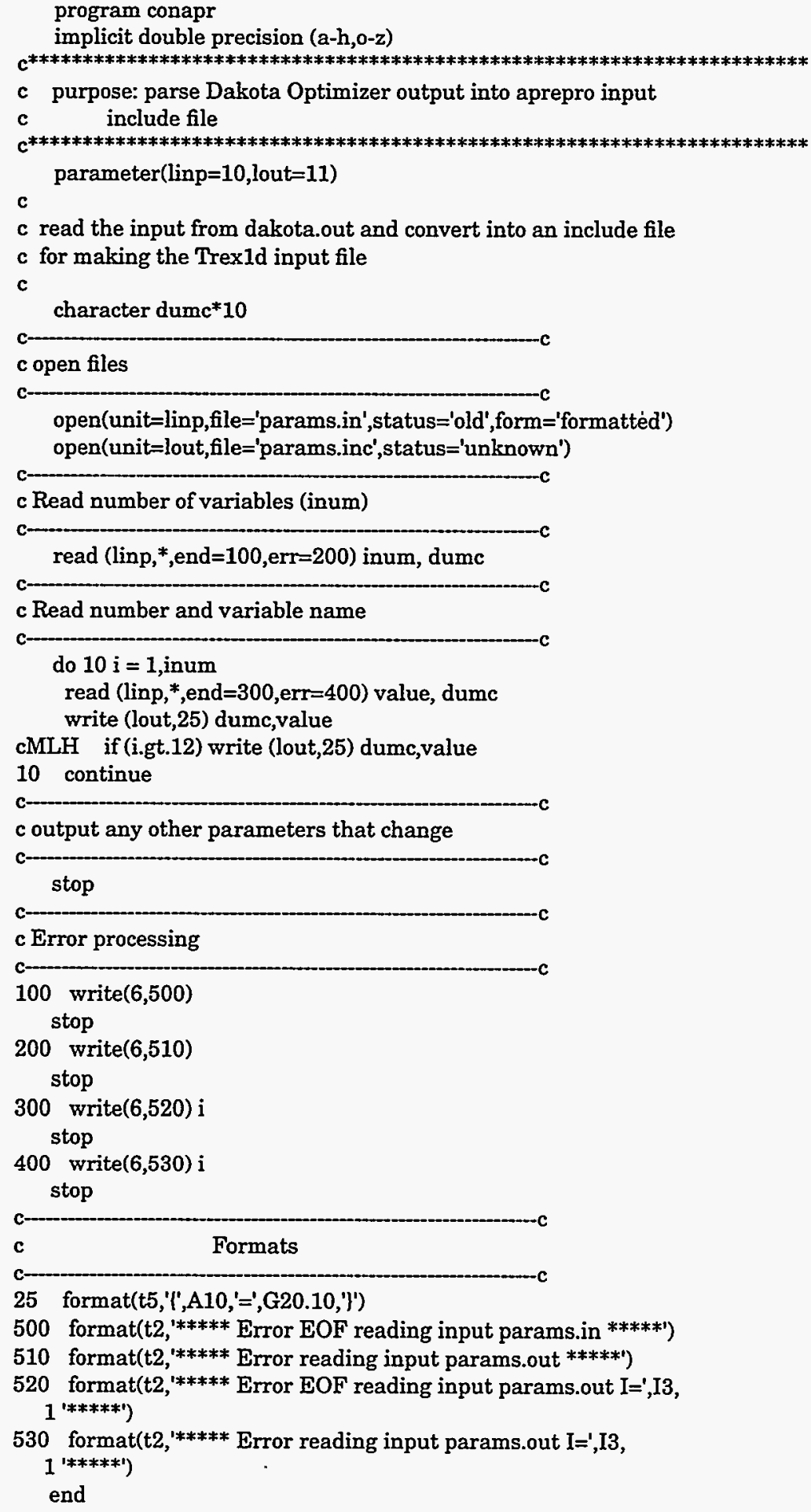




\section{FORTRAN code used to calculate the root mean square error, rms.f.}

program rms

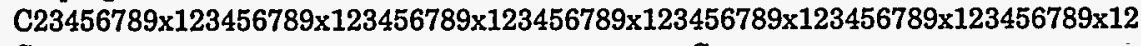

C-

C This program calculates the root mean square (rms) percent difference

$\mathrm{C}$ in calculated and measured Detonation properties.

C.

character*27 junk

character*7 junk2

character*6 spec(25)

parameter (nin1=10,nin2=12,nin3=13,nin4=14,nptmax=150)

parameter (nout1 $=20$, nout $2=30$, nout $3=40$, nout $4=45$, nout $5=55$ )

dimension dexp(nptmax), djcz(nptmax), pexp(nptmax),pjcz(nptmax)

data spec/ 'dp12','afx902','fefo','fm1','pf,',rx36ah','rx41ab',

\& 'Ix17','rx27ad','rx45aa','rx47aa','rx48aa','fefo',

\& $\quad$ 'lx04','lx07','lx09','lx10','Lx11','lx15','lx17',

\& '9010','9404','9407','9502','9503'/

C-..n-C

C open input files

C-

open(nin1,file='D.exp',status='unknown',form='formatted') open(nin2, file='D.jcz',status='unknown', form='formatted') open(nin3,file='P.exp',status='unknown',form='formatted') open(nin4,file='P.jcz',status='unknown',form='formatted') open(nout1,file='D.all',status='unknown',form='formatted') open(nout2,file='P.all',status='unknown', form ='formatted') open (nout3,file='results.out',status='unknown',form='formatted') open(nout4,file='D.rms',status='unknown',form='formatted') open(nout5,file='P.rms',status='unknown',form='formatted') $\mathrm{wt}=1.0$

C-C

$\mathrm{C}$ read in Detonation velocities

C. $\mathbf{i}=\mathbf{0}$

$10 \quad \mathbf{i}=\mathbf{i}+\mathbf{1}$

$\operatorname{READ}(\operatorname{nin} 1, *$, end $=15) \operatorname{dexp}(\mathrm{i})$ goto 10

$15 \mathrm{npt}=\mathrm{i}-1$ $i=0$

$20 \quad \mathrm{i}=\mathrm{i}+1$ READ(nin2,2500, end=25) junk,djcz(i)

2500 format $(\mathrm{a} 27, \mathrm{e} 11.5)$ $\operatorname{djcz}(\mathbf{i})=\operatorname{djcz}(\mathrm{i}) / 1000$. goto 20

25 if(i-1.ne.npt) then write $(6, *)$ 'The \# of points in D.exp and D.jcz are different' npt $=\mathrm{i}-1$. $w t=2.0$ endif

$\mathrm{C}$

C Write out the detonation velcities

$\mathrm{C}$

do $100 \mathrm{i}=1$, npt

if(dexp(i).ne.0.0) then

write(nout1,*) dexp(i), djcz(i)

endif

100 continue

C-C 


\section{Appendix C}

C Calculate the RMS error

C

errd $=0.0$

do $200 \mathrm{i}=1$,npt

if(dexp(i).ne.0.0) then

errd $=\operatorname{errd}+((\operatorname{dexp}(\mathrm{i})-\mathrm{djcz}(\mathrm{i})) / \mathrm{dexp}(\mathrm{i})) * * 2$.

err $=100 . * \operatorname{sqrt}\left(((\operatorname{dexp}(\mathrm{i})-\operatorname{djcz}(\mathrm{i})) / \operatorname{dexp}(\mathrm{i}))^{* * 2}\right.$.)

write(nout4, $\left.{ }^{*}\right) \operatorname{dexp}(\mathrm{i}), \operatorname{djcz}(\mathrm{i}), \mathrm{err},{ }^{\prime}$ ',spec(i)

endif

200 continue

errd $=100 .{ }^{*}$ sqrt(errd/float(npt))

errd $=w^{*}$ errd

C read in Detonation pressures

$\mathrm{wt}=1.0$

count $=0.0$

$\mathrm{i}=\mathbf{0}$

$50 \quad \mathrm{i}=\mathrm{i}+1$

$\mathrm{READ}\left(\right.$ nin $3,{ }^{*}$, end $\left.=55\right)$ pexp(i)

if $($ pexp(i).ne.0.) count $=$ count +1 . $\operatorname{pexp}(\mathrm{i})=10{ }^{*} \mathrm{pexp}(\mathrm{i})$ goto 50

55 if(i-1.ne.npt) then write $(6, *)$ 'The \# of points in D.exp and P.exp are different' endif

$i=0$

$60 \quad i=i+1$

$\operatorname{READ}($ nin 4,2600, end=65) junk2,pjcz(i)

2600 format $(\mathrm{a} 7, \mathbf{8 8 . 1})$

$\operatorname{pjcz}(\mathrm{i})=1.01325^{*} \mathrm{pjcz}(\mathrm{i}) / 1000$.

goto 60

65 if(i-1.ne.npt) then

write $\left(6,{ }^{*}\right)$ 'The \# of points in P.exp and P.jcz are different' $\mathrm{npt}=\mathrm{i}-1$.

wt $=2.0$

endif

$\mathrm{C}$

C Write out the detonation pressures

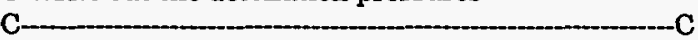

do $300 \mathrm{i}=1$,npt

if(pexp(i).ne.0.0) then

write(nout $\left.2,{ }^{*}\right)$ pexp(i),pjcz(i)

endif

300 continue

C-

C Calculate the RMS error for the pressures

C- C

$\operatorname{errp}=0.0$

do $400 \mathrm{i}=1$,npt

if(pexp(i).ne.0.0) then

$\operatorname{errp}=\operatorname{errp}+((p \exp (\mathrm{i})-\mathrm{pjcz}(\mathrm{i})) / \mathrm{pexp}(\mathrm{i}))^{* * 2}$.

err $=100 .{ }^{*}$ sqrt $\left(((\operatorname{pexp}(\mathrm{i})-\mathrm{pjcz}(\mathrm{i})) / \operatorname{pexp}(\mathrm{i}))^{* * 2 .}\right)$

write(nout,$\left.^{*}\right)$ pexp(i),pjcz(i),err,' ',spec(i)

endif

400 continue

errp $=100{ }^{*}$ sqrt(errp/count)

$\operatorname{errp}=w t^{*}$ errp

C Write out the rms error 


\section{Appendix C}

write(nout4, $\left.{ }^{*}\right)$ errd
write(nout5,*) errp

C Calculate the RMS weighted error to be minimized

$\mathrm{C}$ by only considering the detonation velocities since

C these are measured accurately

write(nout3,1000) errd

1000 format $(t 5, e 15.8, \quad f)$

stop

.end

\section{CHEETAH input deck for the explosives listed in Table 5}

library file, bkwc.chl

\#library file, bkws.chl

gas eos, bkw

\#set, bkw, alpha, 0.5

\#set, bkw, beta, 0.298

\#set, bkw, theta, 6620 .

\#set, bkw, kappa, $\quad 10.5$

\#gas eos, jcz3

\#set, jcz3, m, 6

\#set, jcz3, 1, 13

composition, abh, 1.

hug0, $\mathrm{p}, 1$, rho, 1.64

c-j

composition, compa3, 1.

hug0, p, 1, rho, 1.64

c-j

composition, compb, 1.

hug0, p, 1, rho, 1.72

c-j

\# The following entry is for comp B-3

composition, rdx, 60., tnt, 40.

hug $0, \mathrm{p}, 1$, rho, 1.72

c-j

composition, compc3, 1.

hug0, $\mathrm{p}, 1$, rho, 1.60

c-j

composition, compc4, 1 .

hug0, p, 1, rho, 1.66

$c-j$

\# The following entry is for Cyclotol-78/22

composition, rdx, 78., tnt, 22.

hug $0, p, 1$, rho, 1.76

c-j

\# The following entry is for Cyclotol-77/23

composition, rdx, 77., tnt, 23.

hug0, $\mathrm{p}, 1$, rho, 1.74

c-j

\# The following entry is for Cyclotol-75/25

composition, rdx, 75., tnt, 25.

hug $0, p, 1$, rho, 1.76

c-j

\# The following entry is for Cyclotol-75/25

composition, rdx, 75., tnt, 25.

hug0, p, 1, rho, 1.62

c-j 
\# The following entry is for Cyclotol-70/30 composition, $\mathrm{rdx}, 70$., tnt, 30 .

hug0, p, 1, rho, 1.73

c-j

\# The following entry is for Cyclotol-65/35

composition, rdx, 65., tnt, 35 .

hug0, p, 1, rho, 1.72

c-j

\# The following entry is for Cyclotol-60/40 composition, rdx, 60, tnt, 40 .

hug0; $p, 1$, rho, 1.74

c-j

hug0, p, 1, rho, 1.72

$\mathrm{c}-\mathrm{j}$

\# The following entry is for Cyclotol-50/50

composition, $r d x, 50$., tnt, 50 .

hug0, p, 1, rho, 1.63

$c-j$

composition, datb-snl, 1.0

hug0, $p, 1$, rho, 1.80

$c-j$

hug0, p, 1, rho, 1.78

c-j

composition, degn, 1.0

hug0, $p, 1$, rho, 1.38

$c-j$

composition, dipm, 1.0, tnt, 0.0000000001

hug0, p, 1, rho, 1.76

$c-j$

composition, expd, 1.0

hug0, p, 1, rho, 1.55

c-j .

hug0, $p, 1$, rho, 1.48

$c-j$

composition, $\mathrm{hmx}, 1.0$

hug0, p, 1, rho, 1.89

c-j

hug0, p, 1, rho, 1.60

c-j

hug0, p, 1, rho, 1.40

c-j

hug0, $p, 1$, rho, 1.20

c-j

hug0, p, 1, rho, 1.00

c-j

hug0, p, 1, rho, 0.75

c-j

composition, hnab, 1.0

hug0, p, 1, rho, 1.60

$c-j$

composition, hns, 1.0

hug0, p, 1, rho, 1.60

$c-j$

hug0, p, 1, rho, 1.70

$c-j$

\# The following entry is for LX01

composition, nm, 51.7,tnm,33.2,npro,15.1

hug0, p, 1, rho, 1.24

c-j

\#\#lx14 
composition, hmx, 95.5, estane, 4.5 composition, $\mathrm{hmx}, 95.5$, estane, 4.5 hug0, p, 1, rho, 1.84 $c-j$ composition, men, 1.0 hug $0, p, 1$, rho, 1.02 c-j composition, ng, 1.0 . hug $0, p, 1$, rho, 1.60

$\mathrm{c}-\mathrm{j}$ composition, $\mathrm{nm}, 1.0$ hug0, p, 1, rho, 1.13

$c-j$ composition, nona, 1.0 hug $0, p, 1$, rho, 1.70 c.j composition, nq, 1.0 hug $0, p, 1$, rho, 1.78 c-j hug0, $p, 1$, rho, 1.72

$c-j$ hug0, p, 1, rho, 1.62

c-j hug0, $p, 1$, rho, 1.55

c-j

\# The following entry is for Octol-78/22 composition, hmx, 77.6, tnt, 22.4 hug0, p, 1, rho, 1.82 $c-j$ \# The following entry is for Octol-76/23 composition, hmx, 76.3, tnt, 23.7 hug0, p, 1, rho, 1.81

$c-j$

\# The following entry is for Octol-75/25 composition, hmx, 75.0, tnt, 25.0 hug $0, p, 1$, rho, 1.81 $c-j$

\# The following entry is for Octol-60/40 composition, hmx, 60., tnt, 40 . hug0, $p, 1$, rho, 1.80

c-j composition, pbx9007, 100.

hug0, $p, 1$, rho, 1.64

c-j

composition, pbx9011, 100.

hug0, p, 1, rho, 1.77

c-j

composition, pbx9205, 100.

hug0, p, 1, rho, 1.67

$c-j$

composition, pbx9501, 100.

hug0, p, 1, rho, 1.84

c-j

\# The following entry is for pentolit $50 / 50$ composition, petn, 50., tnt, 50 .

hug0, p, 1, rho, 1.71

c-j

hug0, p, I, rho, 1.70

c-j

hug0, p, 1, rho, 1.68 


\section{Appendix C}

c-j

hug0, $p, 1$, rho, 1.64

c-j

\# The following entry is for PETN

composition, petn, 100 .

hug0, p, 1, rho, 1.76

c-j

hug0, $p, 1$, rho, 1.70

$c-j$

hug0, $p, 1$, rho, 1.60

c-j

hug0, $p, 1$, rho, 1.45

c-j

hug0, $p, 1$, rho, 1.23

c-j

hug0, p, 1, rho, 0.99

c-j

hug0, p, 1, rho, 0.88

$\mathrm{c}-\mathrm{j}$

hug0, p, 1, rho, 0.48

c-j

hug0, p, 1, rho, 0.30

$c-j$

hug0, $p, 1$, rho, 0.25

c-j

\# The following entry is for PICRATOL

composition, expd, 52, tnt, 48.

hug0, p, 1, rho, 1.63

c-j

\# The following entry is for PICRIC ACID

composition, picric acid, 100 .

hug0, p, 1, rho, 1.76

$c-j$

hug0, p, 1, rho, 1.71

c-j

hug0, p, 1, rho, 1.60

$c-j$

\# The following entry is for RDX

composition, rdx, 100 .

hug0, p, 1, rho, 1.80

$c-j$

hug0, $\mathrm{p}, 1$, rho, 1.77

$c-j$

hug0, p, 1, rho, 1.72

c-j

hug0, $\mathrm{p}, 1$, rho, 1.66

c-j

hug0, p, 1, rho, 1.60

$c-j$

hug0, $p, 1$, rho, 1.46

$c-j$

hug0, p, 1, rho, 1.40

$c-j$

hug0, p, 1, rho, 1.29

c-j

hug0, $p, 1$, rho, 1.20

c-j

hug0, p, 1, rho, 1.10

c-j

hug0, p, 1, rho, 1.00 


\section{Appendix C}

$c-j$

hug0, p, 1, rho, 0.95

$c-j$

hug0, p, 1, rho, 0.70

c-j

hug0, $p, 1$, rho, 0.56

c-j

composition, tacot, 100 .

hug0, p, 1, rho, 1.85

c-j

\# The following entry is for TATB

composition, tatb, 100 .

hug0, p, 1, rho, 1.88

$c-j$

hug0, p, 1, rho, 1.85

$c-j$

\# The following entry is for TETRYL

composition, tetryl, 100.

hug0, $\mathrm{p}, 1$, rho, 1.73

$c-j$

hug0, $\mathrm{p}, 1$, rho, 1.71

$\mathrm{c}-\mathrm{j}$

hug0, p, 1, rho, 1.68

$c-j$

hug $0, p, 1$, rho, 1.61

c-j

hug0, $p, 1$, rho, 1.40

$c-j$

hug0, $p, 1$, rho, 1.36

c-j

hug0, p, 1, rho, 1.20

c-j

hug0, p, 1, rho, 1.00

$c-j$

\# The following entry is for TNT

composition, tnt, 100.

hug0, p, 1, rho, 1.64

c-j

hug0, p, 1, rho, 1.45

c-j

hug0, p, 1, rho, 1.36

c-j

hug0, p, 1, rho, 1.00

$c-j$

hug0, p, 1, rho, 0.80

c-j

\# The following entry is for BTF

composition, btf, 100.

hug $0, p, 1$, rho, 1.86

c-j

hug0, p, 1, rho, 1.76

c.j

composition, hnb, 100.

hug0, p, 1, rho, 1.97

c-j

composition, tnm, 100.

hug0, p, 1, rho, 1.64

$c-j$

composition, tntab, 100.

hug0, p, 1, rho, 1.74 


\section{Appendix C}

$c-j$

composition, fefo, 100 .

hug $0, \mathrm{p}, 1$, rho, 1.59

$c-j$

\# The following entry is for LX04 composition, hmx, 85., viton, 15. hug $0, p, 1$, rho, 1.86

c-j

\# The following entry is for LX07 composition, hmx, 90., viton, 10 . hug0, p, 1, rho, 1.87

c-j

composition, LX9, 100.

hug0, p, 1, rho, 1.84

c-j

\# The following entry is for LX10 composition, $\mathrm{hmx}$, 95., viton, 5 .

hug0, p, 1, rho, 1.86

c-j

\# The following entry is for LX11 composition, hmx, 80., viton, 20.

hug0, p, 1, rho, 1.86

c-j

composition, ap, 100 .

hug0, p, 1, rho, 1.00

c-j

\# The following entry is for LX15

composition, hns, 95. , kel-f, 5 .

hug0, p, 1, rho, 1.58

$c-j$

\# The following entry is for LX17

composition, tatb, 92.5, kel-f, 7.5

hug0, p, 1, rho, 1.91

c-j

composition, PBX9010, 100.

hug0, p, 1, rho, 1.78

$c-j$

composition, BKWC9404, 100.

hug0, p, 1, rho, 1.84

c-j

composition, PBX9407, 100.

hug0, $p, 1$, rho, 1.60

$\mathrm{c}-\mathrm{j}$

\# The following entry is for PBX-9502

composition, tatb, 95.0, kel-f, $\mathbf{5 . 0}$

hug0, p, 1, rho, 1.91

c-j

\# The following entry is for PBX-9503

composition, tatb, 80.0, hmx, 15, kel-f, 5.0

hug0, p, 1, rho, 1.90

c-j

STOP 


\section{Distribution}

Alliant Techsystems, Inc.

Attn: Garn Butcher

P. O. Box 98

8400 West 5000 So.

Magna, UT 84044-0098

Brigham Young University (4)

Attn: Merrill Beckstead

Predrag Radulovic

Richard Rowley

L. Douglas Smoot

Department of Chemical Engineering

350 Clyde Building

Provo, UT 84602

California Institute of Technology

Attn: Joe E. Shepherd

306e Guggenheim (GALCIT Building)

1200 East California Boulevard

Pasadena, CA 91125

ChemEnergetics, Inc.

Attn: Remon J. Dihu

799 Roosevelt Road

Building 6, Suite 221

Glen Ellyn, IL 60137

Defense Research Agency

Attn: Philip J. Cheese

Fort Halstead

Sevenoaks, Kent, TN14 7BP, England

DOE Albuquerque Operations Office

Attn: Actg. Director, Weapons Program Div.

Albuquerque, NM 87185

\section{Energetic Materials Laboratory}

Attn: Katsumi Tanaka

Ministry of International Trade and Industry

National Institute of Materials and Chemical

Research, Tsukuba Research Center,

Tskuba, Ibaraki 305 Japan

Enig Associates, Inc. (2)

Attn: Michael Cowperthwaite

J. W. Enig

11120 New Hampshire Avenue, Suite 500

Silver Spring, MD 20904-2633
Fraunhofer Institut (FCT)

Attn: Fred Volk

Josef von Fraunhofer Strasse, Germany

ICI Explosives

Attn: Graeme A. Leiper

K80, ICI plc

Stevenston, Ayrshire, KA20 3LN, Scotland

IIT Research Institute (3)

Attn: Allen J. Tulis

James L. Austing

Ron Pape

10 West 35th Street

Chicago, IL 60616-3799

Lawrence Livermore National Lab. (17)

Attn: Dennis Baum

Tom Deboni

Mark Hoffman

Al Holt

Michael Howard

John Kury

Ronald S. Lee

Jon L. Maienschein

Mike Murphy

Albert Nichols III

David Price

Francis H. Ree

Randy Simpson

Clark Souers

Bill Tao

Craig Tarver

Paul A. Urtiew

P. O. Box 808

Livermore, CA 94555

Lockheed-Martin Missiles \& Space Co., Inc.

Attn: Erik R. Matheson

1111 Lockheed Way, Sunnyvale, CA 94089

Logicon RDA

Attn: William R. Espander

Laser Technology Department

P. O. Box 9273

Albuquerque, NM 87119-9273 
Los Alamos National Laboratory (8)

Attn: Blaine Asay (Group DX-2, MS C920)

Langdon Bennett

Mary S. Campbell

Brian Henson

John F. Kramer

Jonathan Mace

Steve Sheffield

Steve Son

P. O. Box 1663

Los Alamos, NM 87545

McGill University (2)

Attn: David Frost

Jean-Philippe Dionne

Mechanical Engineering Department

817 Sherbrooke St. W.

Montreal, Que Canada H3A 2K6

National Defence Research Establishment Attn: Henric L. Ostmark Sundybyberg, S-17290, SWEDEN

Naval Air Weapons Center (3)

Attn: Alice I. Atwood Thom L. Boggs Don Thompson

China Lake, CA 94555-6001

\section{Naval Reserach Laboratory}

Attn: Thomas P. Russell

Chemistry Division, Code 6110

4555 Overlook Ave.

Washington DC 20375

Naval Surface Warfare Center (8)

Attn: Richard R. Bernecker

Charles S. Coffey

Ruth M. Doherty

R. Guirguis

Philip J. Miller

Susan Peters

Harold W. Sandusky

Gerrit T. Sutherland

Indian Head, MD 20640
New Mexico Tech. (3)

Center for Explosives Technology Research

Attn: Per-Anders Persson

Doug Olsen

L. D. Libersky

RCEM, Campus Station

Socorro, NM 87801

North Carolina State University

Attn: Yasuyuki Horie

Department of Mech. and Aero. Eng.

Box 7908

Raleigh, NC 27695-7908

Polytechnic University

Attn: Leonard I. Stiel

333 Jay Street

Brooklyn, NY 11201

Princeton University

Attn: Richard A. Yetter

Department of Mech. and Aero. Eng.

D312 Engineering Quadrangle

Princeton, NJ 08544-5263

Prins Maurits Laboratory TNO (2)

Attn: Ries Verbeek Albert C. van der Steen

Lange Kleiweg 137

Rijswijk, 2280 AA The Netherlands

\section{Redstone Arsenal}

Attn: Barbara P. Marsh

Propulsion Directorate, Bldg 7156

Redstone Arsenal, AL 35898

\section{Southwest Research Institute}

Attn: Robert D. Young

Materials and Structures Division

6220 Culebra Road

P. O. Drawer 28510

San Antonio, Texas 78228-0510

Stanford Reserach Institute

Attn: Tom Cooper

333 Ravenswood Avenue

Menlo Park, CA 94025 
Thiokol Corporation

Attn: Paul C. Braithwaite

Robert G. Jones

P. O. Box 707

Brigham City, UT 84302-0707

University of Delaware

Attn: Thomas B. Brill

Department of Chemistry and Biochemistry

003 Lammot DuPont Laboratory

Newark, DE 19711

University of Illinois

Attn: Herman Krier

Department of Mechanical Engineering

1206 W. Green Street

Urbana, IL 61801

\section{University of Iowa}

Attn: P. Barry Butler

Department of Mechanical Engineering

2208 Engineering Bldg.

Iowa City, IA 52245

University of Maryland

Attn: Herman L. Ammon

$\mathrm{Rm}$. B214, Chemistry Building

Lanham, MD 20706

\section{University of Notre Dame}

Attn: Joe Powers

Department of Mechanical Eng. and Aerospace

Notre Dame, IN 46556

\section{University of Toronto \\ Attn: Susan McCahan \\ Dept. of Mechanical and Industrial Engineering \\ 5 King's College Road \\ Toronto, Ontario, Canada M5S 3G8}

\section{U. S. Army Armament Research (5)}

Attn: Ernest Baker

B. Fishburn

Gail Tutt

R. Gentner

Daniel Stec

Development and Engineering Center

Picatinny Arsenal, NJ 07806-5000
U.S. Army Ballistic Research Lab. (3)

Attn: Douglas E. Kooker

Robert B.Frey

John Starkenberg

Aberdeen Proving Grounds, MD 21005-5066

Washington State University

Attn: Yogendra M. Gupta

Physical Science 948A

Pullman, WA 99164-2814

Wilfred Baker Engineering, Inc.

Attn: Craig Doolittle

8700 Crownhill, Suite 310

San Antonio, TX 78209-1128

Wright Lab.JArmament Directorate (6)

Attn: Gary H. Parsons

Joseph C. Foster Jr.

Robert L. McKenney Jr.

Paul Bolduc

Phillip Mendicki

David R. Wagnon

2306 Perimeter Road

Eglin Air Force Base, FL 32542-6009

\begin{tabular}{lll}
\multicolumn{3}{l}{ Internal Distribution } \\
MS & Org. & Name \\
9052 & 8361 & L. L. Baxter \\
9052 & 8361 & Behrens, R. \\
9052 & 8361 & Margolis, S. B. \\
9056 & 8120 & Thorne, L. R. \\
9104 & 8120 & Christensen, G. J. \\
1421 & 1152 & Samara, G. A. \\
1421 & 1152 & Graham, R. A. \\
0614 & 1522 & Mitchell, D. E. \\
1452 & 1552 & Harlan, J. G. \\
1452 & 1552 & Loyola, V. M. \\
1452 & 1552 & Massis, T. M. \\
1452 & 1552 & Merson, J. A. \\
1453 & 1553 & Bickes, R. W. \\
1453 & 1553 & Benham, R. A. \\
1453 & 1553 & Fischer, S. H. \\
1453 & 1553 & Grubelich, M. C. \\
1453 & 1553 & Harris, S. M. \\
1453 & 1553 & Vigil, M. G. \\
1454 & 1554 & Bonzon, L. L. \\
1454 & 1554 & Fleming, K. J. \\
1454 & 1554 & Renlund, A. M. \\
0841 & 9100 & Hommert, P. J. \\
0841 & 9101 & Bickel, T. C. (Route to 9113)
\end{tabular}




\section{Distribution}

$\begin{array}{lll}0826 & 9111 & \text { Hermina, W. L. } \\ 0834 & 9112 & \text { Ratzel, A. C. } \\ 0834 & 9112 & \text { Baer, M. R. } \\ 0834 & 9112 & \text { Erickson, K. L. } \\ 0834 & 9112 & \text { Gross, R. J. } \\ .0834 & 9112 & \text { Hobbs, M. L. (25) } \\ 0834 & 9112 & \text { Schmitt, R. G. } \\ 0834 & 9112 & \text { Trott, W. M. } \\ 0827 & 9114 & \text { Griffith, R.O. (Route to 9114) } \\ 0825 & 9115 & \text { Rutledge, W. H. (Route 9115) } \\ 0836 & 9116 & \text { Peterson, C. W. (Route 9116) } \\ 0836 & 9116 & \text { Tieszen, S. R. } \\ 0820 & 9232 & \text { Kipp, M. E. } \\ 0820 & 9232 & \text { Yarrington, P. } \\ 0820 & 9232 & \text { Boslough, M. B. } \\ 0820 & 9232 & \text { Silling, S. A. } \\ 0439 & 9234 & \text { Eldred, M. S. } \\ 1423 & 2000 & \text { Schmitt, H. W. } \\ 9018 & 8940-2 & \text { Central Tech Files (2) } \\ 0899 & 4414 & \text { Technical Library (5) } \\ 0115 & 10300 & \text { McGee, R. H., Jr. } \\ 0619 & 12690 & \text { Review \& Approval Desk (5) } \\ & & \text { for DOE/OSTI } \\ 0871 & 14405 & \text { McGee, B. C. (2) }\end{array}$

